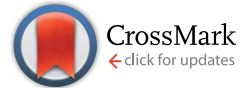

Cite this: RSC Adv., 2014, 4, 43286

Received 13th July 2014

Accepted 26th August 2014

DOI: $10.1039 / c 4 r a 07064 j$

www.rsc.org/advances

\section{Third-generation solar cells: a review and comparison of polymer:fullerene, hybrid polymer and perovskite solar cells}

\begin{abstract}
Junfeng Yan and Brian R. Saunders*
The need for large scale low carbon solar electricity production has become increasingly urgent for reasons of energy security and climate change mitigation. Third-generation solar cells (SCs) are solution processed SCs based on semiconducting organic macromolecules, inorganic nanoparticles or hybrids. This review considers and compares three types of promising 3rd-generation SCs: polymer:fullerene, hybrid polymer and perovskite SCs. The review considers work reported since an earlier review (Saunders et al., Adv. Colloid Interface Sci., 2008, 138, 1) and highlights the great progress that has been made in each area. We consider the operation principles for each SC type and also review the state-of-the-art devices. The polymer:fullerene and hybrid polymer SC open circuit voltages are compared to values predicted from the well-known Scharber equation and similarities and differences discussed. The perovskite SCs are also considered and their remarkable rate of power conversion efficiency performance increase is discussed. The review considers the requirements for large-scale deployment in the contexts of semiconducting polymer and hole transport matrix synthesis and materials selection. It is concluded that the 3rdgeneration SC technologies discussed here are well placed for major contribution to large scale energy production. (This has already been partially demonstrated for polymer:fullerene SCs.) Looking further ahead we propose that several of the 3rd-generation SCs considered here have excellent potential to provide the low cost large-scale deployment needed to meet the terawatt challenge for solar electricity generation.
\end{abstract}

Polymer Science and Technology Group, School of Materials, The University of Manchester, Grosvenor Street, Manchester, M13 9PL, UK. E-mail: Brian.Saunders@ manchester.ac.uk

\section{Introduction}

Third-generation solar cells (SCs) are solution processable SCs with excellent potential for large-scale solar electricity generation. This review updates and greatly extends an earlier review

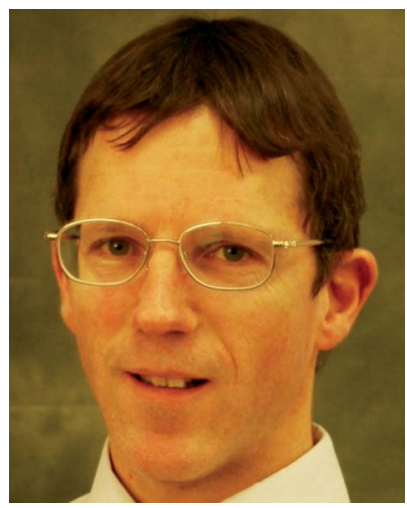

Brian R. Saunders obtained his PhD at Monash University and worked as a postdoc with Prof. Brian Vincent at the University of Bristol between 1994 and 1997. He is a Professor of Polymer and Colloid Chemistry at the School of Materials, University of Manchester. His research career at Manchester began in 2002 and involves the application of polymer and colloid chemistry principles to solar energy and healthcare research. Current research interests involve the use of colloid and polymer chemistry principles to improve the morphology of the photoactive layers of hybrid polymer solar cells. 
by one of us in $2008 .{ }^{1}$ We consider three families of 3rdgeneration SCs technologies and discuss their operational principles. The review focusses on the strong progress in both their understanding and improvements in their power conversion efficiencies (PCEs) achieved in the past 6 years. The 3rdgeneration SCs considered are polymer:fullerene, hybrid polymer and perovskite SCs. The first two SC types allow us to compare and assess SC types where the principle difference is the nature of the acceptor phase. Inclusion of perovskite SCs enables comparison of mixed molecular (perovskite) and colloidal organic/inorganic (hybrid polymer) SC technologies. In each case we focus on systems which have potential for large scale deployment in the future. Whilst excellent progress has been made for dye-sensitised SCs ${ }^{2}$ (DSSCs) and small molecule $\mathrm{SCs}^{3}$ a comprehensive discussion of DSSCs falls outside the scope of this review. Perovskite SCs are a disruptive SC technology that has recently captured great attention due to their outstanding power conversion efficiency (PCE) values. ${ }^{4}$ For the polymer:fullerene and hybrid polymer SCs we compare the performance of a key SC parameters to those predicted from energy level theory. The relative performance of each SC family is also compared and the potential deployment of the SCs for large scale, cost-effective, energy generation is considered. Because each of the 3rd-generation SCs considered are solution processable with PCE values that range from respectable to very high, each of the SC families are considered to have excellent potential for large-scale deployment via roll-to-roll (R2R) production. We propose that polymer:fullerene and perovskite SCs have reached points in their technological evolutions where large scale deployment is possible.

\subsection{Current and future global solar electricity generation}

More than $80 \%$ of the world's energy mix is derived from fossil fuels, ${ }^{5}$ which in turn produce $\mathrm{CO}_{2}$. Coal, oil and gas accounted for $81.6 \%$ of the world's total primary energy supply in 2011 . $^{6}$ Looking ahead, the world's energy demand is forecast to double and electricity demand quadruple by $2050 .^{7}$ The projected future increase in energy use is expected to result in an $80 \%$ increase in $\mathrm{CO}_{2}$ emissions without determined action to incorporate low carbon energy generation alternatives. ${ }^{7}$ Smalley estimated that $60 \mathrm{TW}\left(6 \times 10^{13} \mathrm{~W}\right)$ of power would be required to provide the anticipated future population of 10 billion people with the standard of living enjoyed by the developed world in $2004 .^{8}$ Solar energy is the only renewable energy source capable of providing all of the energy needs of man in a sustainable manner. More energy arrives at the earth's surface in one hour than is used by man in one year. ${ }^{9}$ Whilst impressive gains in solar energy production have been achieved with parity reached with fossil fuel derived electricity already in several countries (below), a major expansion of SC manufacture and deployment is urgently required to answer Smalley's terawatt challenge.

The Inter-governmental Panel on Climate Change (IPCC) recently concluded that (a) the human influence on the climate system is clear; (b) that atmospheric concentration of $\mathrm{CO}_{2}$ has increased to levels unprecedented in at least the last 800000 years and (c) that the largest contribution to total radiative forcing is caused by the increase in $\mathrm{CO}_{2}$ concentration. ${ }^{\mathbf{1 0}}$ The report shows the direct relationship between global temperature and atmospheric $\mathrm{CO}_{2}$ concentration and also how future global temperature increases can be modulated by reducing $\mathrm{CO}_{2}$ output. The IPCC's Impacts, Adaption and Vulnerability report $^{\mathbf{1 1}}$ concluded that there will be many more negative impacts than positive impacts due to climate change in the future. The key risks involving food insecurity, fresh water access, flooding, extreme weather events, loss of marine and costal ecosystems can be reduced by limiting the rate and magnitude of climate change. Clearly, the sustainability of ecosystems that support everyday life requires future atmospheric $\mathrm{CO}_{2}$ increases to be minimised.

Unfortunately, progress toward reducing $\mathrm{CO}_{2}$ output has been slow to date. The International Energy Agency (IEA) estimates that the long term global temperature increase is on track for ${ }^{12} 3.6{ }^{\circ} \mathrm{C}$, which is well above the internationally-agreed increase climate target of $2{ }^{\circ} \mathrm{C}$ (relative to pre-industrial levels). A global temperature increase of $6{ }^{\circ} \mathrm{C}$ is expected if the businessas-usual case persists. ${ }^{13} \mathrm{~A}$ rapid transition to an energy mix containing high proportions of renewable energy is urgently required. The IPCC's mitigation document called for a triplingto-quadrupling of the share of zero to low-carbon energy supply by 2050 to keep the temperature increase to below ${ }^{\mathbf{1 4}} 2{ }^{\circ} \mathrm{C}$. Electricity generation currently emits about $40 \%$ of energyrelated $\mathrm{CO}_{2}$ emissions. ${ }^{15}$ Hence, solar energy, a low-carbon energy source, has a key role to play in mitigating climate change.

Solar energy currently provides $2.6 \%$ of the electricity demand and $5.2 \%$ of the peak electricity demand in Europe. ${ }^{\mathbf{1 6}}$ Global installed photovoltaic capacity has been growing exponentially since 2000 (see Fig. 1) and surpassed $100 \mathrm{GW}$ in $^{\mathbf{1 6}} 2012$. The rate of installation (Fig. 1) is highest when installation is government policy driven. The impressive growth and adoption of the technology in economies such as Europe and China (with strong growth in the US ${ }^{17}$ ) coupled with the falling solar module prices provides good reason for optimism about the potential for solar electricity generation to become a major source of low carbon energy in the future. Indeed, solar electricity has achieved price parity with the electrical grid since 2012 in Denmark, Germany and Italy and many other European countries are expected to follow this trend. ${ }^{18}$ The IEA predicts that by 2050 solar power could generate $22 \%$ of the world's electricity. ${ }^{19}$ However, the percentage of electricity generated could be even

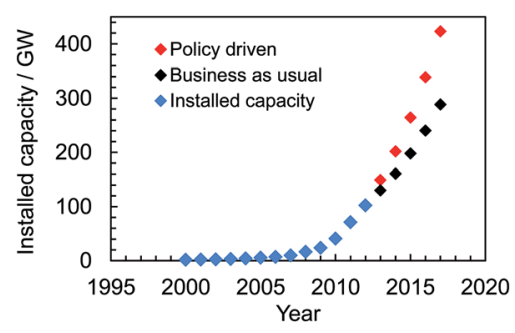

Fig. 1 Global cumulative solar cell capacity installation scenarios until 2017. The data were taken from ref. 16 
higher if low cost, large-scale production of SCs were to occur as a result of new, disruptive, technologies. Here, we discuss new 3rd-generation SC technologies that offer realistic potential to enable this much-needed low cost electricity.

\subsection{Solar cell operational fundamentals}

The principles of SC operation have been described in detail elsewhere. ${ }^{20} \mathrm{~A}$ brief review is given here as a prelude to discussion for the 3rd-generation SCs. 1st-generation SCs are based on crystalline $\mathrm{Si}^{20}$ (c-Si); whilst, 2nd-generation SCs are based on thin film technology which has often involved vapour deposited semiconductors. By contrast, 3rd-generation SCs are solution processed SCs based on organics, hybrids, inorganic semiconductors $^{21}$ and include nanostructured SCs. ${ }^{22}$ All SCs harvest solar radiation and convert this energy into electricity. SCs achieve power conversion using the photovoltaic effect. For the latter, photons that have energies greater than the band gap energy $\left(E_{\mathrm{g}}\right)$ are absorbed and this process excites an electron from the valence band to the conduction band. SCs have a built in asymmetry so that an electrical potential causes the electrons to reach the external circuit. ${ }^{20}$

SC performance is characterised by the measurement of the current density as the voltage across the device is biased with variable load during device irradiation by light (Fig. 2(a)). The PCE is related to the short-circuit current density $\left(J_{\mathrm{sc}}\right)$ and the open circuit voltage $\left(V_{\mathrm{oc}}\right)$ by:

$$
\mathrm{PCE}=\frac{J_{\mathrm{sc}} V_{\mathrm{oc}} \mathrm{FF}}{P_{\text {solar }}}
$$

where $\mathrm{FF}$ and $P_{\text {solar }}$ are the fill factor and incident power from solar irradiation, respectively. The value of $\mathrm{FF}$ is the ratio of $P_{\max }$ ( $=J_{\max } V_{\text {max }}$ ) to the product of $J_{\mathrm{sc}}$ and $V_{\mathrm{oc}}$ and is a measure of the squareness of the $J v s$. $V$ profile. It is noted that a recent article has provided guidelines for how PCE data should be reported. $^{23}$

The $J_{\mathrm{sc}}$ value for a SC depends strongly on the value for $E_{\mathrm{g}}$. Because the photon energy $(E)$ is inversely proportional to the wavelength $(E(\mathrm{eV})=1240 / \lambda(\mathrm{nm})), J_{\text {sc }}$ generally increases with increasing $\lambda$ across the visible and infra-red regions of the solar spectrum provided that $E$ is greater than $E_{\mathrm{g}}$ (Fig. 2(b)). Although the PCE increases with $J_{\mathrm{sc}}$, there is a trade-off involving $V_{\mathrm{oc}}$ which means that an optimum $E_{\mathrm{g}}$ value exists for PCE. Generally, as the value for $E_{\mathrm{g}}$ decreases the values for $V_{\mathrm{oc}}$ decrease. The $E_{\mathrm{g}}$ value for achieving optimum PCE values for c-Si $\mathrm{SCs}^{20}$ is between 1.0 and $1.6 \mathrm{eV}(1240-775 \mathrm{~nm})$. The maximum efficiency for a SC with an $E_{\mathrm{g}}$ of $1.1 \mathrm{eV}$ was calculated by Shockley and Queisser to be $30 \% .^{25}$

The light intensity absorbed in a SC decreases exponentially with film thickness. ${ }^{20}$ Consequently, a key parameter governing the PCE for a SC is the thickness of the photoactive layer compared to the absorption length $(1 / \alpha$, where $\alpha$ is the absorption coefficient in $\mathrm{cm}^{-1}$ ). The latter is the distance over which the $63 \%$ of the incident (non-reflected) light is absorbed. It is because Si SCs have relatively low $\alpha$ values that the thickness of their photoactive layers must be of the order of hundreds of micrometres to millimetres. The latter adds significantly to the material and production costs for c-Si SCs.

\section{Polymer:fullerene solar cells}

The first two SC families discussed are polymer:fullerene and hybrid polymer SCs. Here, we focus on polymer:fullerene SCs. However, many of the principles discussed also apply to hybrid polymer SCs. Polymer:fullerene SCs have photoactive layers comprising a semiconducting polymer and a fullerene and have been the subject of several reviews..$^{1,26-32}$ In the case of hybrid polymer SCs the fullerene is replaced by a semiconducting inorganic nanoparticle. Both of these SC families contain bulk heterojunctions (BHJs). A heterojunction is an interface between two different semiconducting materials. In 1986 Tang reported an excitonic device consisting of two semiconductors in a bilayer and achieved a PCE of about $1 \% .{ }^{33}$ He recognised that the performance depended on the nature of the interface between the two semiconductors. After establishing photoinduced electron transfer between a semiconducting polymer and a fullerene in $1992,{ }^{34}$ Heeger et al. mixed MEH-PPV with PCBM to give the first SC containing a dispersed heterojunction in 1995. They referred to the mixed polymer donor and fullerene

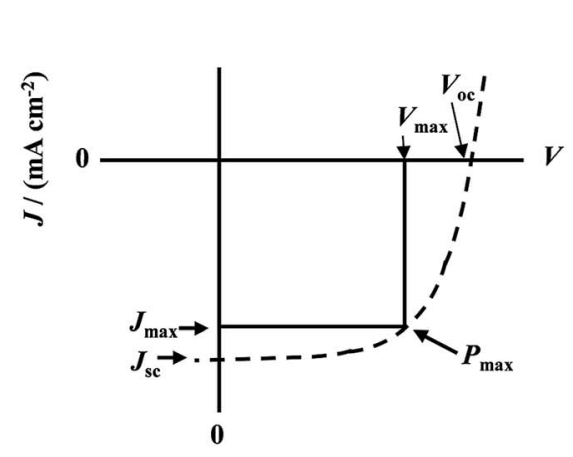

(a)

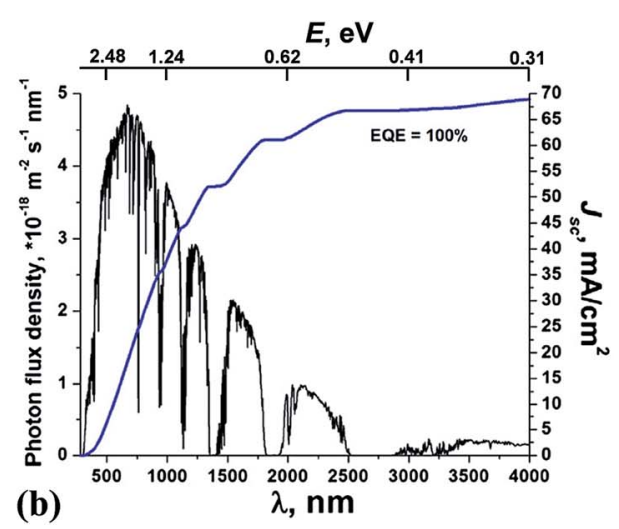

Fig. 2 Solar cell performance and solar radiation. (a) Example of a current density vs. voltage profile for a SC. (b) The global total solar photon flux and maximum achievable integrated short-circuit current density. (b) reproduced with permission from ref. 24 . The values for $E$ have been added to the original figure here. 
composite as a $\mathrm{BHJ} .{ }^{35}$ A key to the success of their SCs was the greatly increased $J_{\mathrm{sc}}$ which improved efficiency in collection of the photogenerated charges. In 1995 Halls et al. reported the first example of a polymer:polymer $\mathrm{BHJ} .{ }^{36} \mathrm{BHJs}$ can be considered as interpenetrating bicontinuous polymer/nanoparticle network. The connected nanoparticle segments are separated by a curved polymer phase. There is increasing evidence that the polymer and fullerene phases may contain a degree of molecular mixing (below).

Fig. 3(a) shows the components of the most widely studied polymer:fullerene SC, poly(3-hexylthiophene):phenyl $\mathrm{C}_{61^{-}}$butyric acid methylester (P3HT:PCBM). Between 2002 and 2010 a total of 579 publications reported the PCE of P3HT:PCBM SCs. ${ }^{37}$ The average PCE value reported for these SCs in 2010 was $3.0 \%$. The use of vertically aligned fullerenes via a template assisted construction strategy, combined with fullerene energy level modification, has enabled a PCE value of $7.3 \%$ for P3HT:fullerene SCs to be achieved. ${ }^{38}$ The energy level diagram (Fig. 3(b)) shows that photoexcited electrons can hop from the LUMO of the P3HT donor to the LUMO of the PCBM acceptor. P3HT and PCBM act as the hole and electron transfer phases, respectively. The phase separated photoactive layer was formed during solvent evaporation and is a non-equilibrium, kinetically trapped structure. The complex morphology of the photoactive layer (Fig. 3(c)) consists of P3HT crystallites, PCBM clusters as well as amorphous P3HT and intercalated (molecularly mixed) PCBM molecules. ${ }^{39}$ Liao et al. showed that annealing promoted PCBM cluster formation and charge transport which enhanced the PCE. ${ }^{39}$ They demonstrated that the nanostructures could evolve with time using moderate heating $\left(150{ }^{\circ} \mathrm{C}\right.$ for $\left.15 \mathrm{~min}\right)$; whereby, PCBM changed from well-separated to a partial attachment regime. Molecular mixing of polymer and fullerene parts is recognised to be present for many polymer:fullerene SCs and this plays an important role in both charge separation and recombination. ${ }^{26}$ The end-stage morphology for thermally annealed P3HT:PCBM films is phase separated domains of P3HT and PCBM crystals. ${ }^{40}$ The latter morphology does not enable efficient charge transport to the external circuit. (We discuss polymer:fullerene morphology further in Section 2.5.) The search for lower band gap semiconducting polymers (e.g., PTB7 (ref. 41)) and the use of processing aids for morphology enhancement (e.g., 1,8-diiodoctane, $\mathrm{DIO}^{\mathbf{4 2 - 4 4}}$ ) have resulted in major improvements of the PCE of research grade polymer:fullerene SCs, which are approaching $10 \%$ for single junction devices (later).

\subsection{Charge generation and transport processes within polymer:fullerene solar cells}

The process of photo-generation and charge transport to the external circuit within a photoactive layer consisting of a donor and acceptor ${ }^{47}$ is depicted in Fig. 4 and can be separated into five steps. The first step is light absorption and photogeneration of an exciton (Fig. 4(a)). An exciton is an electrostatically bound electron-hole pair. In the depiction given the geminate (initially formed) exciton is created within the donor polymer phase. The efficiency of the initial exciton generation is given by the photon absorption efficiency, $\eta_{\mathrm{A}}$. This parameter depends on factors such as the film thickness compared to the absorption length as well as $E_{\text {g. }}$.

Excitons in semiconducting polymers are short-lived species that tend to rapidly recombine (annihilate). Because most semiconducting donor polymers have low dielectric constants (of about ${ }^{48} 3$ ), excitons are tightly bound due to coulombic attraction and have an exciton diffusion length $\left(L_{\mathrm{ex}}\right)$ less than about $10 \mathrm{~nm}^{26}$ Consequently, the polymer phase domains should be less than about $20 \mathrm{~nm}$ in size in order for an interface with an acceptor to be close enough to permit exciton dissociation prior to geminate recombination. ${ }^{29}$ The efficiency of the excitons reaching this heterojunction without geminate recombination is given by the exciton diffusion efficiency ( $\left.\eta_{\text {diff }}\right)$ (Fig. 4(b)).

Having reached the donor/acceptor interface (Fig. 4(c)), exciton dissociation may occur if the energy difference (offset) between the LUMOs for the donor and acceptor exceeds the exciton binding energy. The latter can be as low as $0.12 \mathrm{eV}^{49}$ Charge generation (from dissociation) for polymer-based excitons involves electron transfer (rather than hole transfer). ${ }^{26}$ The efficiency of the dissociation process can be described in terms of the exciton dissociation efficiency, $\eta_{\text {diss }}$. The value for $\eta_{\text {diss }}$ approaches zero as the energy offset between the LUMOs approaches zero.
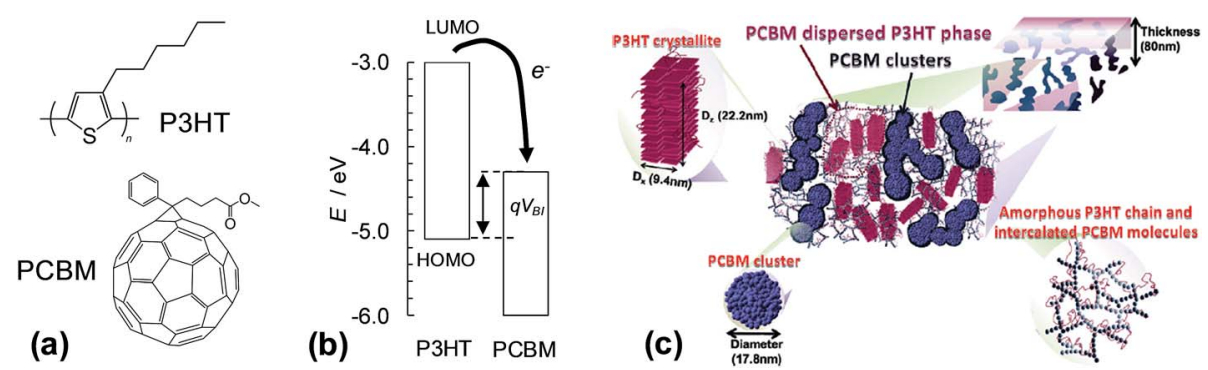

Fig. 3 Structures, energy levels and morphologies for polymer:fullerene composites. (a) shows the structures of P3HT and PCBM. (b) Energy level diagram for P3HT:PCBM. $V_{B 1}$ is the built-in voltage (see text) and $q$ is the electron charge. The energy levels for P3HT and PCBM are from ref. 45 and 46, respectively. (c) Schematic of the phase-separated morphology for P3HT:PCBM film comprising PCBM-dispersed P3HT phase, P3HT crystallites, an amorphous P3HT chain region and a network of intercalated PCBM molecules and PCBM clusters. (c) reproduced with permission from ref. 39. 

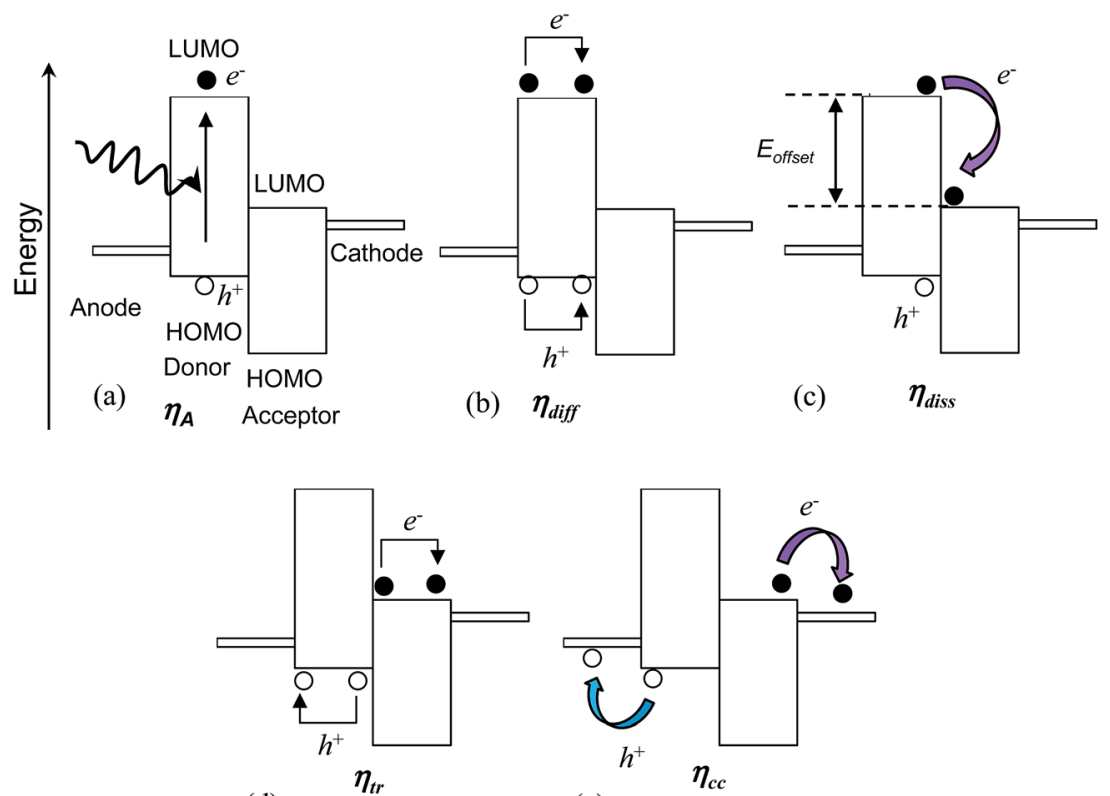

(e)

Fig. 4 Processes responsible for photocurrent within photoactive donor/acceptor composites. The processes involve light absorption and photogeneration of an exciton (a). The latter is followed by exciton diffusion to the donor/acceptor interface (b), exciton dissociation (c), transport to the photoactive layer/electrode interface (d) and collection of the charges by the electrodes (e) which transfers the photogenerated charges to the external circuit. Note that $\mathrm{e}^{-}$and $\mathrm{h}^{+}$represent an electron and hole, respectively.

Once the exciton has dissociated the free electron and hole migrate to the photocathode and photoanode, respectively. There are a number of processes that may direct the flow of charge carriers. The migration may occur due to the driving force from the gradient in chemical potentials of the electrons and holes at the donor-acceptor junction. ${ }^{27}$ The potential energy gradient originates from the difference between the donor HOMO and acceptor LUMO. Furthermore, charge concentration gradients can produce diffusion currents. ${ }^{27}$ Electron- and hole-blocking layers are often included in BHJ SCs to direct the charge migration to the desired electrodes in order to decrease recombination.

The photo-generated holes and electrons within $\mathrm{BHJ}$ photoactive layers migrate (via hopping) through interconnected donor and acceptor phases, respectively. In order to reach the respective electrode holes and electrons must avoid coming into contact at an interface, and undergoing non-geminate (bimolecular) recombination. Unfortunately, a high interfacial area favours non-geminate recombination, even though it reduces geminate recombination. The efficiency of the separated charges reaching the electrodes is given by the charge carrier transport efficiency $\left(\eta_{\text {tr }}\right)$ (Fig. $4(d)$ ).

Finally, the separated charges must cross the photoactive layer/electrode interfaces to reach the external circuit (Fig. 4(e)). The efficiency of charge transfer across this interface is given by the charge collection efficiency ${ }^{\mathbf{4 7}}\left(\eta_{\mathrm{cc}}\right)$. This parameter is sensitive to the nature of the electrical contact between the photoactive layer and the electrodes and decreases if these interfacial connections are highly resistive. It is also sensitive to the energy levels of each phase. ${ }^{47}$
The product of the above efficiencies gives the external quantum efficiency (EQE):

$$
\mathrm{EQE}=\eta_{\mathrm{A}} \eta_{\mathrm{diff}} \eta_{\mathrm{diss}} \eta_{\mathrm{tr}} \eta_{\mathrm{cc}}
$$

The EQE is the ratio of the number of electrons collected in the external circuit to the number of incident photons. Eqn (2) illustrates the difficulty of achieving high panchromatic EQE values for BHJ SCs because each of the five efficiency parameters must be optimised to give values as close as possible to unity. The parameters $\eta_{\text {diff }}$ and $\eta_{\text {tr }}$ are highly dependent on morphology. For some polymer:fullerene SCs EQE values of $100 \%$ have been reported over a limited spectral range. ${ }^{50}$ However, the EQE is usually significantly less than $100 \%$ over the whole solar wavelength range. Whilst the PCE generally increases with $\mathrm{EQE}$, a high EQE is not sufficient to guarantee a high PCE. This caveat originates from the dependence of the PCE on $V_{\text {oc }}$ and FF (eqn (1)). Conditions that favour high EQE values (and high $J_{\mathrm{sc}}$ values) may lead to non-optimal $V_{\mathrm{oc}}$ values.

Whilst the majority of polymer:fullerene SCs have a conventional design, ${ }^{1}$ some of the more recent, highest PCE devices, have adopted an inverted architecture. ${ }^{51,52}$ An example inverted device is shown in Fig. 5(a). Inverted structures can provide a PCE benefit because of vertical phase segregation and increased $\mathrm{FF}$ values. ${ }^{51}$ Inverted architectures are also more compatible with $\mathrm{R} 2 \mathrm{R}$ processing and their design avoids the necessity of using reactive cathode materials (e.g., Al), which can be detrimental to device stability. ${ }^{53}$ An inverted geometry enables the use of $\mathrm{Ag}$ which can be screen printed and is compatible with R2R processing. ${ }^{54}$ For the research grade device architecture shown in Fig. 5(a), $\mathrm{ZnO}$ and $\mathrm{MoO}_{x}$ acted as the 


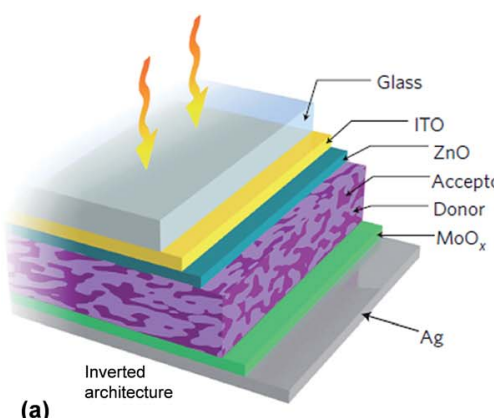

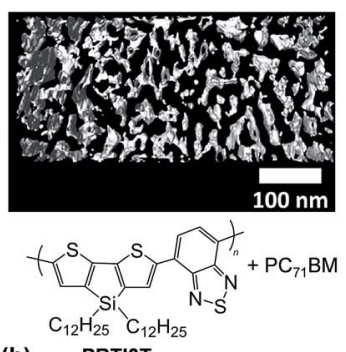

(b)

PBTI3T

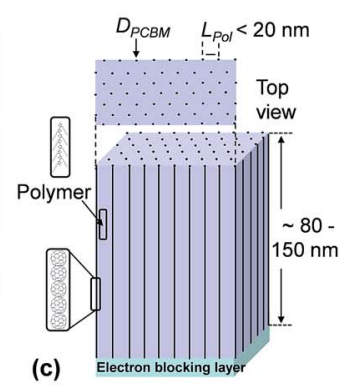

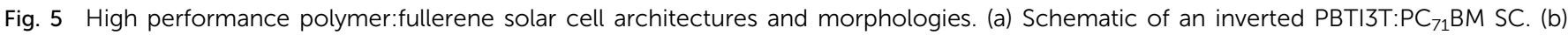
Electron tomography image showing morphology for a polymer:PC ${ }_{71} B M$ photoactive layer. The black and white areas are the $P C_{71} B M$ and polymer, respectively. (c) Depiction of one ideal morphology for a polymer:PCBM layer. $D_{\mathrm{PCBM}}$ and $L_{\mathrm{Pol}}$ are the PCBM column diameter and polymer domain length, respectively. Figures reproduced with permission from (a) ref. 51 and (b) ref. 29.

electron transport and hole transport matrix, respectively. ${ }^{51}$ Those layers prevented contact of the polymer and PCBM phases with the electrodes. ITO and Ag were the cathode and anode, respectively. For a conventional polymer:fullerene SC architecture, ITO is usually the photoanode. ${ }^{1}$

The overwhelming majority of $\mathrm{BHJ}$ SCs reported in the literature comprise small area devices and have usually been prepared using spin coating. Typically, a low concentration polymer solution and a fullerene solution are prepared separately and then mixed. Shortly after mixing spin-coating of the mixed solution onto substrate is conducted. Spin coating results in rapid solvent evaporation and phase separation. Solution processing additives such as $\mathrm{DIO}^{51}$ may be added to the organic solvent (e.g., chloroform ${ }^{51}$ ) prior to spin-coating to enhance the PCE. The composite films are then thermally annealed. ${ }^{51,52}$ The aim of these treatments is to increase the structural order present within the photoactive layers so as to reduce recombination. It is generally believed that establishing more direct pathways to the electrodes decreases the probability of bimolecular recombination. The photoactive layer thickness for BHJ SCs is often 80 to $200 \mathrm{~nm} .^{1,52}$

Fig 5(b) shows a high resolution electron tomography image of a polymer: $\mathrm{PC}_{71} \mathrm{BM}$ film. ${ }^{29}$ The latter diffracts electrons more strongly than the polymer phase and appears black. The length scale of the polymer phase separated domains $\left(L_{\text {pol }}\right)$ within these films is of the order of $\sim 20 \mathrm{~nm}$ which is about twice the value for $L_{\mathrm{ex}}$ and this morphology is considered ideal in terms of achieving high $\eta_{\text {diff }}$ values. Whilst the morphology shown in Fig. 5(b) is isotropic, the optimum morphology for a BHJ SC to achieve maximum $\eta_{\text {diff }}$ and $\eta_{\text {tr }}$ values is believed to be anisotropic and is depicted in Fig. 5(c). This morphology would consist of columns of vertically aligned acceptor phase (with electrically connected acceptor species and for aggregates within each column). The columns would be located within and separated by the polymer donor phase. Ideally, the columns should be equally spaced. The columns are depicted to be separated by $L_{\text {pol }} \simeq 20 \mathrm{~nm}$. An ultimate goal of BHJ SC research is to devise methods whereby this anisotropic, vertically oriented, morphology spontaneously forms both in research grade SCs and R2R-processed modules. Progress towards achieving this goal is discussed in Section 2.5.

\subsection{Factors controlling polymer:fullerene solar cell performance parameters}

We next consider factors controlling the three parameters that determine the PCE in eqn (1). Although the discussion given below concentrates on polymer:fullerene SCs, it also applies to the hybrid polymer SCs that are discussed in detail later.

The value for $J_{\mathrm{sc}}$ is determined by the EQE. Indeed, the integrated area of an EQE vs. wavelength plot is often used to test the validity of $J_{\mathrm{sc}}$ measured from $J-V$ plots. ${ }^{55}$ Therefore, the $J_{\text {sc }}$ value is controlled by the optical properties of the light absorbing phase ( $E_{\mathrm{g}}$ and $\alpha$ ) as well as the blend morphology. In addition, a key factor controlling $J_{\mathrm{sc}}$ is the charge mobility within the polymer phase. Photoactive layers with thicknesses that are small compared to the absorption length have low $\eta_{\mathrm{A}}$ values. Although thicker films will have higher $\eta_{\mathrm{A}}$ values, the relatively low mobility of the polymer phase (typically $10^{-3}$ to $10^{-4} \mathrm{~cm}^{2} \mathrm{~V}^{-1} \mathrm{~s}^{-1}$ (ref. 56)) means that higher series resistance decreases FF and, hence, PCE. A low charge mobility also increases recombination. Polymer-based SCs require a thickness trade-off to be made between $\eta_{\mathrm{A}}$ and $\eta_{\mathrm{tr}}$.

According to eqn (1) the PCE is proportional to the $V_{\text {oc }}$ value. In a seminal study, Scharber et al. ${ }^{45}$ compared the $V_{\mathrm{oc}}$ values for 26 polymer:PCBM SCs to the HOMO positions of the polymer donors. They showed that the following relationship applied:

$$
V_{\mathrm{oc}}=\frac{1}{q}\left\{\left|E_{\mathrm{D}(\mathrm{HOMO})}\right|-\left|E_{\mathrm{PBCM}(\mathrm{LUMO})}\right|\right\}-0.3
$$

where $q$ is the electron charge. The value of $0.3 \mathrm{~V}$ was initially considered to be an empirical factor, ${ }^{45}$ but was later shown to result from the temperature-dependence of the quasi-Fermi levels in the polymer and fullerene domains. ${ }^{57}$ The value for $\left(E_{\mathrm{D}(\text { HOMO })}-E_{\mathrm{A}(\mathrm{LUMO})}\right) / q$ is equal to the built-in potential $\left(V_{\mathrm{BI}}\right)$ and the latter is depicted in Fig. 3(b).

Eqn (3) was (and remains) very important for the design of polymer:fullerene SCs because it showed that $V_{\text {oc }}$ could be maximised by using polymer donors with deep HOMO energy levels. Scharber et al. $^{\mathbf{4 5}}$ also established a quantitative theoretical contour plot to guide polymer design to achieve improved PCE values. Their work showed that achieving a single polymer:fullerene with a PCE of $10 \%$ was theoretically possible. It followed from their study that to achieve a PCE of $10 \%$ for a 
polymer:PCBM SC the value for $E_{\mathrm{D}(\mathrm{LUMO})}$ of the polymer donor should be less than $\sim-3.9 \mathrm{eV}$ and $E_{\mathrm{g}}$ should be less than ${ }^{45}$ $1.74 \mathrm{eV}$. A suitable $E_{\mathrm{D}(\text { номо) }}$ value would be $\sim-5.7 \mathrm{eV}$. Fig. 6 shows PCE data from plotted as a function of polymer $E_{\mathrm{g}}$ for 60 polymer:fullerene SCs. It can be seen that the devices with the top 7 PCE values contained polymers with $E_{\mathrm{g}}$ values of $1.7 \pm 0.2 \mathrm{eV}$, which supports the recommendation regarding $E_{\mathrm{g}}$. We consider the other parameters later.

The FF value is determined by competition between sweepout of the photogenerated charge carriers and their recombination. ${ }^{29}$ The sweep-out of charge carriers is driven by the internal electric field, $V_{\text {int }}$, which is given by: $:^{29}$

$$
V_{\text {int }}=\frac{V_{\mathrm{oc}}-V_{\text {applied }}}{d}
$$

where $V_{\text {applied }}$ and $d$ are the applied potential and thickness of the $\mathrm{BHJ}$ layer, respectively. The sweep-out rate is limited by the polymer mobility and also the distance the holes and electrons must travel to reach their respective electrodes. It follows that the morphology of the $\mathrm{BHJ}$ layer has a strong influence on the sweep-out rate. For the morphology depicted in Fig. 5(c) the sweep-out rate and $\mathrm{FF}$ should be maximised because the distance the dissociated charges have to travel to the electrodes and also the probability of non-geminate recombination occurring would be minimised.

\subsection{Polymer donors}

Semiconducting polymers are the electron donors of the $\mathrm{BHJ}$ SCs discussed here and have been the subject of comprehensive reviews. ${ }^{24,56,58}$ Here, we focus on the key aspects of the polymers from the viewpoints of $V_{\mathrm{oc}}$, PCE and potential scale up. The overall aim of semiconducting polymer backbone design is to decrease and optimise $E_{\mathrm{g}}$ and $E_{\mathrm{D}(\text { номо) }}$, respectively, to maximise $J_{\mathrm{sc}}$ and $V_{\mathrm{oc}}$. Strategies for decreasing $E_{\mathrm{g}}$ include ${ }^{58}$ using polymer backbones with donor-acceptor units; ${ }^{59,60}$ stabilising the quinoid structure and incorporation of electron withdrawing groups.

Fig. 7 shows the structures and reported $E_{\mathrm{D}(\text { номо) }}$ and $E_{\mathrm{D}(\mathrm{LUMO})}$ energy levels for polymers that have been frequently been used for polymer:fullerene SCs. The polymers are classified as homopolymers (P3HT, MEH-PPV and MDMO-PPV), donor-acceptor (PCPDTBT, PDTPBT) ${ }^{\mathbf{6 1}}$ and quinoid type (PTB7

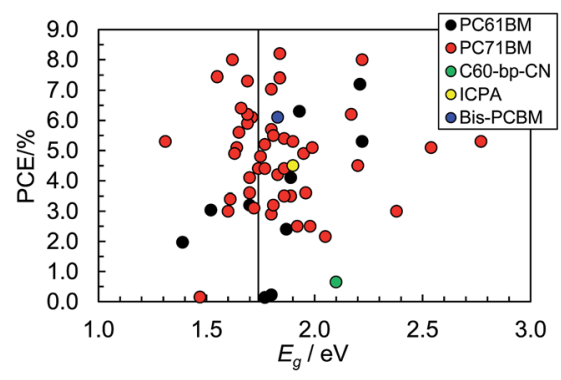

Fig. 6 Variation of PCE with $E_{\mathrm{g}}$ for polymer:fullerene SCs. The vertical line corresponds to $1.74 \mathrm{eV}$ (see text). These data were taken from Table 1. The identities of the acceptors are shown in Fig. 8.

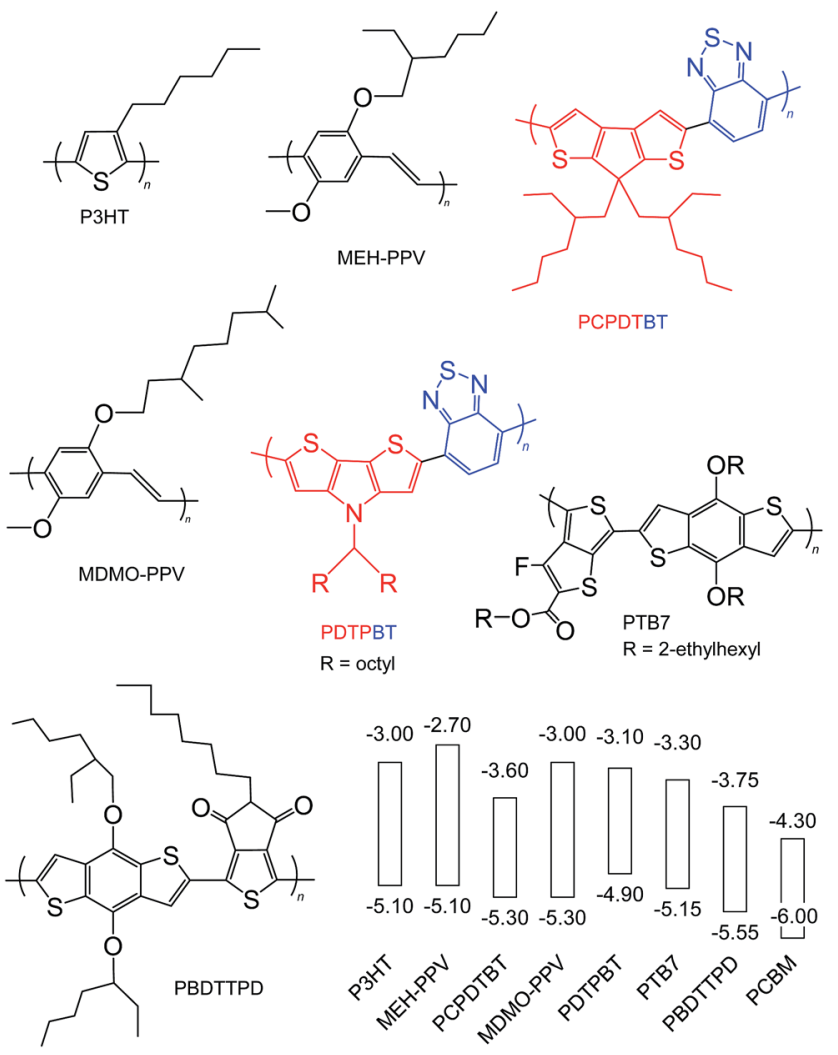

Fig. 7 Structures and energy levels for selected polymer donors. The energy levels for P3HT are taken from ref. 45 and 46 . The energy levels for MEH-PPV, PCPDTBT, MDMO-PPV, PDTPBT, PTB7 and PBDTTPD are taken from ref. 62, 63, 64, 65, 41 and 66. The energy levels for PCBM are shown for comparison and are from ref. 45. The red and blue units are the donor and acceptor units, respectively.

and PBDTTPD). ${ }^{58} \mathrm{D}-\mathrm{A}$ polymers contain alternating electronrich (donor) and electron deficient (acceptor) units. Internal charge transfer (ICT) from the donor to acceptor promotes backbone copolarity and is responsible for the decreased $E_{\mathrm{g}}$ values. One of the key advantages of D-A polymers is the ability to individually tune the $E_{\mathrm{D}(\text { номо) }}$ and $E_{\mathrm{D}(\mathrm{LUMO})},{ }^{56}$ which results from the ability to independently adjust the electron donating ability of the donor and electron affinity of the acceptor. ${ }^{58}$ Fig. 7 illustrates donor and acceptor units. Whilst a weak donor decreases $E_{\mathrm{D}(\mathrm{HOMO})}$ a strong acceptor decreases $E_{\mathrm{g}}$ by enhancing ICT. $^{58}$

Because the quinoid form has a lower resonance energy than the aromatic, polymer backbone design to favour quinoid formation across the repeat unit has been an effective strategy to decrease $E_{\mathrm{g}}{ }^{67}{ }^{67}$ This approach uses two aromatic units fused together whereby one of the units has a larger resonance energy than the other. ${ }^{58}$ Substituent engineering can be used to decrease $E_{\mathrm{D}(\text { номо) }}{ }^{68}$ for semiconducting polymers. Fluorine is the smallest electron withdrawing group and has a high Pauling electronegativity and decreases the $E_{\mathrm{D}(\text { номо })}{ }^{41,67}$ Fluorine also has a strong effect on polymer interactions and physical properties. Conversely, inclusion of electron donating groups increases $E_{\mathrm{D}(\text { НОмо). }}{ }^{69}$ In addition to altering the electronic properties, substituents can also affect the overall crystallinity 
of photoactive layers. Meager et al. showed that improved crystallinity and SC performance were obtained for diketopyrrolopyrrole polymers where the alkyl chain branching point was moved further from the backbone. ${ }^{70}$

The electrochemical $E_{\mathrm{g}}$ values for PCPDTBT, PDTPBT, PTB7 and PBDDTTPD are 1.7, 1.8, 1.85 and $1.8 \mathrm{eV}$, respectively. In this respect, these polymers (especially PBDDTTPD) most closely match the $E_{\mathrm{g}}$ design criteria from Scharber et al. ${ }^{45}$ discussed above $\left(E_{\mathrm{g}}<1.74 \mathrm{eV}\right)$. It can be seen from Fig. 7 (and elsewhere ${ }^{56}$ ) that there are now a wide range of polymers available for maximising the difference between $E_{\mathrm{PBCM}(\mathrm{LUMO})}$ and $E_{\mathrm{D} \text { (номо) }}$ as well as minimising $E_{\mathrm{g}}$. Many of these are commercially available; however, their cost generally increases strongly with repeat unit complexity.

A limitation of the D-A polymers is that they generally have poor spectral coverage at low wavelengths. SCs containing D-A polymers often rely on the acceptor (usually $\mathrm{PC}_{71} \mathrm{BM}$ ) to absorb photons from the lower wavelength region (to give complementary absorption) and contribute photocurrent. ${ }^{24}$ In this case excitons are created within the $\mathrm{PC}_{71} \mathrm{BM}$ phase and dissociation may involve hole charge transfer to the polymer phase. ${ }^{26}$ By tuning the $E_{\mathrm{g}}$ to the region of $1.74 \mathrm{eV}$ the new D-A and quinoidtype polymers have enabled major increases in $J_{\mathrm{sc}}$ to be achieved.

An important property that has favoured success of polymer:fullerene SCs is the tendency of substituted fullerenes (e.g., PCBM and $\mathrm{PC}_{71} \mathrm{BM}$ ) to have good compatibility with semiconducting polymers. The fullerenes are small enough and are sufficiently structurally similar to polymers such as P3HT that they can diffuse through the polymer matrix during annealing which improves the morphology. Cates et al. ${ }^{71}$ showed that intercalation of fullerenes could occur (i.e., molecular mixing) between the polymer side chains provided the latter were sufficiently well spaced to allow fullerene entry into this region. In that work intercalation increased the PCE due to an increased $J_{\mathrm{sc}}{ }^{71}$ The structure of the polymer can strongly influence (and even direct) the packing of the fullerene acceptors within polymer:fullerene SCs.

Whilst D-A and quinoid polymers have enabled preparation of BHJ SCs with very high PCE values, their complicated synthesis and high expense severely limits their potential for large scale use. Synthesis for the monomers usually involves more than 6 steps. In the case of PTB7 a total of 16 synthetic steps is required. ${ }^{24}$ Whilst multistep synthesis and expensive materials may be acceptable for the pharmaceutical industry, this is not likely to be the case for large scale deployment of polymer:fullerene SCs. For example a recent calculation for P3HT:PCBM SCs indicated that a solar array with an area of 137 $\mathrm{km}^{2}$ of SC foil would be required for production of $1 \mathrm{GW}_{\text {peak }}$. (The required area will of course decrease with increasing PCE.) The P3HT:PCBM SC foil in that study had a PCE of $1.5 \% .^{72}$ If we assume a hypothetical PTB7:fullerene SC foil efficiency of 3.0\% it can be shown that about 7 tons of $\mathrm{D}-\mathrm{A}$ polymer would be required to achieve $1 \mathrm{GW}_{\text {peak }}$ ! The masses of starting materials for a 16 step synthesis would be enormous. (Our PCE value used for this calculation may be optimistic because the PCE of scaledup polymer:fullerene SCs does not always follow that of research grade devices. ${ }^{72}$ ) Clearly, semiconducting polymers with low numbers of high yield (low cost) synthetic steps are essential for achieving low-cost large-scale deployment of polymer:fullerene SCs with short energy payback times.

\subsection{Fullerene acceptors}

Fullerenes are both n-type semiconductors and good electron acceptors. They have been reviewed extensively elsewhere. ${ }^{73} \mathrm{We}$ focus on the key aspects of fullerenes here. PCBM (i.e., $\mathrm{PC}_{61} \mathrm{BM}$ ) was first synthesised by Hummelen and Wudl et al. ${ }^{74}$ and can be synthesised in four steps. ${ }^{73}$ PCBM has good solubility in many organic solvents. Unfortunately, PCBM has a weak absorption in the visible region (Fig. 8) and relatively high absorption lengths (below). Consequently, PCBM does not contribute substantially to $J_{\mathrm{sc}}$ within polymer:fullerene SCs. Because of this deficiency fullerenes which absorb more strongly in the solar spectrum have been developed.

$\mathrm{PC}_{71} \mathrm{BM}$ was synthesised from $\mathrm{C}_{70}$ in order to increase the acceptor $\alpha$ value and spectral range. ${ }^{78} \mathrm{PC}_{71} \mathrm{BM}$ is used in

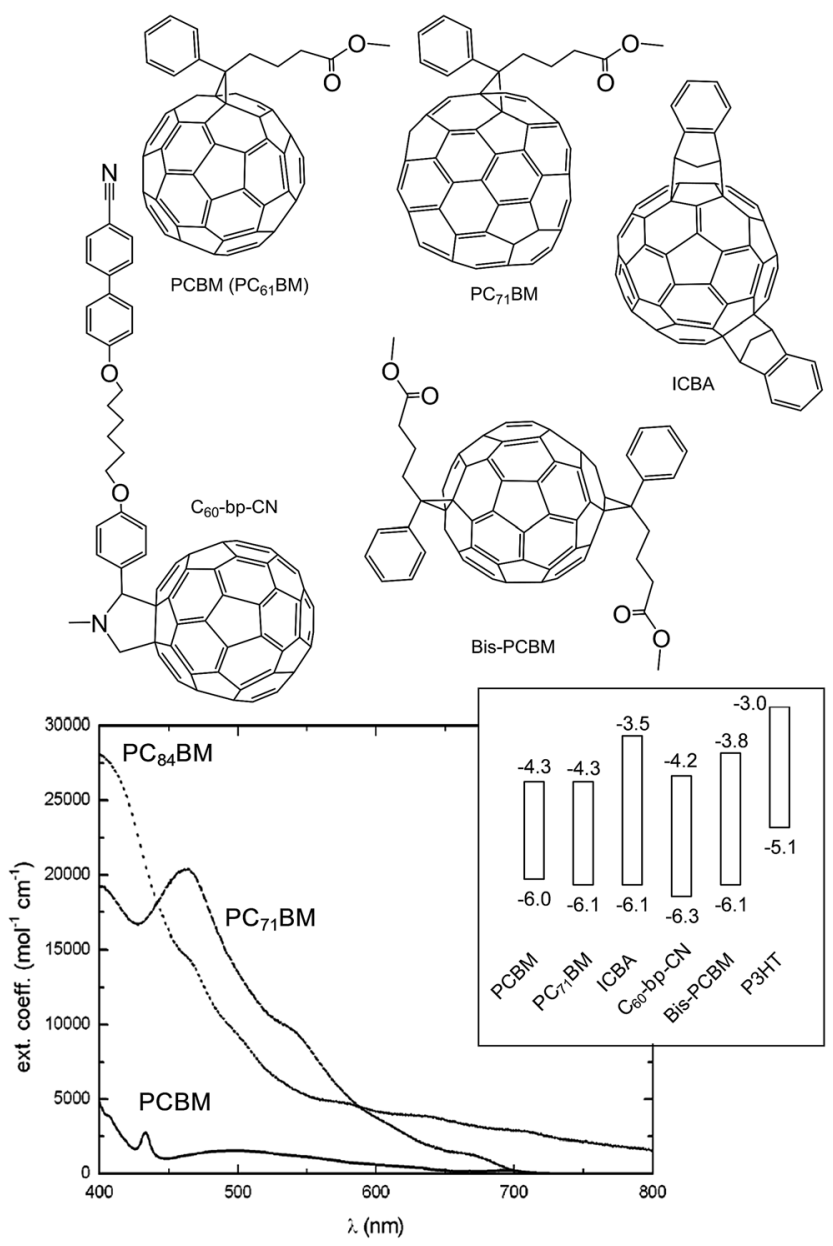

Fig. 8 Structures and energy levels for selected fullerenes. The energy levels for PCBM, $\mathrm{PC}_{71} \mathrm{BM}, \mathrm{ICBA}_{2} \mathrm{C}_{60}-\mathrm{bp}-\mathrm{CN}$ and bis-PCBM are from ref. 45, 52 and 75, 76 and 77, respectively. The energy levels for P3HT are shown for comparison. The UV-visible spectrum is reproduced with permission from ref. 73 . 
polymer:fullerene SCs to extend the absorption to $380-500 \mathrm{~nm}$ and is reported to give a PCE increase for polymer:fullerene SCs of about $10 \%$ compared to $\mathrm{PC}_{61} \mathrm{BM} .^{73}$ This success led to the synthesis of fullerenes with larger sizes (and more extensive conjugation) in order to further increase the light harvesting contribution from the acceptor. An increase in the size of the fullerenes to $\mathrm{PC}_{84} \mathrm{BM}$ increased $\alpha$ further and the absorption in the red part of the visible spectrum (Fig. 8). Unfortunately, the solubility of $\mathrm{PC}_{84} \mathrm{BM}$ decreased compared to PCBM. MDMOPPV:PC ${ }_{84} \mathrm{BM}$ SCs had relatively low $V_{\text {oc }}$ and PCE values ${ }^{79}$ compared to MDMO-PPV:PCBM.

Considerable effort has been applied to synthesising substituted fullerenes with HOMO and LUMO levels that can be tuned by the substituents. Substituted PCBM derivatives have been used to adjust the $V_{\text {oc }}$ values of the SCs through modification of the $E_{\mathrm{A}(\mathrm{LUMO})}$ levels (Fig. 8.). Although relatively high $V_{\mathrm{oc}}$ values have been achieved, ${ }^{75,77}$ the PCE values for these polymer:fullerene SCs have not yet surpassed those of the highest reported values for the leading polymer: $\mathrm{PC}_{71} \mathrm{BM} \mathrm{SCs}$ to our knowledge.

\subsection{Polymer:fullerene morphology}

The morphology of polymer:fullerene photoactive layers is a major factor affecting SC performance ${ }^{\mathbf{8 0 - 8 3}}$ It is widely accepted that efficient polymer:fullerene SCs require a $\mathrm{BHJ}$ morphology that achieves a compromise between charge dissociation and transport. ${ }^{82}$ Perfect dispersion of the acceptor within the donor matrix would maximise dissociation but not provide a pathway for the electrons to the photocathode. A morphology that provided perfect connectivity of an acceptor phase for electron transport would minimise dissociation. The best morphology for achieving high PCE values is believed to have a significant fraction of molecularly mixed polymer:fullerene phase next to phase separated pure material ${ }^{\mathbf{8 2}}$ (polymer and fullerene domains). Indeed, as the PCBM concentration is increased within the photoactive layer it can be considered to fill the mixed phase until saturated and excess PCBM phase separates. ${ }^{\mathbf{8 0}}$

The morphology of polymer fullerene SCs has a significant effect on $E_{\mathrm{g}}$ and $V_{\mathrm{oc}}$. For example, aggregation of P3HT can cause a red shift of up to $0.5 \mathrm{eV} \cdot{ }^{84}$ It is for these reasons that annealing of P3HT:PCBM, which promotes phase separation, usually results in a decrease of $V_{\mathrm{oc}}$ and an increase in $J_{\mathrm{sc}}{ }^{82}$ PCBM aggregates are proposed to have a deeper $E_{\mathrm{A}(\mathrm{LUMO})}$ compared to dispersed PCBM. ${ }^{85}$ This morphology is depicted in Fig. 3(c) and provides a mechanism whereby dissociated electrons can be transported from the mixed phase to the better inter-connected aggregated PCBM phase. Accordingly, the morphology of P3HT:PCBM is considered as a ternary blend of pure P3HT and PCBM phases with a P3HT:PCBM mixed phase.$^{80}$ Annealing or the use of solvent additives or polymer structural modification alter the proportions of each of the phases. Generally, solvent additives (such as DIO) provide increased fullerene solvency and facilitate domain development ${ }^{82}$ in the phase separated regions.
One exciting area of polymer:fullerene morphology study involves vertically aligning the morphologies to achieve the type shown in Fig. 5(c). The highest PCE example of this general morphology for a polymer:fullerene SC to date involves the use of anodised alumina template-assisted nanoimprint lithography. ${ }^{38}$ Although much progress has been made using this nanoimprint lithography ${ }^{\mathbf{8 6} 87}$ which is a potentially scalable technique, there have yet to be any studies reported that have demonstrated large-scale vertically aligned BHJ SCs. More work is urgently required with a view to applying the nanoimprinting stage to R2R production methods. Indeed, this could be an area where the PCE of large-scale R2R modulus could be greatly improved with major energy payback time reductions.

\subsection{Comparing $V_{\text {oc }}$ values for polymer:fullerene solar cells} with the Scharber equation

The Scharber equation (eqn (3)) has been widely used in the literature to guide rational design of polymer:fullerene SCs. Fig. 9(a) shows $V_{\text {oc }}$ data from 60 polymer:fullerene SCs plotted as a function of $E_{\mathrm{D}(\text { номо) }}-E_{\mathrm{A}(\mathrm{LUMO})}$. The data shown do not include inverted SCs. ${ }^{51,52}$ The values used for $E_{\mathrm{D} \text { (номо) }}$ and $E_{\mathrm{A}(\mathrm{LUMO})}$ are shown in Table 1 . Whilst the data are scattered they are generally consistent with the values calculated from eqn (3). The polymer:bis-PCBM (blue circle) and polymer:ICBA (yellow circle) SCs were designed to provide increased $V_{\mathrm{oc}}$ as discussed above. (These acceptors are shown in Fig. 8.). Although high $V_{\text {oc }}$ values were obtained (close to $1.0 \mathrm{~V}$ ), they were well below that predicted from eqn (3). It appears from the data shown in Fig. 9(a) that the maximum $V_{\text {oc }}$ values that can be readily achieved for polymer:fullerene SCs is in the vicinity of $1.0 \mathrm{~V}$. This
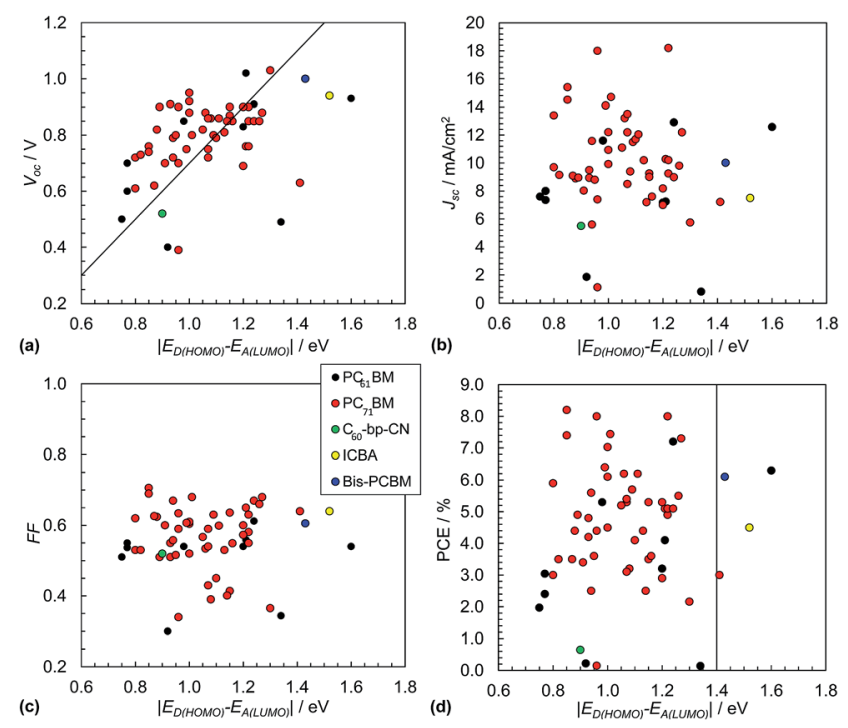

Fig. 9 Polymer:fullerene solar cell performance characteristics. Literature data for $V_{\text {oc }}(\mathrm{a}), J_{\mathrm{SC}}$ (b), FF (c) and PCE (d) from 60 selected polymer:fullerene SCs plotted as a function of $E_{\mathrm{D}(\mathrm{HOMO})}-E_{\mathrm{A}(\mathrm{LUMO})}$. The latter energy levels are depicted in Fig. 4(a). The full list of data appears in Table 1. Eqn (3) is plotted as the diagonal line in (a). The vertical line in $(\mathrm{d})$ corresponds to $E_{\mathrm{D}(\mathrm{HOMO})}=-5.7 \mathrm{eV}$. The legend applies to all of the graphs. The $x$-axis for these figures is equal to $q V_{\mathrm{BI}}$ and has the same numerical value as $V_{\mathrm{BI}}$. 
Table 1 Materials and performance parameters for polymer:fullerene SCs ${ }^{a}$

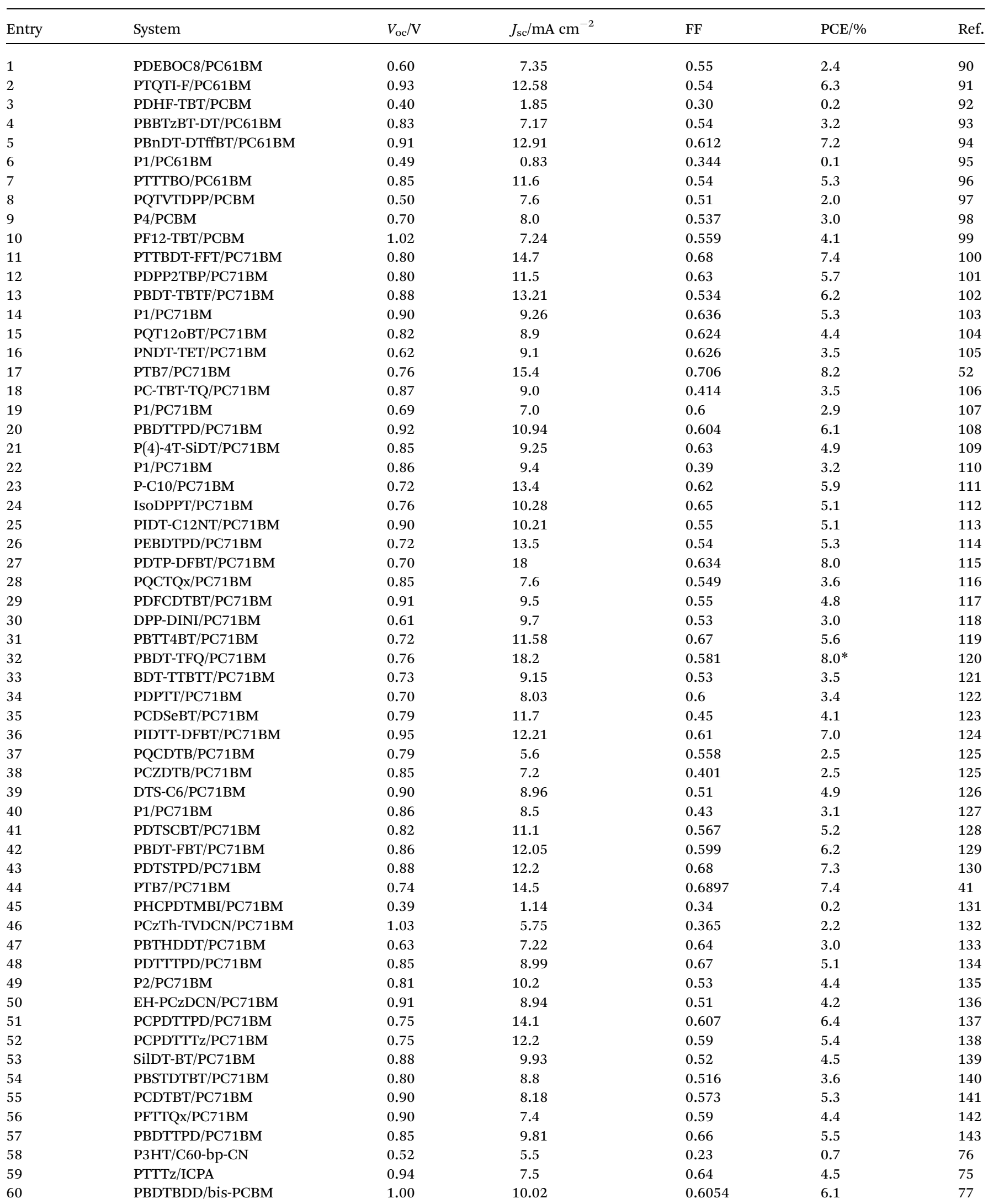

${ }^{a}$ Certified PCE values indicated with an asterisk. 
conclusion is further supported by the recent study of Casey et al. ${ }^{88}$ There may be an intrinsic maximum $V_{\text {oc }}$ value limitation in the region of $1.0 \mathrm{~V}$ for polymer:fullerene SCs.

The variation of $J_{\mathrm{sc}}$ with $E_{\mathrm{D}(\text { номо) }}-E_{\mathrm{A}(\mathrm{LUMO})}$ is shown in Fig. 9(b). The average $J_{\mathrm{sc}}$ values for these polymer:fullerene SCs containing $\mathrm{PC}_{71} \mathrm{BM}$ and PCBM were, respectively, $10.3 \mathrm{~mA} \mathrm{~cm}^{-2}$ $\left(\mathrm{SD}=3.1 \mathrm{~mA} \mathrm{~cm}^{-2}\right)$ and $7.7 \mathrm{~mA} \mathrm{~cm} \mathrm{~cm}^{-2}(\mathrm{SD}=4.1)$. The variation of the FF values with $E_{\mathrm{D}(\text { номо) }}-E_{\mathrm{A}(\mathrm{LUMO})}$ is shown in Fig. 9(c). The average $\mathrm{FF}$ for the polymer: $\mathrm{PC}_{71} \mathrm{BM}$ and polymer:PCBM SCs are $0.57(\mathrm{SD}=0.09)$ and $0.51(\mathrm{SD}=0.1)$, respectively. The average $J_{\mathrm{sc}}$ and $\mathrm{FF}$ values are much less than the maximum values possible (e.g., Fig. 2(b)) which is due to considerable recombination. A recent study has shown that the value for $J_{\mathrm{sc}}$ is sensitive to polymer orientation and increases as the polymer chains become increasingly face-on with respect to the polymer/ fullerene interface. ${ }^{89}$

Fig. 9(d) shows the variation of the PCE values with $E_{\mathrm{D}(\text { номо) }}$ $-E_{\mathrm{A}(\mathrm{LUMO})}$. The vertical line corresponds to a $E_{\mathrm{D}(\text { номо) }}$ of -5.7 $\mathrm{eV}$ for SCs containing PCBM and $\mathrm{PC}_{71} \mathrm{BM}$. The latter was reported by Scharber ${ }^{45}$ as being one factor that should provide SCs with a PCE of $10 \%$. Accordingly, SCs with values of $E_{\mathrm{D}(\text { номо) }}$ - $E_{\mathrm{A}(\mathrm{LUMM})}$ to the left of the vertical line in Fig. 7(d) (and $E_{\mathrm{D}(\text { номо) }}$ values greater than $-5.7 \mathrm{eV}$ ) are expected to have high PCE values (depending on other factors such as $E_{\mathrm{g}}$ and $E_{\mathrm{D}(\mathrm{LUMO})}$ values). It is noticeable that many of the PCE values obtained for SCs near the middle of this region are relatively high.

For the data shown in Fig. 9(d) the average PCE values for the polymer:fullerene SCs containing $\mathrm{PC}_{71} \mathrm{BM}$ and PCBM were $4.8 \%$ $(\mathrm{SD}=1.7 \%)$ and $3.4 \%(\mathrm{SD}=2.4 \%)$. These values are statistically different based on a student's $t$-test. Whilst the data shown indicate significant improvements in the PCE for polymer: $\mathrm{PC}_{71} \mathrm{BM}$ SCs compared to polymer:PCBM SCs, this must be tensioned against the fact that the former devices generally contained more advanced polymers with lower $E_{\mathrm{g}}$ values. Nevertheless, the view that the PCE for polymer: $\mathrm{PC}_{71} \mathrm{BM}$ SCs is higher than that of polymer:PCBM $\mathrm{SCs}^{73}$ is supported from the present limited analysis.

Table 2 shows data for the polymer:fullerene SCs published in the open literature that had the highest PCE values between 2008 and the time of writing (May, 2014). Polymer:PC ${ }_{71}$ BM SCs had the highest PCE values for each years between 2010 and May 2014. Whilst we have searched the literature as best we

Table 2 Materials and performance parameters for high efficiency polymer:fullerene solar cells reported in the open literature ${ }^{a}$

\begin{tabular}{llllllll}
\hline Polymer & Acceptor & PCE/\% & $V_{\text {oc }} / \mathrm{V}$ & $\begin{array}{l}J_{\text {sc }} / \mathrm{mA} \\
\mathrm{cm}^{-2}\end{array}$ & $\mathrm{FF}$ & Year & Ref. \\
\hline PTB7 & PC $_{71} \mathrm{BM}$ & 8.2 & 0.76 & 16.4 & 0.658 & 2014 & 144 \\
PBTI3T & PC $_{71} \mathrm{BM}$ & 8.7 & 0.85 & 12.8 & 0.763 & 2013 & 51 \\
PTB7 & PC $_{71} \mathrm{BM}$ & $9.2^{*}$ & 0.75 & 17.5 & 0.70 & 2012 & 52 \\
PBTTPD & PC $_{71} \mathrm{BM}$ & 7.3 & 0.92 & 13.1 & 0.61 & 2011 & 145 \\
PTB7 & PC $_{71} \mathrm{BM}$ & 7.4 & 0.74 & 14.5 & 0.69 & 2010 & 41 \\
PBDTTT-CF & PCBM & $6.8^{*}$ & 0.76 & 13.4 & 0.664 & 2009 & 67 \\
PSiF-DBT & PCBM & 5.4 & 0.9 & 9.5 & 0.507 & 2008 & 146
\end{tabular}

${ }^{a}$ Certified PCE values indicated with an asterisk.
Table 3 Materials and performance parameters for hybrid polymer $\mathrm{SCs}^{a}$

\begin{tabular}{|c|c|c|c|c|c|c|}
\hline Entry & System & $V_{\mathrm{oc}} / \mathrm{V}$ & $\begin{array}{c}J_{\mathrm{sc}} / \mathrm{mA} \\
\mathrm{cm}^{-2}\end{array}$ & $\mathrm{FF}$ & PCE $/ \%$ & Ref. \\
\hline 1 & $\mathrm{P} 3 \mathrm{HT} / \mathrm{CdS}$ & 0.84 & 4.85 & 0.532 & 2.17 & 156 \\
\hline 2 & P3HTcopol/CdS & 0.75 & 5.1 & 0.53 & 2.03 & 180 \\
\hline 3 & P3HT/CdS & 0.8 & 1.9 & 0.4 & 0.6 & 155 \\
\hline 4 & P3HT/CdS & 1.1 & 10.9 & 0.35 & 4.1 & 155 \\
\hline 5 & MEH-PPV/CdSe & 0.69 & 2.86 & 0.46 & 1.13 & 62 \\
\hline 6 & P3HT/CdSe & 0.616 & 6.04 & 0.562 & 2.09 & 181 \\
\hline 7 & PCPDTBT/CdSe & 0.76 & 7.25 & 0.38 & 2.1 & 182 \\
\hline 8 & PCPDTBT/CdSe & 0.67 & 9.0 & 0.515 & $3.13 *$ & 183 \\
\hline 9 & PCPDTBT/CdSe & 0.614 & 6.89 & 0.276 & 1.9 & 184 \\
\hline 10 & PCPDTBT/CdSe & 0.588 & 8.16 & 0.553 & 2.65 & 181 \\
\hline 11 & MEH-PPV/CdSe ${ }_{0.53} \mathrm{Te}_{0.47}$ & 0.63 & 0.65 & 0.35 & 0.18 & 62 \\
\hline 12 & MEH-PPV/CdSe ${ }_{0.78} \mathrm{Te}_{0.22}$ & 0.69 & 1.57 & 0.36 & 0.49 & 62 \\
\hline 13 & $\mathrm{P} 3 \mathrm{HT} / \mathrm{HgTe}$ & 0.44 & 7.1 & 0.419 & 1.3 & 185 \\
\hline 14 & PDPPTPT/PbS & 0.46 & 11 & 0.45 & 2.3 & 186 \\
\hline 15 & $\mathrm{PDTPBT} / \mathrm{PbS}$ & 0.57 & 13.06 & 0.51 & 3.8 & 161 \\
\hline 16 & PDTPQx/PbS & 0.38 & 4.2 & 0.34 & 0.55 & 187 \\
\hline 17 & $\mathrm{P} 3 \mathrm{HT} / \mathrm{TiO}_{2}$ & 0.6 & 1.65 & 0.42 & 0.42 & 176 \\
\hline 18 & $\mathrm{P} 3 \mathrm{HT} / \mathrm{TiO}_{2}$ & 0.44 & 2.76 & 0.36 & 0.42 & 166 \\
\hline 19 & MDMO-PPV/ZnO & 1.14 & 2.3 & 0.42 & 1.1 & 188 \\
\hline 20 & MDMO-PPV/ZnO & 1.03 & 2.0 & 0.41 & 0.7 & 189 \\
\hline 21 & $\mathrm{P} 3 \mathrm{HT} / \mathrm{ZnO}$ & 0.73 & 3.2 & 0.47 & 1.1 & 189 \\
\hline 22 & P3HT/ZnO & 0.69 & 2.19 & 0.55 & 0.92 & 190 \\
\hline 23 & P3HT/ZnO & 0.75 & 5.2 & 0.52 & 2.0 & 157 \\
\hline 24 & MDMO-PPV/ZnO & 0.81 & 2.4 & 0.59 & 1.6 & 191 \\
\hline 25 & MEH-PPV/ZnO & 0.88 & 3.45 & 0.5 & 1.52 & 192 \\
\hline 26 & PDTPBT/PbSe ${ }_{0.4} S_{0.6}$ & 0.57 & 14.66 & 0.66 & 5.5 & 193 \\
\hline
\end{tabular}

could, it is not possible to be certain that we have captured the record SCs for each of the years considered. However, the trend is certainly clear. The PCE and $J_{\mathrm{sc}}$ values have been increasing steadily over the past 6 years. We return to this point later.

There have been several announcements from companies concerning polymer SCs with efficiencies greater than $10 \%$. Mitsubishi Chemical Corporation announced PCE values of 11.0 (ref. 147) and $11.7 \%$ (ref. 148) in 2012 and 2013. Heliatek announced a PCE of $12.0 \%$ in $2013 .{ }^{149}$ At least one or more of these SCs may have two or more junctions. It is hoped that their processes are able to maintain high PCEs upon scale-up and their technologies translate to large scale, low cost, SC deployment in the near future.

\section{Hybrid polymer solar cells}

Hybrid polymer SCs contain photoactive layers comprising at least two components each with a distinct chemical composition. For this discussion one component is an organic semiconducting polymer and the other is an inorganic semiconducting nanoparticle (NP). A number of reviews have been published concerning hybrid polymer SCs.,150-153 The blending of the NPs with the polymer matrix can be achieved either by mixing, ${ }^{154}$ linking both components together ${ }^{155}$ or by in situ NP growth. ${ }^{156,157}$ One-pot preparation methods have also been used. ${ }^{158}$ The term nanocrystal (NC) is used here to describe 
nanometre-sized crystals; whereas, nanorods (NRs) represents rod-shaped nanometre-sized particles. NP is used to encompass NC and NR or nanometre-sized particles of arbitrary shape. Semiconducting NCs and NRs are also known as quantum dots and quantum rods, respectively.

The first demonstration of a hybrid polymer SC was by Alivisatos et al. ${ }^{159} \mathrm{~A}$ design aim for hybrid polymer SCs is to use the high $\alpha$ values for semiconducting NPs to provide acceptors that strongly contribute to $J_{\mathrm{sc}}$. Semiconductor NPs typically have $\alpha$ values of about ${ }^{160} 10^{5} \mathrm{~cm}^{-1}$, which gives absorption lengths of about $100 \mathrm{~nm}$. The latter value is within the thickness range of hybrid polymer SC photoactive layers. ${ }^{1}$ The high $\alpha$ values for NPs can extend to near-IR wavelengths, which is an additional advantage for hybrid SCs.

Semiconducting NPs can be prepared using solution based methods (i.e., solvothermal methods). Their synthesis procedures allow fine control of the NP size and this, in turn, allows fine control of their $\alpha$ values, energy levels ${ }^{161,162}$ and $E_{\mathrm{g}}$ values. Moreover, the NP synthesis can often be simply modified to enable preparation of $\mathrm{NRs}^{163}$ and other geometries ${ }^{164}$ which means that there is design flexibility afforded by NPs that is not present for fullerenes. Whilst NCs (Fig. 10(a)) and NRs (Fig. 10(b)) are common other morphologies have been used in hybrid polymer SCs. CdSe is one of the most versatile in this regard and can be prepared as NCs, NRs, tetrapods (Fig. 10(c)) and hyperbranched forms (Fig. 10(d)). Semiconducting NPs usually have high crystallinity and mobilities, which are qualities that are advantageous for charge transport.

Semiconducting NPs usually aggregate when dispersed in the organic solvents used to prepare hybrid polymer SCs (such as chlorobenzene or dichlorobenzene). An exception to this rule is $\mathrm{ZnO}$ NCs which have good dispersion stability due to surface acetate groups that are produced during synthesis. ${ }^{163}$ The dispersibility of semiconducting NPs can be improved greatly by coating the NPs with ligands that comprise binding groups and hydrophobic sequences. The ligands also increase the compatibility of the NPs with the hydrophobic semiconducting polymers during film deposition. Unfortunately, the ligands are usually insulating, which obstructs charge transport involving the NPs within photoactive films. Consequently, the ligands must be removed in order to enable efficient charge separation and transport.

The NP dispersion stability decreases upon ligand removal which has adverse effects on photoactive layer morphology if the ligand is removed prior to solvent evaporation. An early approach to removing bulky ligands used ligand exchange with pyridine $^{154}$ for CdSe NPs. Pyridine was subsequently removed from the CdSe surface by heating. Although this approach was successful in increasing the PCE of the SCs the colloidal stability of the dispersions was compromised and NP aggregation was evident in the composite films..$^{154}$ The morphology of films prepared from colloidally unstable dispersions is very sensitive to the mixing procedures used and can adversely affect reproducibility. Achieving reproducible, controlled, morphologies is especially important in the context of future translation of hybrid SCs to large scale deployment.

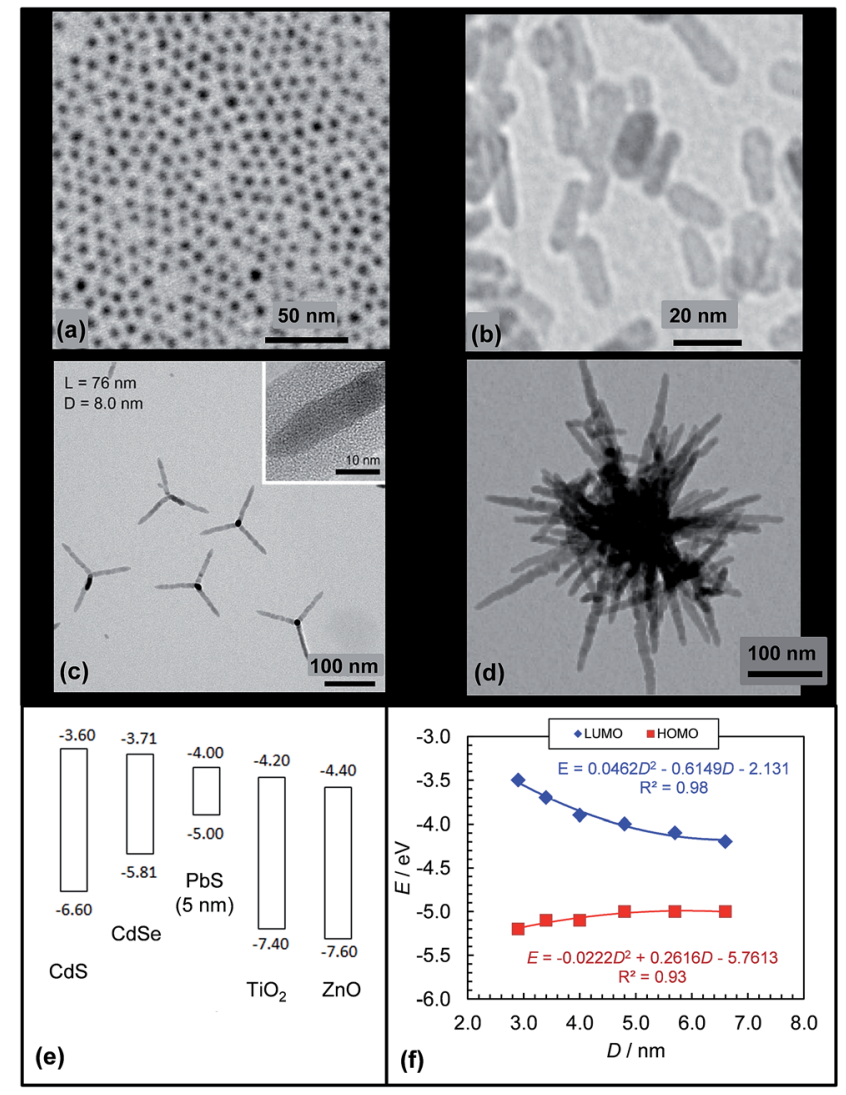

Fig. 10 Architectures and energy levels for selected inorganic acceptors. TEM images of PbS NCs (a), ZnO NRs (b), CdSe tetrapods (c) and hyperbranched CdSe (d). (e) Energy levels for various NCs. The energy levels for $\mathrm{CdS}, \mathrm{CdSe}, \mathrm{PbS}, \mathrm{TiO}_{2}$ and $\mathrm{ZnO}$ were obtained from ref. 62, 155, 165, 166 and 167. (f) Size dependence of PbS NC energy levels plotted from the data reported in ref. 165. Figures reproduced with permission from: (b) ref. 168, (c) ref. 163 and (d) ref. 164.

Whilst it is understood that valence and conduction bands are strictly more appropriate for bulk semiconductors, many of the inorganic semiconducting NPs discussed here are subject to quantum confinement. The latter causes the energy levels to become discrete. Consequently, HOMO and LUMO will be used throughout this discussion for NP energy levels, as is often used for semiconducting NCs such as PbS. ${ }^{165}$ When the size of semiconducting NCs is comparable to their Bohr radius, sizetuneable energy levels and also $V_{\mathrm{oc}}$ and $E_{\mathrm{g}}$ values result. This size-tuneability of the energy levels is unique to semiconducting NCs and NRs and is readily achieved by varying the reaction time. ${ }^{169}$

There are a range of NPs that have been used for hybrid polymer SCs and the energy levels for selected systems are shown in Fig. 10(e). In order to provide suitable energy offsets to act as efficient acceptors the relative order of the NP HOMO and LUMOs compared to the polymer donors should be the same as those for the P3HT:PCBM SCs (see Fig. 3(b)). In addition to sizetuneable energy levels, NPs also provide the ability to tune the energy levels and $E_{\mathrm{g}}$ values by alloying. A recent hybrid polymer SC used $\mathrm{PbS}_{x} \mathrm{Se}_{1-x} \mathrm{NC}$ alloys. ${ }^{170} \mathrm{~A}$ key advantage of alloying is that energy level tuning can be conducted at constant NC size. 
$\mathrm{PbS}$ NCs have recently been shown to provide relatively high PCEs (of up to $3.8 \%$ ) for hybrid polymer SCs. ${ }^{161}$ This improvement became possible due to identification of the energy levels for PbS NCs. Hyun et al. ${ }^{\mathbf{1 6 5}}$ were the first to report the variation of the HOMO and LUMO energy levels for PbS NCs (Fig. 10(f)). Those data enabled the rational design and selection of a polymer donor with a HOMO that was less deep than that of $\mathrm{PbS}^{161}$ (energy levels shown in Fig. 11(b)).

NCs subject to quantum confinement have the potential to provide more than one electron per photon within SCs. ${ }^{171}$ This process, termed multi-exciton generation (MEG) could provide SCs with efficiencies that exceed the Shockley-Queisser theoretical limit ${ }^{25}$ of $30 \%$. The thermodynamic limit for the PCE from a MEG-based cell is $66 \% .{ }^{171}$ MEG has been reviewed in detail elsewhere. ${ }^{\mathbf{1 7 1 - 1 7 3}}$ When the energy levels within NCs are quantised the rate of thermal energy loss from a photoexcited electron decreases. A photoexcited electron may give up some of its energy to the lattice through collisions and excite another electron across the band gap. In order for MEG to occur the incident photon energy must be at least integer multiples of $E_{\mathrm{g}}$. Multiple electrons have been extracted from PbS NCs within photosensitised dye sensitised solar cells. ${ }^{174}$ However, multiple electron collection required an incident photon energy that was at least $2.5 E_{\mathrm{g}}$. MEG has recently been successfully used to increase photocurrent generation by about $4 \%$ in a solid state PbSe NC based SC. ${ }^{175}$ However, more work is needed to push the MEG-onset threshold closer to $2 E_{\mathrm{g}}$, where a $30 \%$ increase in photocurrent is predicted. ${ }^{\mathbf{1 7 5}}$ MEG would seem to have good potential for increasing the PCE for hybrid polymer SCs. In order to fully benefit from MEG the donor and acceptor should have complementary absorptions and the $J_{\text {sc }}$ contribution due to the acceptor should be maximised. A high NP content within the hybrid polymer SC would also be needed.

\subsection{Overcoming the ligand and morphology challenges for hybrid polymer solar cells}

Two key challenges that adversely affect the PCE of hybrid polymer SCs are the presence of residual insulating ligand and poor morphology. Dispersed semiconducting NPs have significant inter-particle attraction due van der Waals attraction, depletion interactions and dipole-dipole interactions (for CdSe NRs). ${ }^{1}$ These attractive interactions cause NP aggregation and polymer phase separation during solvent evaporation and hybrid polymer film formation. This feature is pronounced for inorganic NPs ( $c f$. fullerenes) because of their larger size. Consequently, there are strong driving forces that promote uncontrolled NP aggregation within hybrid polymer films prepared by blending NP dispersions and semiconducting polymer solutions. ${ }^{1}$ Furthermore, because of their large size the NPs are less able to migrate when hybrid polymer films are annealed. Consequently, the kinetically trapped NP phase is locked in place. NP aggregation results in low $J_{\mathrm{sc}}$ values due to geminate recombination which occurs because a high proportion of excitons formed in the relatively large polymer domains do note reach a NP interface before recombining. NP aggregation increases the average polymer domain size to beyond about $20 \mathrm{~nm}$. A number of workers have developed innovative alternative approaches for avoiding NP aggregation as well as insulating problems from residual insulating ligand and these will be discussed below.

Fig. 11(a) shows a novel hybrid polymer SC fabrication approach used for PDTPBT:PbS SCs. Seo et al. ${ }^{161}$ established a method for avoiding the colloidal stability problems associated with ligand displacement prior to hybrid film deposition. After spin coating PDTPBT:PbS films, they added 1,2-ethanedithiol (EDT) to the top of the films using another spin coating step. EDT was able to permeate through the PDTPBT:PbS layer and displaced the oleic acid (OA) ligand. Moreover, EDT acted as a

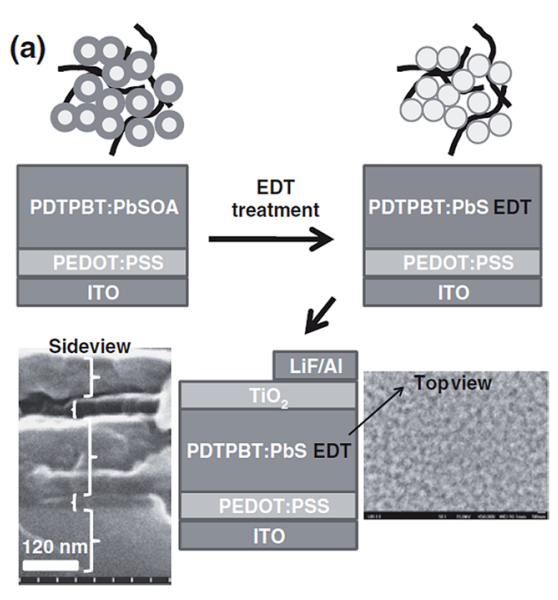

(b)
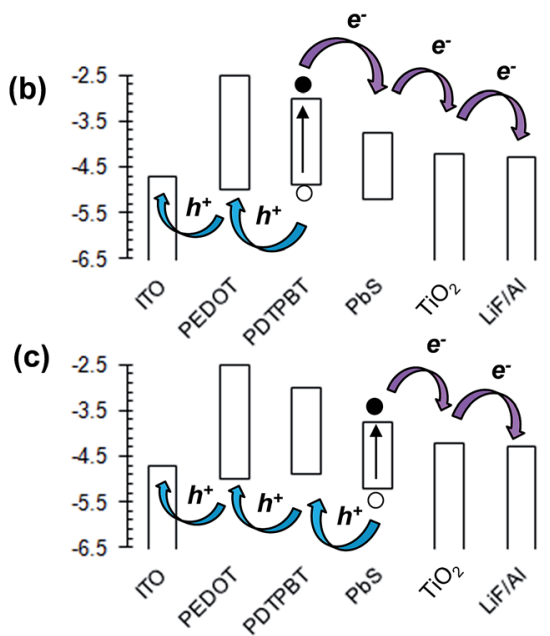

Fig. 11 Hybrid polymer solar cell construction and energy levels. (a) Assembly of EDT-treated PDTPBT:PbS SC. The SEM image shows a side view of the SC photoactive layer. ${ }^{161}$ The structure of PDTPBT is shown in Fig. 7. OA and EDT are oleic acid and 1,2-ethanedithiol. (b) Energy level diagram for the SC constructed using values in ref. 161. The arrows used here depict photogeneration of charges from both PDTPBT and PbS. The excitons depicted in (b) were created in the polymer phase; whereas, those depicted in (c) were created in the NC phase. (a) reproduced with permission from ref. 161. 
(short) bridging ligand that promoted electrical contact between neighbouring PbS NCs. Their hybrid polymer SCs had photocurrent contributions from both the PDTPBT and Pb NCs. Although the NC sizes were not reported, ${ }^{\mathbf{1 6 1}}$ when the HOMO and LUMO energy levels given in that study are compared to those reported by Hyun et al. ${ }^{\mathbf{1 6 5}}$ (see Fig. 10(f)) an average PbS NC diameter was between about 3 and $4 \mathrm{~nm}$ can be estimated. Their hybrid polymer SCs had a maximum PCE of $3.8 \%$, which was a record for hybrid polymer SCs containing PbS.

Fig. 11(b) and (c) depict the proposed exciton formation and transport pathway for the hybrid:polymer SC where both the polymer and NC produce excitons when irradiated. For illustration purposes we use the energy levels that apply to the SC reported by Seo et al. ${ }^{\mathbf{1 6 1}}$ The general charge transport pathway for hybrid polymer SCs depicted in Fig. 11(b) and (c) has been discussed by Reiss et al. ${ }^{152}$ The diagram shows how judicious selection and control of the energy levels within hybrid polymer SCs is required to provide exciton dissociation from the polymer and NC phase and maximise contributions to $J_{\mathrm{sc}}$. The PDTPBT:PbS SCs of Seo et al. ${ }^{161}$ contained polymer and NCs that absorbed photons in complementary regions of the spectrum, and gave two sources of photocurrent that contributed to the relatively high PCE values obtained.

Another method for reducing the effects of poor morphology control within hybrid polymer SCs is to use anisotropic NPs. Recently, scanning transmission electron microscopy using high-angle annular dark-field imaging (STEM-HAADF) was used to visualise the morphologies of $\mathrm{P} 3 \mathrm{HT}: \mathrm{TiO}_{2} \mathrm{NC}$ and $\mathrm{NR}$ films ${ }^{\mathbf{1 7 6}}$ (Fig. 12(a)-(d)). Those workers found that the NRs provided fewer network junctions and reduced inter-NP hopping which increased the charge transport efficiency. The conclusion that the use of high aspect ratio nanoparticles (i.e., NRs) increases the PCE of hybrid polymer:nanoparticle films confirmed the earlier conclusion reached by Alivisatos et al. in their study of
P3HT:CdSe SCs. ${ }^{177}$ Although the values for $V_{\text {oc }}$ for the P3HT: $\mathrm{TiO}_{2}$ SCs were respectable $(0.60$ to $0.69 \mathrm{~V})$ the $J_{\mathrm{sc}}$ values were low (less than or equal to $3.10 \mathrm{~mA} \mathrm{~cm}^{-2}$ ). The impressive high resolution topography images (Fig. 12(a)-(d)) reveal significant nanometre scale inhomogeneity of the NC and NR distributions within the composite films, which suggests that aggregation occurred. It appears that randomly oriented NRs do not seem capable of providing a solution to the aggregation problem on their own. Several groups have blended NRs with NCs in an attempt to use the NCs to fill the voids between $\mathrm{NRs}^{168,170}$ and beneficial increases in PCE occurred.

Ren et $a l .{ }^{155}$ used added non-solvent to form P3HT nanowires and grafted CdS NCs onto the nanowire surfaces via a solvent exchange method. They suggested that addition of specific solvents changed the NC deposition from a non-grafted (Fig. 12(e)) to a chemically grafted state (Fig. 12(f)) which used the heterocyclic S on the P3HT as a ligand for the CdS NCs. Good electrical contact between neighbouring CdS NCs was achieved using a post film-deposition EDT treatment. Although important questions remain concerning the design rules for driving the heterocyclic S-CdS interaction using added nonsolvent, the study is arguably the best example of achieving morphology control for hybrid polymer SCs. The PCE of $4.1 \%$, was a record value for a hybrid polymer SC.

An innovative approach for circumventing both the ligand and morphology problems for hybrid polymer:NP films involves in situ NP formation within semiconducting polymer films. ${ }^{156,157}$ The advantages of an in situ approach are that the initial state for the NP precursors is a molecularly dispersed solution and ligand is not required. This approach has been used for P3HT:ZnO (ref. 157) and CdS:P3HT (ref. 156) films. The maximum PCE value achieved for these NC-based SCs were 2.0 (ref. 157) and $2.2 \%,{ }^{156}$ respectively. The limitations of in situ NC preparation approaches are that it is difficult to achieve very
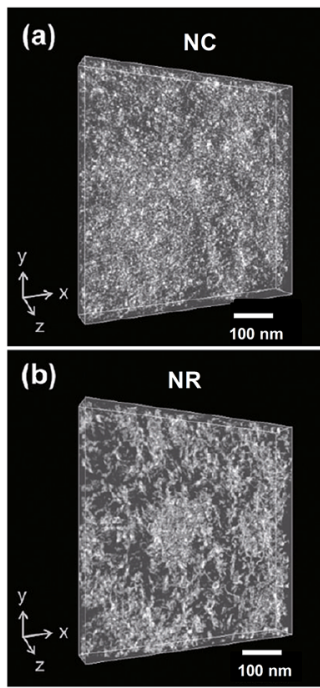
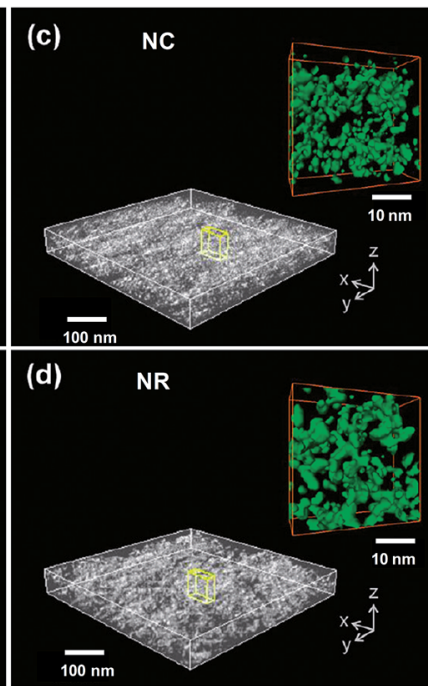

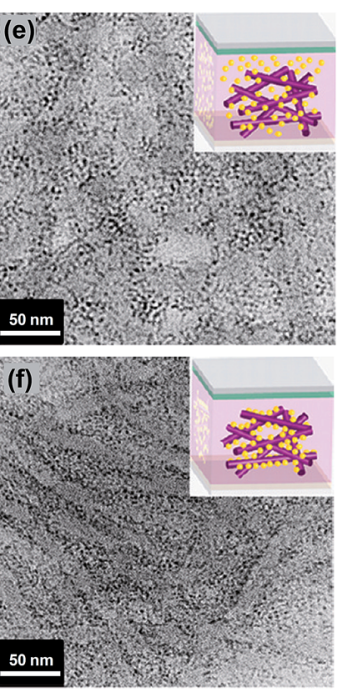

Fig. 12 Nanomorophologies of $\mathrm{P} 3 \mathrm{HT}: \mathrm{TiO}_{2}$ films. STEM-HAADF electron tomography images of P3HT: TiO $2 \mathrm{NC}^{(a}$ and c) and NR (b and d) hybrid thin films viewed from different angles. The insets for (c) and (d) show connective networks along the film direction. (e) and (f) show TEM images of P3HT:CdS films prepared (e) without grafting and (f) with grafting using by a solvent exchange method. The images from (a)-(d) and (e) to (f) are from ref. 176 and 155, respectively. Figures reproduced with permission from: (a)-(d), ref. 176; (e) and (f), ref. 155. 
high NC loadings and control over the NP particle size polydispersity. In both studies discussed above there was evidence of NP aggregation. ${ }^{156,157}$

\subsection{Comparing $V_{\text {oc }}$ values for hybrid polymer solar cells with the Scharber equation}

It is often assumed that the $V_{\mathrm{oc}}$ value for hybrid polymer SCs is proportional to the magnitude of $E_{\mathrm{D} \text { (номо) }}-E_{\mathrm{A}(\mathrm{LUMO})} \cdot{ }^{152}$ This was tested using polymer:NC SC data from 26 systems (see Fig. 13(a)). The polymer:ZnO systems were exemplary because they had relatively high $V_{\mathrm{oc}}$ values with all values greater than those predicted from eqn (3). ZnO appears to behave as an exceptional acceptor for hybrid polymer SCs in this regard. The $V_{\text {oc }}$ behaviour for the polymer:ZnO SCs contrasts to the other polymer:NC SCs which had $V_{\text {oc }}$ values that were mostly much lower than those expected from eqn (3). This trend contrasts to the behaviour observed for the polymer:fullerene SCs (Fig. 9(a)). There is also some evidence of linearity for the data from the hybrid polymer SCs not containing ZnO shown in Fig. 13(a) with a gradient that is lower than that predicted from eqn (3) if the P3HT nanowire/CdSe system ${ }^{\mathbf{1 5 5}}$ is neglected (red open square).

Whilst it is not possible to be certain about the origin of the differences in the trends for the $V_{\mathrm{oc}}$ values between the hybrid polymer SCs containing ZnO NCs and the others shown in Fig. 13(a) there appears to be one general feature that distinguishes the data sets, which is the absence of added ligand during NC preparation. ZnO dispersions do not require added ligand for colloidal stability. ${ }^{163}$ By contrast the other (non-ZnO) NC dispersions required added ligand, which was often trioctylphosphine oxide (TOPO) or OA, or else the NCs were generated in situ. It is known that coordinating ligands can
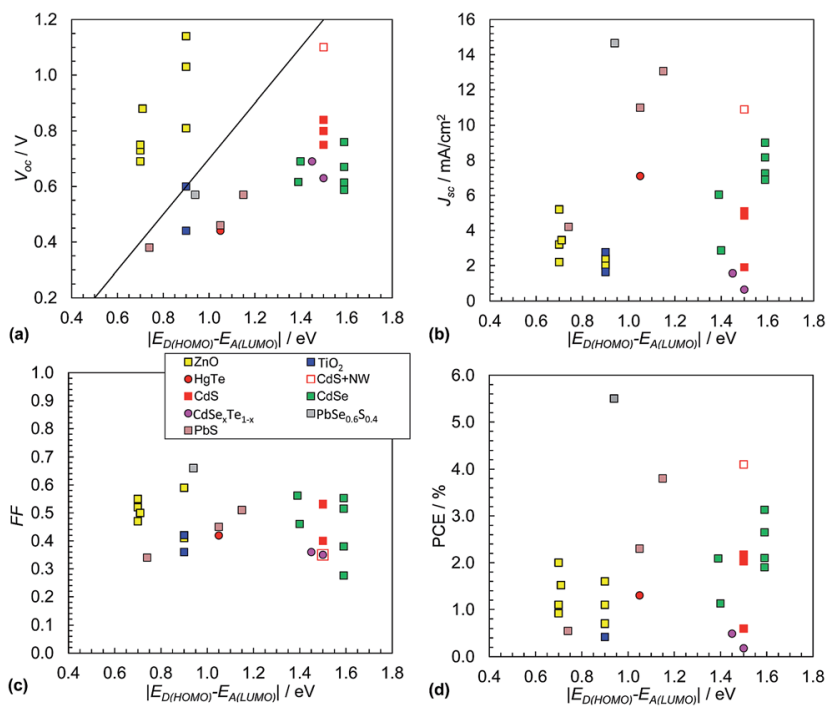

Fig. 13 Hybrid polymer:nanocrystal solar cell performance characteristics. Literature data for $V_{\text {OC }}(a)$ and $J_{\text {SC }}$ (b), FF (c) and PCE (d). The data are from 26 selected polymer:NC SCs. The data appear in Table 3. Eqn (3) is plotted as the diagonal line in (a). Data for hybrid polymer SCs containing NRs or tetrapods are not included. The legend for (c) applies to all figures. The $x$-axis for these figures is equal to $q V_{\mathrm{BI}}$ and has the same numerical value as $V_{\mathrm{BI}}$. affect $V_{\mathrm{oc}}$ through modification of $E_{\mathrm{A}(\mathrm{LUMO}) \cdot{ }^{178}}$ It can be seen from Fig. 13(a) that a major challenge for the majority of the non-ZnO containing hybrid polymer SCs is to increase the $V_{\text {oc }}$ values to closer to that predicted by the Scharber equation. A recent study has shown that NC size is important in determining $V_{\text {oc }}$ for polymer:CdSe SCs. It was found that $V_{\mathrm{oc}}$ decreased due to traps, which became increasingly significant as the NC size decreased. ${ }^{179}$

The hybrid polymer SCs that have given the highest $J_{\mathrm{sc}}$ values to date are those containing $\mathrm{PbS}$ or $\mathrm{PbSe}_{0.6} \mathrm{Se}_{0.4}$ alloys (Fig. 13(b)). The CdS/P3HT nanowire $\mathrm{SC}^{\mathbf{1 5 5}}$ is an exception to this trend and demonstrates how increasing order of the NCs and polymer can increase $J_{\mathrm{sc}}$. The average $J_{\mathrm{sc}}$ value for the hybrid polymer SCs $\left(5.4 \mathrm{~mA} \mathrm{~cm}^{-2}, \mathrm{SD}=3.8 \mathrm{~mA} \mathrm{~cm}^{-2}\right)$ is about half that for the polymer: $\mathrm{PC}_{71} \mathrm{BM}$ SCs (Fig. 9(b)). The lower $J_{\mathrm{sc}}$ for the hybrid polymer SCs is attributed to NC aggregation and/or the presence of residual ligand.

The FF values for the hybrid SCs (Fig. 13(c)) have an average value of 0.46 ( $\mathrm{SD}=0.09$ ), with the highest being 0.67 for the SCs containing $\mathrm{PbSe}_{0.6} \mathrm{~S}_{0.4}$. These are relatively low $\mathrm{FF}$ values compared to the average FF for the polymer: $\mathrm{PC}_{71} \mathrm{BM}$ SCs above. This difference is probably due to the greater extent of recombination that occurs within hybrid polymer SCs.

Whilst it is difficult to discern a clear trend for the PCE values (Fig. 13(d)) the highest values occurred when $\mid E_{\mathrm{D} \text { (номо) }}-$ $E_{\mathrm{A}(\mathrm{LUMO})} \mid$ is 0.9 to $1.5 \mathrm{eV}$, which is broadly in line with the results for the polymer:fullerene SCs (Fig. 9(d)). The average PCE value was $1.8 \%$ ( $\mathrm{SD}=1.3 \%$ ) which is about $40 \%$ of the average value for the polymer: $\mathrm{PC}_{71} \mathrm{BM}$ films determined from the data shown in Fig. 9(d). The lower PCE is mostly due to relatively low average $J_{\mathrm{sc}}$ and FF values (above). The hybrid polymer SCs that achieved the highest PCE values are those containing PbS, CdS or CdSe. For each of these SCs the NCs can contribute photocurrent to the overall $J_{\text {sc }}$ value.

Table 4 shows device performance data for hybrid polymer SCs that achieved the highest PCE value (that we were able to find) in the literature each year since 2008. The best hybrid polymer SC to date in terms of PCE is ${ }^{193}$ PDTBT:PbS ${ }_{0.4} \mathrm{Se}_{0.6}$ which achieved an impressive PCE of 5.5\%. In order to achieve that PCE a NC layer was required on top of the PDTBT:PbS ${ }_{0.4^{-}}$ $\mathrm{Se}_{0.6}$ layer which acted as a hole blocking layer. The PDTBT: $\mathrm{PbS}_{0.4} \mathrm{Se}_{0.6} \mathrm{SC}$ currently holds the world record PCE for hybrid polymer:NP SCs to the best of our knowledge.

When compared to the state-of-the-art for hybrid polymer SCs in $2008,{ }^{1}$ remarkable improvements in the PCE values have occurred in the past 6 years. However, more progress is required if the full potential of hybrid polymer SCs is to be reached. The morphology and ligand challenge discussed in the earlier review $^{1}$ still seem to plague hybrid polymer SCs although very good progress has been made in minimising their effects. ${ }^{\mathbf{1 5 5 , 1 6 1 , 1 9 3}}$ What is still lacking are ligand-free methods to improve the compatibility of the NPs with the conjugated polymers and a method to control NP morphology to optimise $J_{\text {sc }}$. Part of the reason why hybrid polymer SCs are lagging behind polymer:fullerene SCs is because fewer researchers are working on hybrid polymer SCs. Also, there appears to be fewer (if any) major industrial research programmes for the hybrid 
Table 4 Materials and performance parameters for high efficiency hybrid polymer solar cells ${ }^{a}$

\begin{tabular}{|c|c|c|c|c|c|c|c|c|}
\hline Polymer & Acceptor & NP type & PCE/\% & $V_{\mathrm{oc}} / \mathrm{V}$ & $J_{\mathrm{sc}} / \mathrm{mA} \mathrm{cm}^{-2}$ & $\mathrm{FF}$ & Year & Ref. \\
\hline P3HT & CdSe & Tetrapods & 2.2 & 0.63 & 7.56 & 0.471 & 2014 & 194 \\
\hline PDTPBT & $\mathrm{PbS}_{0.4} \mathrm{Se}_{0.6}$ & NC \& bilayer ${ }^{b}$ & 5.5 & 0.57 & 14.66 & 0.66 & 2013 & 193 \\
\hline P3HT & CdSe & $\mathrm{NC}$ & 4.1 & 1.10 & 10.9 & 0.35 & 2011 & 155 \\
\hline PCPDTBT & CdSe & Tetrapods & $3.1^{*}$ & 0.67 & 9.02 & 0.515 & 2010 & 183 \\
\hline P3HT & CdS & NR & 2.9 & 0.65 & 9.0 & 0.48 & 2009 & 195 \\
\hline
\end{tabular}

${ }^{a}$ Certified PCE values shown with an asterisk. ${ }^{b} \mathrm{NC}$ BHJ and NC bilayer present.

polymer SCs as far as the authors are aware. Hopefully, the good progress reviewed here will attract more workers (and industries) into this field to accelerate the rate of PCE improvement.

\section{Perovskite solar cells}

Remarkable increases in the PCE of perovskite SCs has occurred since 2008. The latter are a new family of SC. The principles governing their operation are increasingly becoming clear. ${ }^{4,197,198}$ Perovskite SCs are new 3rd-generation SCs that appear to have a very good chance of contributing to large scale solar energy production based on their high PCE and compatibility with scalable processes ${ }^{199}$ and are therefore included in this review. Perovskite SCs warrant discussion because never before in the history of SC research has such rapid progress in increasing the PCE been witnessed as that which has occurred for these SCs.

We briefly introduce DSSCs here because they led to the development of perovskite SCs. DSSCs are third-generation SCs and consist of several major components. ${ }^{200}$ These are a transparent conductive substrate, a high surface area n-type semiconductor (usually $\mathrm{TiO}_{2}$ ), a dye (sensitiser) which absorbs light and an electrolyte containing a redox mediator and a counter electrode. The dye is usually strongly bound to the surface of the n-type semiconductor. DSSCs have reached impressive PCE values of $\sim 11 \%$ (ref. 201) and have also been studied in solid state form. ${ }^{202}$ It was the replacement of dyes with $\mathrm{CH}_{3} \mathrm{NH}_{3} \mathrm{PbI}_{3}$ and $\mathrm{CH}_{3} \mathrm{NH}_{3} \mathrm{PbBr}_{3} \mathrm{NCs}^{203}$ within DSSCs that provided the first demonstration of the ability of perovskite to act as light harvesting materials within SCs and was a key step that led to the explosion of interest of perovskite-based SCs. The reader is directed to several very good reviews to learn more about DSSCs. ${ }^{2,200,204,205}$

Perovskites have the general formula of $\mathrm{ABX}_{3}$ where $\mathrm{A}$ and $\mathrm{B}$ are monovalent and divalent ions, respectively. $\mathrm{X}$ is either $\mathrm{O}, \mathrm{C}$, $\mathrm{N}$ or a halogen..$^{22}$ They are named after L. A. Perovski, a Russian mineralogist and have a cubic structure. ${ }^{206}$ The earliest perovskite example is $\mathrm{CaTiO}_{3}$. The most common perovskites currently used for SC applications are $\mathrm{CH}_{3} \mathrm{NH}_{3} \mathrm{PbI}_{3}, \mathrm{CH}_{3} \mathrm{NH}_{3}$ $\mathrm{PbBr}_{3}$ and the mixed halide system, $\mathrm{CH}_{3} \mathrm{NH}_{3} \mathrm{PbI}_{3-x} \mathrm{Cl}_{x}$. Both materials are semiconductors. The structures for $\mathrm{CH}_{3} \mathrm{NH}_{3} \mathrm{PbI}_{3}$ and $\mathrm{CH}_{3} \mathrm{NH}_{3} \mathrm{PbBr}_{3}$ are shown in Fig. 14(a). Part of the success of perovskites is due to their ability to form crystals of very high quality rapidly using solution processing methods and moderate temperatures. Temperatures in the range of room temperature to $150{ }^{\circ} \mathrm{C}$ have given crystalline perovskite material. $^{207}$ The energy levels for the key perovskites are shown in Fig. 14(b). Whilst the HOMO position is similar for all three systems, it can be seen that the LUMO energy is sensitive to the nature of the halogen. This feature allows energy level and $E_{g}$ tuning and has been found to be particularly effective for $\mathrm{CH}_{3} \mathrm{NH}_{3} \mathrm{~Pb}\left(\mathrm{I}_{3-x} \mathrm{Br}_{x}\right)_{3}$ perovskites. ${ }^{208}$ For the latter the $E_{\text {g }}$ value varied from 1.55 to $2.3 \mathrm{eV}$ following a quadratic relationship as $x$ was changed from 0 to 1.0 (see Fig. 14(c)).

One of the earliest studies of $\mathrm{CH}_{3} \mathrm{NH}_{3} \mathrm{PbI}_{3}$ and $\mathrm{CH}_{3} \mathrm{NH}_{3} \mathrm{PbBr}_{3}$ was reported by Tanaka et al. ${ }^{212}$ They investigated optical absorption and magnetoabsorption spectra for these systems. Table 5 shows selected PCE values that exemplify the rapid progress made by perovskite SCs since 2008. In 2008 Kojima et al. ${ }^{203}$ measured a PCE of $3.8 \%$ for a NC-sensitised SC that contained $\mathrm{CH}_{3} \mathrm{NH}_{3} \mathrm{PbI}_{3}$ and $\mathrm{CH}_{3} \mathrm{NH}_{3} \mathrm{PbBr}_{3} \mathrm{NCs}$ deposited on $\mathrm{TiO}_{2}$. Im et al. ${ }^{213}$ conducted a systematic study of perovskite NCsensitised SCs in 2011 and reported a PCE value of $6.5 \%$. In 2012 the first solid-state mesoscopic SC employing $\mathrm{CH}_{3} \mathrm{NH}_{3} \mathrm{PbI}_{3}$ and spiro-MeOTAD as the hole transporting was reported ${ }^{2 \mathbf{1 4}}$ and an impressive PCE of $9.7 \%$ was reported. The rate of PCE improvement accelerated well past $10 \%$ during this period. Lee et al. reported meso-superstructured perovskite SCs in 2012 where mesoporous alumina was used as an inert scaffold for perovskite photoactive. ${ }^{215}$ That paper established that the mixed halide perovskites $\left(\mathrm{CH}_{3} \mathrm{NH}_{3} \mathrm{PbI}_{3-x} \mathrm{Cl}_{x}\right)$ behaved both as a charge generator and transporter and a PCE of $10.9 \%$ was reported. Burschka et al. prepared $\mathrm{CH}_{3} \mathrm{NH}_{3} \mathrm{PbI}_{3}$ perovskite SCs using a sequential deposition method and achieved PCEs of about 15\% in 2013. Wang et al. ${ }^{216}$ reported mixed halide perovskite SCs containing graphene which enhanced charge collection and gave a PCE of $15.6 \%$ (Table 5). The entire device was prepared using solution based approach with temperature less than $150{ }^{\circ} \mathrm{C} .{ }^{216}$ It would seem to be ready for R2R processing if graphene can be prepared at large scale, cost-effectively, and a low cost HTM could be used. Liu et al. ${ }^{217}$ reported a PCE of $15.7 \%$ from $\mathrm{CH}_{3} \mathrm{NH}_{3} \mathrm{PbI}_{3}$ perovskite SCs prepared using $\mathrm{ZnO}$ NCs as the photocathode. This value has also been equalled in recent work by the Snaith group using meso-superstructured SCs and halogen bond passivation. ${ }^{218}$ The fact that three different groups achieved very high PCEs (greater than or equal to 15\%) 


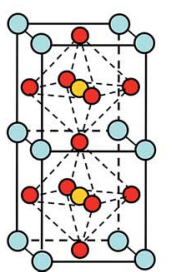

(a)

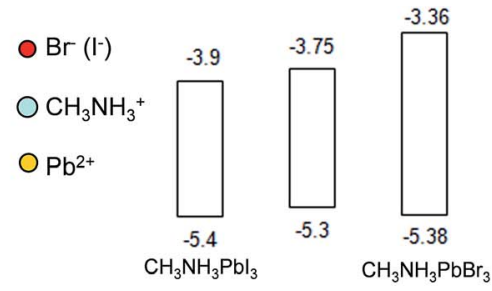

(b) $\mathrm{CH}_{3} \mathrm{NH}_{3} \mathrm{Pbl}_{3-\mathrm{C}} \mathrm{Cl}_{x}$

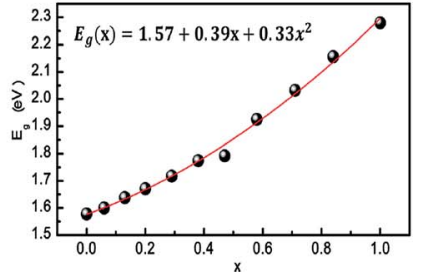

(c)

Fig. 14 Structure and energy levels for perovskites used in solar cells. (a) Unit cell for $\mathrm{CH}_{3} \mathrm{NH}_{3} \mathrm{Pbl}_{3}$ and $\mathrm{CH}_{3} \mathrm{NH}_{3} \mathrm{PbBr}_{3}$ perovskites. (b) Energy levels for $\mathrm{CH}_{3} \mathrm{NH}_{3} \mathrm{Pbl}_{3}, \mathrm{CH}_{3} \mathrm{NH}_{3} \mathrm{PBI}_{3-x} \mathrm{Cl}_{x}$ and $\mathrm{CH}_{3} \mathrm{NH}_{3} \mathrm{PbBr}_{3}$. The energy levels for the latter were taken from ref. 209,210 and 211 respectively. (c) Variation of $E_{g}$ with $\mathrm{Br}$ composition for $\mathrm{CH}_{3} \mathrm{NH}_{3} \mathrm{~Pb}\left(\mathrm{I}_{3-x} \mathrm{Br}_{x}\right)_{3}$. (c) reproduced with permission from ref. 208.

with a variety of SC architectures shows that the preparation of high quality perovskite photoactive layers is robust. This preparation robustness differs markedly from the BHJ SCs discussed above where the preparation method employed has a major influence on the morphology obtained as well as the PCE values achieved.

Table 6 lists selected physical, spectroscopic and electronic data for the key perovskites used for SCs. The exciton binding energy is comparable to the thermal energy and this gives rise to large diffusion lengths for perovskites. Because of their relatively low exciton binding energies both free charge carriers and weakly bound excitons are believed to coexist. ${ }^{21}$

Perovskites have direct band gaps, panchromatic light absorption and high $\alpha$ values. The latter values were initially reported as $1.5 \times 10^{4} \mathrm{~cm}^{-1}$ at $550 \mathrm{~nm}(1 / \alpha=665 \mathrm{~nm})$ by Im et al. ${ }^{213}$ who studied perovskite NCs deposited onto $\mathrm{TiO}_{2}$. Later, Stranks et al. ${ }^{21}$ reported absorption lengths of 100-200 $\mathrm{nm}$ (Table 6).

The average diffusion length $\left(L_{\mathrm{D}}\right)$ for $\mathrm{CH}_{3} \mathrm{NH}_{3} \mathrm{PbI}_{3-x} \mathrm{Cl}_{x}$ was determined $^{21}$ using $L_{\mathrm{D}}=\sqrt{D \tau_{\mathrm{e}}}$ where $D$ and $\tau_{\mathrm{e}}$ are the diffusion coefficient and recombination lifetime in the absence of a quenching species, respectively. The values for $D$ and $\tau_{\mathrm{e}}$, and hence $L_{\mathrm{D}}$, were measured using photoluminescence quenching measurements. ${ }^{21}$ The authors noted that the possibility that the $L_{\mathrm{D}}$ values for the holes and electrons corresponded to diffusion of a weakly bound exciton could not be excluded. ${ }^{21}$ They reported $L_{\mathrm{D}}$ values of more than $1 \mu \mathrm{m}$ (Table 6). Edri et al. have also reported that the $L_{\mathrm{D}}$ values for holes and electrons within mixed halide perovskite SCs are more than $1 \mu \mathrm{m} .{ }^{222}$ The diffusion lengths for $\mathrm{CH}_{3} \mathrm{NH}_{3} \mathrm{PbI}_{3-x} \mathrm{Cl}_{x}$ are 5-10 times greater than ${ }^{21}$ $1 / \alpha$. This difference is in striking contrast to the $\mathrm{BHJ}$ systems discussed above (when $L_{\mathrm{ex}} \ll 1 / \alpha$ ). As a consequence the requirement of nanostructuring the photoactive layer is relaxed for $\mathrm{CH}_{3} \mathrm{NH}_{3} \mathrm{PbI}_{3-x} \mathrm{Cl}_{x}$ SCs.

\subsection{Preparation of perovskite solar cells}

A number of different methods have been used to prepare perovskite SCs and methods are depicted in Fig. 15. They illustrate the inherent robustness of perovskite SCs because the three different SCs provided high $(6.0 \%)$ to very high $(15.4 \%)$ PCE values. Other designs have also been used which give very high PCEs. ${ }^{217}$ Each device depicted in Fig. 15 has the formation of a $\mathrm{TiO}_{2}$ (hole) blocking layer on FTO coated glass as the first step. The latter should be scrupulously cleaned and a variety of cleaning methods have been reported.9,21,223 The method reported by Christians et al. for hole blocking layer formation ${ }^{9}$ is the most straightforward because it does not require specialist equipment. The hole blocking layer can be formed either by spin casting ${ }^{213}$ or spray pyrolysis. ${ }^{223}$ The method reported by Im et $a l^{213}$ only requires a spin coater and an oven. The hole blocking layer thickness is typically about $100 \mathrm{~nm} .{ }^{9}$

After depositing the blocking layer, the SC fabrication processes shown in Fig. 15 diverge. The first design considered here in more detail is that shown in Fig. 15(a). This SC was designed with a sintered mesoporous $\mathrm{TiO}_{2} \mathrm{NP}$ network as the medium to transfer photoexcited electrons to the photocathode (FTO). The $\mathrm{TiO}_{2} \mathrm{NP}$ network was essential because the $L_{\mathrm{D}}$ values of $\mathrm{CH}_{3} \mathrm{NH}_{3} \mathrm{PbI}_{3}$ were less than $1 / \alpha$ (Table 5). This layer is typically prepared by spin coating a commercial $\mathrm{TiO}_{2}$ dispersion, followed by washing and sintering at $500{ }^{\circ} \mathrm{C}$ to give good electrical contact between neighbouring $\mathrm{TiO}_{2} \mathrm{NPs}$.

Table 5 Materials and performance parameters for high efficiency perovskite SCs

\begin{tabular}{|c|c|c|c|c|c|c|c|c|}
\hline Perovskite & SC type ${ }^{a}$ & SC components & $\mathrm{PCE} / \%$ & $V_{\mathrm{oc}} / \mathrm{V}$ & $J_{\mathrm{sc}} / \mathrm{mA} \mathrm{cm}^{-2}$ & $\mathrm{FF}$ & Year $^{c}$ & Ref. \\
\hline $\mathrm{CH}_{3} \mathrm{NH}_{3} \mathrm{PbI}_{3-x} \mathrm{C}_{\mathrm{l} x}$ & Meso-super & Graphene $/ \mathrm{TiO}_{2} / \mathrm{CH}_{3} \mathrm{NH}_{3} \mathrm{PbI}_{3-x} \mathrm{C}_{\mathrm{l} x} /$ Spiro $^{b}$ & 15.6 & 1.04 & 21.9 & 0.73 & 2013 & 216 \\
\hline $\mathrm{CH}_{3} \mathrm{NH}_{3} \mathrm{PbI}_{3}$ & Planar & $\mathrm{ZnO} / \mathrm{CH}_{3} \mathrm{NH}_{3} \mathrm{PbI}_{3} /$ Spiro & 15.7 & 1.03 & 20.4 & 0.75 & 2013 & 217 \\
\hline $\mathrm{CH}_{3} \mathrm{NH}_{3} \mathrm{PbI}_{3}$ & ${\mathrm{Meso}-\mathrm{TiO}_{2}}_{2}$ & $\mathrm{TiO}_{2} /\left(\mathrm{CH}_{3} \mathrm{NH}_{3}\right) \mathrm{PbI}_{3} /$ Spiro & 9.7 & 0.89 & 17.6 & 0.62 & 2012 & 214 \\
\hline $\mathrm{CH}_{3} \mathrm{NH}_{3} \mathrm{PbI}_{3}$ & Sensitised & $\mathrm{TiO}_{2} / \mathrm{CH}_{3} \mathrm{NH}_{3} \mathrm{PbI}_{3} / \mathrm{DSSC}$ & 6.5 & 0.71 & 15.8 & 0.59 & 2011 & 213 \\
\hline $\mathrm{CH}_{3} \mathrm{NH}_{3} \mathrm{PbI}_{3}$ & Sensitised & $\mathrm{TiO}_{2} / \mathrm{CH}_{3} \mathrm{NH}_{3} \mathrm{PbI}_{3} / \mathrm{DSSC}$ & 3.8 & 0.61 & 11.0 & 0.57 & 2008 & 203 \\
\hline
\end{tabular}

${ }^{a}$ Perovskite-sensitised SC, meso-TiO ${ }_{2}=$ mesoscopic $\mathrm{TiO}_{2}$ infiltrated with perovskite, meso-super $=$ meso superstructured photoactive layer. ${ }^{b}$ Spiro is spiro-OMeTAD (see Fig. 15(d)). ${ }^{c}$ Year of submission of work. 
Table 6 Selected perovskite physical, spectroscopic and electronic data

\begin{tabular}{|c|c|c|c|c|c|c|}
\hline Perovskite property & $\mathrm{CH}_{3} \mathrm{NH}_{3} \mathrm{PbI}_{3}$ & Ref. & $\mathrm{CH}_{3} \mathrm{NH}_{3} \mathrm{PbI}_{3-x} \mathrm{Cl}_{x}$ & Ref. & $\mathrm{CH}_{3} \mathrm{NH}_{3} \mathrm{PbBr}_{3}$ & Ref. \\
\hline $\mathrm{Wt} \% \mathrm{~Pb}$ & 33.4 & - & 39.2 & - & 43.3 & - \\
\hline Mobility $\left(\mathrm{cm}^{2} \mathrm{~V}^{-1} \mathrm{~s}^{-1}\right)$ & 66 & 219 & - & - & - & - \\
\hline Dielectric constant & 6.5 & 220 & - & - & 4.8 & 212 \\
\hline Electron $L_{\mathrm{D}}{ }^{a} / \mathrm{nm}$ & $129 \pm 41$ & 21 & $1069 \pm 204$ & 21 & - & - \\
\hline Absorption length $(1 / \alpha) / \mathrm{nm}$ & $\sim 100$ & 21 & $100-200$ & 21 & - & - \\
\hline$E_{\mathrm{LUMO}} / \mathrm{eV}$ & -3.9 & 209 & -3.75 & 210 & -3.36 & 211 \\
\hline$E_{\mathrm{HOMO}} / \mathrm{eV}$ & -5.4 & 209 & -5.3 & 210 & -5.38 & 211 \\
\hline$E_{\mathrm{g}} / \mathrm{eV}$ & 1.5 & - & 1.55 & - & 2.02 & - \\
\hline
\end{tabular}

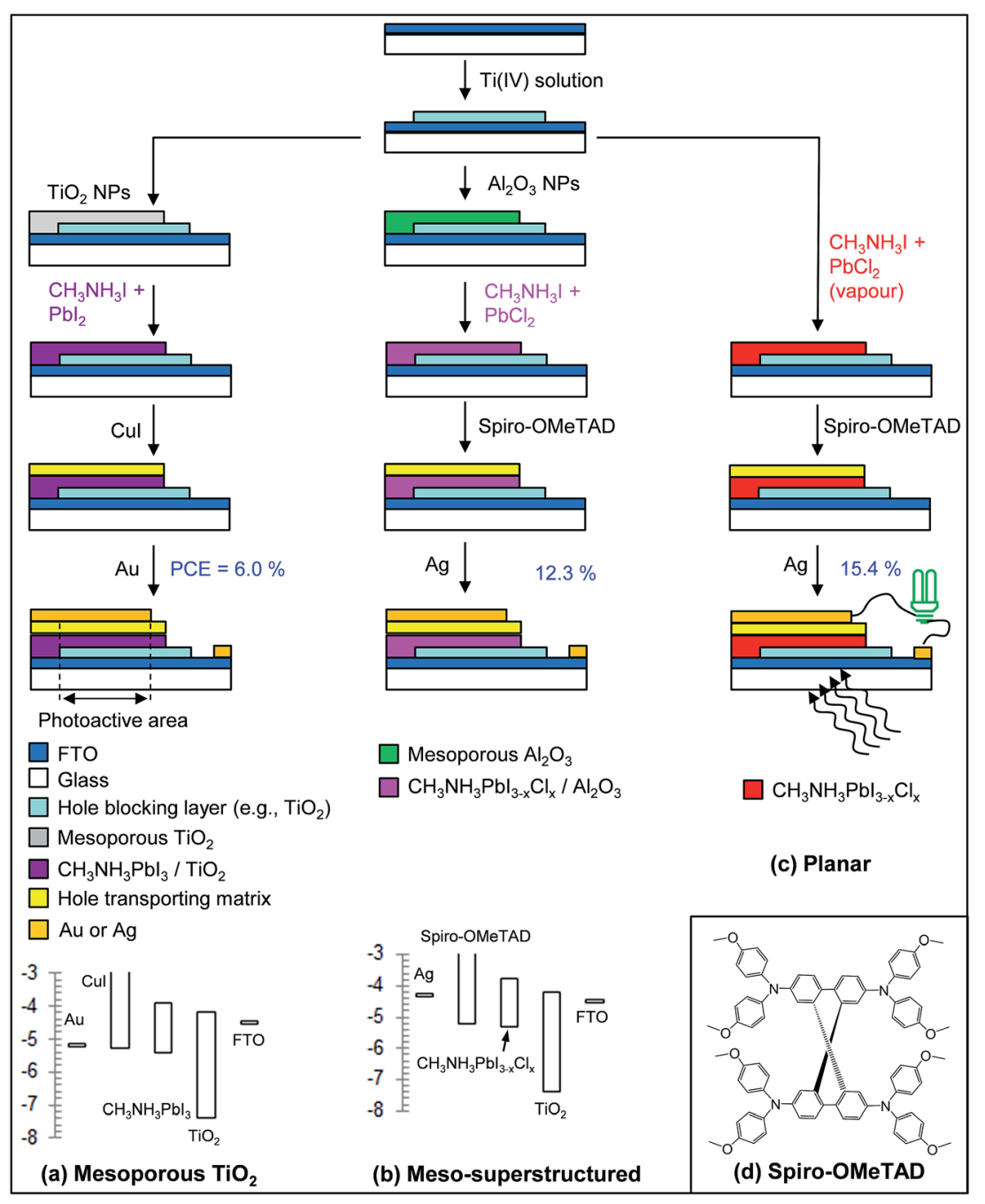

Fig. 15 Assembly of different perovskite solar cells. (a) A device for which a $\mathrm{TiO}_{2} \mathrm{NP}$ network interpenetrates the perovskite phase. The example PCE and design for this type of SC are taken from ref. 9. (b) A meso-superstructured perovskite SC. This SC design and PCE are taken from ref. 224. (c) A planar perovskite SC design which used a vapour deposited mixed perovskite. This SC design and PCE are taken from ref. 225. The energy level diagram for this device is assumed to be the same as that shown in (b). (d) Structure of spiro-OMeTAD. The energy levels for TiO ${ }_{2}$, $\mathrm{CH}_{3} \mathrm{NH}_{3} \mathrm{Pbl}_{3}, \mathrm{Cul}, \mathrm{Au}, \mathrm{CH}_{3} \mathrm{NH}_{3} \mathrm{~Pb}_{3-x} \mathrm{Cl}_{x}$, spiro-OMETAD, Ag, and FTO are taken from ref. 166, 209, 9, 216, 210, 217, 217 and 216, respectively. 
The next step is the formation of the $\mathrm{CH}_{3} \mathrm{NH}_{3} \mathrm{PbI}_{3}$ phase within the mesoporous $\mathrm{TiO}_{2}$ network. This step can be conducted using pre-mixed solutions of $\mathrm{CH}_{3} \mathrm{NH}_{3} \mathrm{I}$ and $\mathrm{PbI}_{2}$ (ref. 9) or sequentially by first infiltrating and drying $\mathrm{PbI}_{2}$ and subsequently $\mathrm{CH}_{3} \mathrm{NH}_{3} \mathrm{I}^{223}$ The latter work resulted in SCs with a PCE of $15.0 \%$. In the case of a one-step infiltration ${ }^{9}$ high concentrations of $\mathrm{CH}_{3} \mathrm{NH}_{3} \mathrm{PbI}_{3}$ solutions are used, e.g., $40 \mathrm{wt} \% .^{9}$

Ball et al. ${ }^{224}$ replaced the $\mathrm{TiO}_{2}$ with an insulating mesoporous $\mathrm{Al}_{2} \mathrm{O}_{3}$ network. Because the $\mathrm{Al}_{2} \mathrm{O}_{3}$ did not play a direct role in charge transport, the SCs were termed meso-superstructured thin film perovskite SCs. ${ }^{224} \mathrm{CH}_{3} \mathrm{NH}_{3} \mathrm{PbI}_{3-x} \mathrm{Cl}_{x}$ was used for that system (Fig. 15(b)). Remarkably, those SCs showed very high PCE values (e.g., 12.3\%). That work demonstrated that mixed halide perovskites can fulfil the three key SC operations of light absorption, free charge carrier generation and efficient ambipolar charge transport. The mesoporous $\mathrm{Al}_{2} \mathrm{O}_{3}$ scaffold decreased the perovskite crystal size to less than $100 \mathrm{~nm}$ (ref. 224) (as determined from X-ray diffraction data and the Scherrer equation) and was believed to act as a buffering layer that inhibited leakage of current between the electrodes. ${ }^{224}$ The landmark study of Ball et al. was also highly significant for future large-scale production of perovskite SCs because the scaffold was prepared using temperatures that did not exceed $150{ }^{\circ} \mathrm{C}$. Hence, low temperature solution processing of highly efficient perovskite SCs was demonstrated. The same group has recently demonstrated that the thermal annealing protocol used during perovskite phase crystallisation is critical for the performance of mixed halide SCs. ${ }^{226}$

Fig. 15(c) shows a planar mixed halide perovskite that was also established by the Snaith group. ${ }^{225}$ In that important study, which used vapour deposition, it was demonstrated that nanostructuring of the perovskite was not required to achieve very high PCE values (15.4\%). The work demonstrated that simplified planar architectures could be used, which brought the SC architecture closer to traditional Si SCs. A simple, planar, SC device architecture offers major production benefits. However, for low cost R2R production to be realised using this geometry, a key step that will be required is the demonstration of highly efficient planar pervoskite SCs processed using low temperature (and low energy), solution, methods.

The penultimate step in SC preparation for all of the device geometries after perovskite layer formation is deposition of a hole transporting matrix (HTM). A good HTM should have high hole mobility, thermal and UV stability as well as a HOMO energy level that is well matched to that of the perovskite. ${ }^{27}$ Furthermore, it should infiltrate the mesoporous phase efficiently to optimise device efficiency. ${ }^{228}$ Spiro-OMeTAD (Fig. 15(d)) has been used as the HTM in perovskite SCs that have given the highest PCE values to date. ${ }^{21,223,225}$ However, the complexity of the spiro-OMeTAD synthesis and this materials high cost (greater than 10 times the cost of $\mathrm{Au}^{9}$ ) imply that it is not likely to be a viable multi-ton scale, commodity, HTM for the preparation of large scale, low cost perovskite SCs. Alternative, lower cost, HTMs are therefore urgently required. A promising alternative HTM to Spiro-OMeTAD appears to be poly(triarylamine) because of its higher hole mobility and high work function. ${ }^{227} \mathrm{CuI}$ has also been investigated as a low cost
HTM (see Fig. 15(a)). This family of SCs was shown to give a good $\mathrm{PCE}^{9}(6.0 \%)$ and the SC was prepared using a solution deposition method. The primary reason for the lower PCE compared to perovskite SCs prepared using spiro-OMeTAD was a reduced $V_{\text {oc }}$ due to an enhanced recombination rate. ${ }^{9}$ However, the good potential for low cost scale up will surely warrant further study on this type of HTM. Furthermore, the initial investigations of stability appeared promising. ${ }^{9}$ Recently, it has been reported that perovskite SCs can be prepared with an efficiency of $10.5 \%$ without a HTM. ${ }^{229}$ The latter were considered to be heterojunction SCs and offer considerable potential cost saving if the high efficiencies can be maintained upon scale up. The final step of perovskite SC construction is evaporation of the photocathode ( $\mathrm{Ag}$ or $\mathrm{Au}$ ). $\mathrm{Ag}$ can be applied using low temperature methods.

\subsection{Perovskite solar cell operation principles}

Perovskite SCs have been identified as a new type of $\mathrm{SC}^{\mathbf{1 9 7}}$ with unique operation principles. Because of their low exciton binding energies (Table 5), the photoexcited charges exist as Wannier-type excitons. ${ }^{212}$ These excitons can dissociate in the bulk of a perovskite layer at room temperature. ${ }^{224}$ For $\mathrm{CH}_{3}$ $\mathrm{NH}_{3} \mathrm{PbI}_{3-x} \mathrm{Cl}_{x}$ SCs cast onto an inert scaffold (e.g., $\left.\mathrm{Al}_{2} \mathrm{O}_{3}\right)$ a builtin electric field is induced by the two selective (asymmetric) contacts which can drive charge separation throughout the photoactive layer. ${ }^{230}$ In cases where the electrodes result in a built-in voltage that is small, the hole-blocking and hole transporting layers (electron blocking) direct electron and hole flow. ${ }^{209}$ The energy offset between the perovskite valence band and hole-transporter valence band is responsible for selective charge transfer. ${ }^{4}$ It has been noted that exciton diffusion can occur both within the bulk and at interfaces. ${ }^{209}$

Ponseca et al. have recently attributed the nearly ideal perovskite solar properties to highly mobile electrons and holes that form rapidly (within picoseconds) and mobilities for both species that are balanced and remain high for timescales of microseconds. ${ }^{198}$ In a recent SEM-based study Edri et al. ${ }^{222}$ reported the first direct evidence that perovskite SCs operate as a $\mathrm{p}-\mathrm{i}-\mathrm{n}$ device. An addition beneficial feature of perovskite SCs is that there is no requirement for a $\mathrm{BHJ}$ due to the low exciton binding energies. Consequently energy losses due energy level offsets required for $\mathrm{BHJ}$ SCs are not present and the ratio of $V_{\mathrm{oc}}$ to $E_{\mathrm{g}}$ is very high, ${ }^{4}$ which, in turn, increases the PCE (eqn (1)). The main factor that is believed to limit perovskite SC performance is the equilibrium between the series and shunt resistance. $^{227}$ Whilst a relatively thick HTM layer is required to prevent leakage through pinholes, it also increases the series resistance. Hence, HTM thickness optimisation is required.

The value of $V_{\text {oc }}$ for perovskite SCs is in part determined by deep level defects which act as non-radiative recombination centres. Yin et al. have shown ${ }^{231}$ that perovskite defects have low formation energies and shallow trap levels. This behaviour, which provides low recombination rates and higher $V_{\text {oc }}$ values, results from strong $\mathrm{Pb}$ lone pair s orbital and I p orbital antibonding coupling and high ionicity of $\mathrm{CH}_{3} \mathrm{NH}_{3} \mathrm{PbI}_{3}$. It follows that $\mathrm{Pb}$ plays a critical role in the excellent device performance 
of Pb-containing perovskite SCs. Accordingly, it may not be possible to achieve the high PCE values for perovskite SCs without $\mathrm{Pb}$ being present. The presence of $\mathrm{Pb}$ should not need to be a "show stopper" for widespread use of this technology provided appropriate safeguards are built into the modules to prevent environmental contamination as discussed below.

\subsection{Perovskite solar cell performance and implications for scale-up}

Given the very high PCEs achieved with research grade perovskite SCs (Table 5), low cost versions of perovskite SCs may already be ready for mass production. Furthermore, perovskite SCs have been demonstrated on flexible substrates (e.g., PET $^{232}$ ) which also implies compatibility with R2R processes. Because of the enormous potential for cost effective production of perovskite SCs it is highly likely that low cost alternatives to spiro-OMeTAD will be found. The potential for large scale production of perovskite SCs appears to be excellent because (a) the photoactive materials are relatively cheap and abundant (below), (b) the PCE values are already above 15\% for R2Rfriendly solution processed systems ${ }^{216}$ and (c) PCE efficiency increases to beyond $20 \%$ are considered likely. ${ }^{227,233}$ However, about 33 to $43 \mathrm{wt} \%$ of the perovskite photoactive layer contains $\mathrm{Pb}$ (Table 5). An important (and perhaps critical) environmental concern is the possible release of water-soluble $\mathrm{Pb}$ species in the event of rainfall on modules where the encapsulation has ruptured..$^{207}$ The presence of soluble $\mathrm{Pb}$ in drinking water can cause diseases such as anaemia. ${ }^{234}$ The $\mathrm{EU}$ limit for $\mathrm{Pb}$ in drinking water is $0.05 \mathrm{mg} \mathrm{l}^{-1} .^{235}$

A potentially important question is what the maximum potential release of $\mathrm{Pb}$ (II) is from perovskite SCs. To answer this question we assume a $\mathrm{CH}_{3} \mathrm{NH}_{3} \mathrm{PbI}_{3} / \mathrm{TiO}_{2}$ photoactive layer with a porosity of 0.6 (ref. 236) that is fully infiltrated with $\mathrm{CH}_{3}$ $\mathrm{NH}_{3} \mathrm{PbI}_{3}$. Using a layer thickness of $1 \mu \mathrm{m}$ and a perovskite density of $4.1 \mathrm{~g} \mathrm{~cm}^{-3}$ (Table 6) it can be shown that the $\mathrm{Pb}$ (II) content per unit area of active SC top surface corresponds to 23 $\mathrm{Pb}$ (II) ions per $\AA^{2}$. (The value per unit module area would be less than this value because the geometric fill factor would less than unity.) This value corresponds to the nominal maximum concentration of $\mathrm{Pb}$ (II) that could be released at the surface of this SC if all the release were to occur at once and the $\mathrm{Pb}$ (II) was to be placed at the top surface.

There are a wide range of materials that remove $\mathrm{Pb}(\mathrm{II})$ from water and these include functional polymers. ${ }^{237-239}$ It can be shown that a surface containing a sufficiently high surface density of polymer chains with repeat units that bind $\mathrm{Pb}$ (II) could be produced that could bind all of the $\mathrm{Pb}$ (II) present within the SC photoactive layer (equivalent to $23 \mathrm{~Pb}$ (II) ions per $\AA^{2}$ ). It should be possible to build in an efficient, transparent (and automatic) lead binding/absorption system within the encapsulating layer for perovskite SCs. A fail-safe design should be capable of mitigating potential contamination. Containment appears to be the key to this issue. We already live in close proximity to $\mathrm{Pb}(\mathrm{II})$, which can be contained safely in car batteries. Of course, non-Pb containing perovskites that provide high PCE values are an obvious solution to the Pb concern and are being investigated ${ }^{\mathbf{2 4 0}}$ with $\mathrm{Sn}$ (ref. 241) and $\mathrm{Cu}$ (ref. 227) based perovskites attracting interest as possible replacements. A recent study has reported lead-free $\mathrm{CH}_{3} \mathrm{NH}_{3} \mathrm{SnI}_{3} \mathrm{SCs}$ with a PCE of $5.73 \%{ }^{242}$ If the improvements of PCE for the latter system can follow a similar path for the $\mathrm{Pb}$-based perovskite SCs, then there will be much excitement generated by these SCs in the future. To be truly scalable, $\mathrm{Pb}$-free replacement perovskites should comprise abundant elements that have relatively low toxicity. Alternatively, the SC modules should be designed so as to prevent release of toxic elements in the event of rupture.

\section{Comparisons of the different third- generation solar cells}

Comparison of the data shown in Tables 2, 4 and 5 show that the PCE's for 2013-2014 decreased in the order: perovskite > polymer:fullerene $>$ hybrid polymer SCs. Table 7 presents a qualitative comparison of the three different SC types discussed here. Whilst the polymer:fullerene and hybrid SCs require $\mathrm{BHJS}$ for maximising PCEs, the perovskite SCs do not. This difference is because of the excitons for the former two systems are Frenkel type with higher binding energies than the weakly bound Wannier excitons present within perovskites. The principle difference between the polymer:fullerene and hybrid polymer SCs is that the acceptors are inorganic. The perovskite SCs can also be considered as an hybrid organic/inorganic blend on the molecular level (Fig. 14(a)). Each of these SC types can be constructed using solution processing methods, which is one criteria that enable them to be capable of $\mathrm{R} 2 \mathrm{R}$ processing. The latter has been demonstrated for P3HT:PCBM SCs. ${ }^{72}$ For R2R processing, the films must also have mechanical stability when strained. The strain which a thin film (e.g., $100 \mathrm{~nm})$ can withstand upon bending before fracturing is strongly determined by its thickness. ${ }^{243}$ P3HT:PCBM films have a crack onset strain of 9\%. ${ }^{243}$ Although similar data are not available for polymer:hybrid or perovskite SCs to our knowledge, flexible perovskite SCs on PET that withstood repeated strain cycling have been reported. ${ }^{244}$ P3HT:PCBM films have been shown to have sufficient mechanical stability for R2R processing. ${ }^{72}$

Cost analyses have been conducted for polymer:fullerene $\mathrm{e}^{245-247}$ and hybrid polymer ${ }^{245}$ SCs. In a comprehensive study Azzopardi et al. $^{246}$ calculated a levelised electricity cost (LEC) of between 0.19 and $0.50 €$ per $\mathrm{kW}$ h for a $1 \mathrm{~kW}_{\mathrm{p}}$ system with an efficiency of $7 \%$ and a 5 year module lifetime. An equivalent analysis has not been reported for polymer hybrid or perovskite SCs to our knowledge. From a related study that considered the energy payback time for hybrid polymer $\mathrm{SCs}^{\mathbf{2 4 5}}$ it is reasonable to conclude that these SCs should have an LEC cost comparable to that of the polymer:fullerene SCs because the NCs should be solution processable.

An important question concerns the compatibility (or benignity) of each of the SC types with the environment. The latter is a particularly important issue considering the very large scale manufacture that will be required in the future for mass produced modules to significantly contribute to $\mathrm{CO}_{2}$ mitigation. The work of Azzopardi et al. ${ }^{245}$ indicated a lower $\mathrm{CO}_{2}$-eq per $\mathrm{kW}$ 
Table 7 Comparison of properties for the three 3rd generation solar cell types considered ${ }^{a}$

\begin{tabular}{|c|c|c|c|}
\hline Property & $\begin{array}{l}\text { Polymer: } \\
\text { fullerene }\end{array}$ & $\begin{array}{l}\text { Hybrid } \\
\text { polymer }\end{array}$ & Perovskite \\
\hline Bulk heterojunction & Yes & Yes & No \\
\hline Exciton type & Frenkel & Frenkel & Wannier \\
\hline Hybrid organic/inorganic & No & Yes & Yes \\
\hline Solution processable & Yes & Yes & Yes \\
\hline Roll-to-roll friendly & Yes & Yes & Yes \\
\hline Levelised electricity cost & Low & Low & Not known \\
\hline $\begin{array}{l}\text { Environmental } \\
\text { compatibility }\end{array}$ & Best & $\begin{array}{l}\text { Good if } \\
\text { recycled }\end{array}$ & Not known \\
\hline Mechanical stability & Good & Not known & Good \\
\hline Environmental stability & Good & Not known & In progress \\
\hline
\end{tabular}

$\mathrm{h}$ for hybrid polymer SCs compared to polymer:fullerene SCs. Equivalent data for perovskite SCs are not yet available. The Pbcontaining hybrid polymer $\mathrm{SCs}^{161,193}$ and perovskites share the potential problem of $\mathrm{Pb}$ contamination discussed above. However, the $\mathrm{Pb}$ content is lower for the hybrid polymer SCs compared to most perovskites. The organic polymer:fullerene SCs have a potential advantage in terms of environmental compatibility because they do not contain significant quantities of heavy metal ions.

\section{Towards large scale deployment of third-generation solar cells}

$\mathrm{R} 2 \mathrm{R}$ processing is generally considered to offer a viable route to mass production of polymer:fullerene modules cost effectively. ${ }^{248}$ Polymer:fullerene SCs have recently been argued to be the only PV technology that enables fast manufacture of an energy producing system with a thin outline using abundant elements. ${ }^{72}$ The recent, rapid, progress for perovskite SCs implies that these new SCs may soon challenge this claim, especially since R2R-friendly processing methods have been established. ${ }^{\mathbf{1 9 9}, 216}$

For large scale production to be feasible simple synthesis and processing procedures are essential. Small research grade SCs based on components which involve (costly and low yield) multiple-step synthesis are not consistent with the needs of large scale, cost-effective, processing and mass deployment even if the PCE of the SC is high. ${ }^{72}$ Cost-effective photoactive layer components are required. Scale-up using mass production processes (such as R2R) results in substantial efficiency decreases for modules compared to small area research grade SCs. ${ }^{72}$ Two sources that contribute to the PCE decrease for SC modules are ohmic losses due to relatively low conductivity of transparent electrodes and also aperture loss (or area loss). ${ }^{249} \mathrm{~A}$ key parameter for SC modules is the geometric fill factor, which is the ratio of the photoactive area to the total module area. This factor is usually significantly lower than 1.0. However, innovations in SC architecture such as formation of metal-filamentary nanoelectrodes within photoactive layers ${ }^{249}$ may offer a means to reduce aperture and ohmic losses on scale up, and increase the geometric fill factor.
The best candidate for large scale preparation of polymer:fullerene SC is currently considered to be P3HT:PCBM. ${ }^{72}$ Because the PCE values of these systems are modest, large areas are needed which, in turn, requires fast, efficient, deployment processes. An innovative Infinity concept for simultaneously installing and removing P3HT:PCBM SC foil at rates of $100 \mathrm{~m} \mathrm{~min}^{-1}$ has been demonstrated..$^{72}$ Furthermore, the energy pay back times have decreased to 0.5 years in Spain. The technology appears viable for low carbon energy generation. The SCs had a constant PCE of about 1.6 to $1.8 \%$ (ref. 72 ) (14.7 $\mathrm{m}^{2}$ active area) on flexible ITO-free substrates. These SC foils require relatively large areas for energy generation. However, even modest improvements in PCE will greatly reduce the area requirement.

Krebs et al. have proposed that the materials developed for SCs should fit the process (R2R) if realistic large-scale deployment is to be viable. ${ }^{72}$ Their pioneering work defines a clear direction for 3rd-generation SC scientists committed to designing new SCs with realistic potential for scale-up. It follows that scalable SC systems should comprise materials which can be prepared with relatively few synthetic steps and are prepared from abundant raw materials that are cheap. The device architectures should be compatible with flexible (polymeric) substrates (and low temperature processing) to enable R2R processing with layers that can be deposited and solidified rapidly. A number of other design criteria for polymer fullerene SCs destined for R2R manufacture have been identified. The polymers (or other SC materials) should be accessible as pure materials ${ }^{250}$ and be cost-effective to manufacture. ${ }^{72}$ The photoactive material should also be sufficiently stable in solution to give ink formulations that can be deposited. These general criteria would also apply for hybrid polymer and perovskite SCs.

Because the NCs used to prepare hybrid polymer SCs can be prepared by solution methods they are also scalable. For example the PDTPBT/ $\mathrm{PbS}_{0.4} \mathrm{Se}_{0.6} \mathrm{SC}$ has the highest reported PCE for a hybrid polymer SC of $5.5 \%$ (Table 4). For that system the NCs were prepared using a solution based solvothermal method and a maximum temperature of $150{ }^{\circ} \mathrm{C} .{ }^{193}$ The preparation method used is scalable in principle. Moreover, the fact that there are companies that focus on the scalable manufacture of semiconducting $\mathrm{NCs}^{251}$ provides greater opportunity for large scale NC preparation.

\subsection{Raw material supply constraints for large-scale production of third-generation solar cells}

Material supply for SCs is a key factor for future large scale deployment. Wadia et al. investigated 23 different semiconductor materials for potential large scale SC deployment. ${ }^{252}$ Of those materials, 9 were identified as having the capacity to meet or exceed the annual worldwide electricity consumption (17 000 TW h) whilst being more cost effective than c-Si (see red and yellow diamonds in Fig. 16). A number of well-known semiconductors appear in the lower left quadrant which indicates that they were not considered to be viable alternatives for generating a large proportion of the World's future energy demands. 


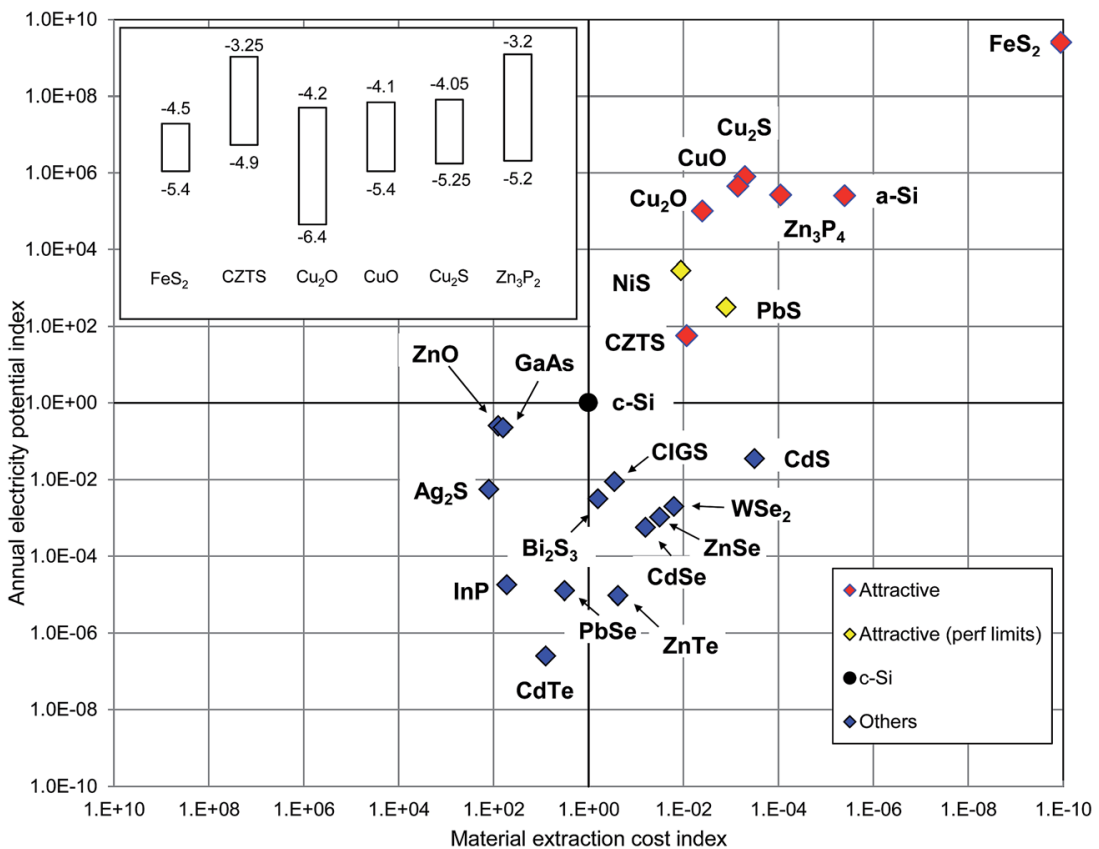

Fig. 16 Indexed materials extraction costs and annual potential energy production relative to crystalline Si. All values were calculated as the natural logarithm of the calculated values divided by the result for crystalline silicon (c-Si). Materials that are most attractive for large-scale future deployment appear in the upper right quadrant (in red). Materials in yellow were considered as attractive but have lower performance limits. The inset in the upper left quadrant shows energy band diagrams for selected "red diamond" systems. The main graph has been redrawn from ref. 252. The energy levels for $\mathrm{FeS}_{2}, \mathrm{CZTS}, \mathrm{Cu}_{2} \mathrm{O}, \mathrm{CuO}, \mathrm{Cu}_{2} \mathrm{~S}$ and $\mathrm{Zn}_{3} \mathrm{P}_{2}$ were obtained from ref. 253, 254, 255, 256, 257 and 258 , respectively.

Considering the hybrid polymer SCs discussed above in the context of Fig. 16 it is suggested that polymer:PbS SCs ${ }^{161}$ have good potential for meeting future worldwide energy production requirements in principle. A number of the other NPs have energy levels that may enable useful hybrid P3HT SCs to be prepared and these are shown in the inset of Fig. 16. These NPs include $\mathrm{FeS}_{2}, \mathrm{CuO}$ and $\mathrm{Cu}_{2} \mathrm{O}$. Unfortunately, a study of P3HT:FeS ${ }_{2}$ SCs did not show high PCE values. ${ }^{259}$ Further work is warranted for polymer: $\mathrm{FeS}_{2}$ SCs given the potential for large scale production of these hybrid SCs. Perovskite semiconductors were not considered by Wadia et al. ${ }^{252}$ The perovskites contain $\mathrm{Pb}$ and $\mathrm{I}$. Whilst $\mathrm{Pb}$ is abundant, I is less abundant. Iodine occurs naturally in the world's oceans. The Sn- and Cu-based perovskites mentioned in Section 4.3 are compositionally related to CZTS and $\mathrm{Cu}$ species shown in the top right quadrant of Fig. 16, which implies good potential for mass deployment. Research into hybrid polymer SCs using the nine semiconductors in the upper right quadrant is encouraged because overcoming technical barriers for their use in SCs should provide realistic opportunities for large scale SC deployment.

\subsection{Solar cell stability}

Long term SC PCE stability is an important issue affecting the potential for deployment. Methods for measuring polymer SC stability have been explained in detail by Gevorgyan et al. ${ }^{260}$ The different test protocols have been detailed. ${ }^{53}$ The latter includes thermal cycling between -40 and $85^{\circ} \mathrm{C}$. An aim of SC research is to prepare SCs which show little degradation in performance with time. The gold standard for stability performance is Si SCs. The latter can have operational lifetimes of about 25 years.

Organic polymers undergo reaction when illuminated by light via photolytic and photochemical reactions. ${ }^{53}$ They also react to oxygen and water. The susceptibility of conjugated polymers to chemical degradation is linked to their backbone structure, side chains and substituents. The stability tends to decrease with inclusion of side chains for donor groups. ${ }^{53}$ For polymer SCs the use of inverted architectures has positively contributed to device stability ${ }^{54}$ because high work function metals (e.g., Ag) can be used in place of more reactive metals (e.g., Al).

Polymer SCs also suffer from morphological instability when heated at temperatures consistent with operation (up to $80{ }^{\circ} \mathrm{C}$ under full sun illumination). Heating enables thermally assisted reorganisation of their morphology (i.e., annealing). This process occurs because of the low glass transition temperature of the polymer phase and can lead to macroscopic phase separation..$^{53} \mathrm{~A}$ realistic balance between stability and cost effectiveness has been achieved for large scale (solar park) deployment of P3HT:PCBM SCs with recycling forming a key part of the overall deployment strategy ${ }^{72}$. Impressive stabilities have been reported by Peters et al. ${ }^{261}$ for encapsulated PCDTBT:PC ${ }_{71} \mathrm{BM}$ SCs with lifetimes approaching 7 years.

Hybrid polymer SCs have been less studied in terms of stability, which is probably due to the major emphasis for this family of SCs still residing on PCE improvement. Meanwhile, perovskite SCs have been the subject of stability studies and the initial results appear promising. Leijtens et al. ${ }^{262}$ reported that 


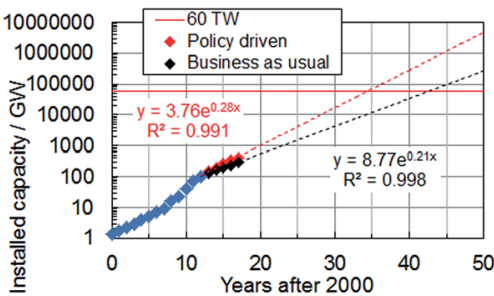

Fig. 17 Extrapolation of global installed solar cell capacity. The graph shows fits of the data between 2012 and 2017 from Fig. 1 using years since 2000 as the time axis. The horizontal line corresponds to Smalley's 60 TW figure required for a global population of 10 billion (see text).

their SCs retained a PCE of $6 \%$ after $1000 \mathrm{~h}$ exposure to white light after undergoing an initial PCE decrease. Matteocci et al. ${ }^{263}$ reported the first solar modules based on perovskites very recently and found that those prepared using spiro-OMeTAD as the HTM retained $60 \%$ of their initial PCE in air after $170 \mathrm{~h}$. In each of these cases ${ }^{262,263}$ there was an initial decrease in PCE which implies some form of instability was present. However, the subsequent PCE stabilisation is encouraging and more work will undoubtedly be performed on this aspect. The sources of perovskite SC instability include UV-photodegradation caused by $\mathrm{TiO}_{2}$ (ref. 262) and also decomposition under humid conditions. ${ }^{\mathbf{2 0 8 , 2 6 4}}$ The stability of polymer:fullerene SCs can be good compared to the other systems considered here (Table 7) if encapsulated. The stability for hybrid polymer SCs is less clear. For perovskite SCs, the treatments/encapsulation required to achieve long term stability are still being optimised. Clearly, a barrier to water vapour will be required for the latter.

\section{Conclusions and outlook}

There are a number of reasons to believe the third-generation SCs have the potential to meet the Smalley TW challenge. ${ }^{8}$ Polymer:fullerene SCs are already at the point where they can be provide the most rapid power supply deployment of any $\mathrm{SC}^{72}$ and there is good potential for PCE improvement within that process. Furthermore, high efficiency perovskite SCs are an exciting new SC technology that have now been produced using low temperature R2R-friendly processes ${ }^{216}$ and modules. ${ }^{263}$ Moreover, the tremendous achievements for the published PCE's of perovskite SCs do not appear to have benefited (yet) from industrial collaborations - which are in progress. Positive results from these collaborations are eagerly anticipated. All three 3rd-generation technologies continue to improve in terms of their PCEs (Tables 2, 4 and 5) and many researchers are mindful of future large scale deployment processes (e.g., R2R). Extrapolations of global installed SC capacity are shown in Fig. 17 based on exponential relationships that are already established for current modules. If cost-effective 3rd-generation modules can be manufactured via $\mathrm{R} 2 \mathrm{R}$ processing and deployed using concepts such as Infinity (Section 6) then the exponential growth in the installation capacity could be maintained and the Smalley 60 TW figure could be achieved well before 2050 . Of course this is a very optimistic scenario; however, it is one that 3rd-generation solar scientists and industrialists should strive to achieve. Indeed, there is good reason to be critical of the major emphasis that is currently given by most research groups and funding organisations to obtaining record breaking PCE values of laboratory-scale devices fabricated using processes and materials that have little realistic chance of being mass produced. The taxpayer, who ultimately fund most this research, may well expect a greater proportion of their research investment to be spent on truly transformative (and scalable) solar electricity generation research. ${ }^{265}$ That research will more closely relate to low cost electricity generation with significant $\mathrm{CO}_{2}$ mitigation. There is a strong argument that it is this direction that the 3rd-generation SC community and funders should move towards in order to provide realistic solutions to the urgent energy issues discussed above that challenge mankind.

There are several areas that warrant further work. For polymer:fullerene SCs more research is required on improving the PCE of P3HT:PCBM modules prepared by the R2R process. Methods that enable control of the morphology (e.g., Fig. 5(c)), perhaps using scaled up versions of nanoimprint lithography, ${ }^{87}$ and fit that process should provide important PCE increases and greatly reduce the area required for GW electricity production. Of course, efforts to prepare perovskite modules are important $^{263}$ and their fabrication using R2R processes should be accelerated. Hybrid polymer SCs continue to hold a great deal of promise; however, they need more investment to increase the gradient of the PCE evolution. For these SCs new approaches to addressing the ligand and morphology challenges are needed. For perovskite SCs replacing the spiroOMeTAD HTM with a cheap (sustainable) alternative is clearly required. Of course, replacing $\mathrm{Pb}$ with one of the abundant (less toxic) elements from Fig. 16 is desirable and may be critical to mass deployment. However, research to build in $\mathrm{Pb}$ (II) trapping systems into the perovskite modules would be strategic as this may help enable their larger scale deployment.

The 3rd-generation SC research reviewed here has shown very impressive progress. At least two of the technologies are well placed to contribute new SC types that could enable SCs to contribute substantially to the low $\mathrm{CO}_{2}$ energy required for the future that is urgently needed now. Indeed, it is through low cost module production (and R2R) that the future "Smalley" target of 60 TW shown in Fig. 17 might be achievable by 2050 (or earlier with policy driving) through enabling the current rate of exponential deployment to be maintained.

\section{Acknowledgements}

The authors would like to thank the EPSRC for funding our 3rdgeneration solar energy research. We would also like to thank Alois Mispelon for proof-reading the manuscript. We would like to thank the referees for their helpful comments.

\section{References}

1 B. R. Saunders and M. L. Turner, Adv. Colloid Interface Sci., 2008, 138, 1.

2 M. Grätzel, Acc. Chem. Res., 2009, 42, 1788-1798. 
3 Y. Chen, X. Wan and G. Long, Acc. Chem. Res., 2013, 46, 2645-2655.

4 H. J. Snaith, J. Phys. Chem. Lett., 2013, 4, 3623-3630.

5 World Energy Outlook 2013 Fact sheet, International Energy Agency, http://www.worldenergyoutlook.org.

6 Key World Energy Statistics, 2013, International Energy Agency, http://www.iea.org.

7 World Energy Technology Outlook - 2050, WETO-H2, European Commission, http://www.europa.eu/research/ energy/.

8 R. E. Smalley, Mater. Matters, 2005, 30, 412-417.

9 J. A. Christians, R. C. Fung and P. V. Kamat, J. Am. Chem. Soc., 2014, 136, 758-764.

10 L. Alexander, S. Allen, N. L. Bindoff, F.-M. Breon and J. Church. Working Group I Contribution to the IPCC Fifth Assessment Report Climate Change 2013: The Physical Science Basis; Summary for Policymakers 2013.

11 C. B. Field, V. R. Barros, M. D. Mastrandrea, K. J. Mach and M. A.-K. Abdrabo. IPCC WGII AR5: Climate Change 2014: Impacts, Adaptation, and Vulnerability; Summary for Policy Makers 2014.

12 Press Release from World Energy Outlook (WEO-2013), International Energy Agency, http://www.worldenergyoutlook. org/, Downloaded Feb 2014.

13 IEA - Scenarios and Projections, International Energy Agency, http:/www.iea.org/publications/scenariosandprojections/, Downloaded Feb 2014.

14 O. Edenhofer, R. Pichs-Madruga, Y. Sokona, S. Agrawala and I. A. Bahmakov, IPCC WGIII AR5: Climate Change 2014: Mitigation; Summary for Policy Makers.

15 Secure and efficient electricity supply during the transitions to low carbon power systems, International Energy Agency, http://www.iea.org, 2013.

16 Global market outlook for photovoltaics 2013-2017, European Photovoltaic Industry Association, http:// www.epia.org, Downloaded Feb 2014.

17 Renewable energy technologies: solar energy perspectives, International Energy Agency, http://www.iea.org, Downloaded Feb 2014.

18 Solar photovoltaics competing in the energy sector, On the road to competitiveness (September 11), European Photovoltaic Industry Association, http://www.epia.org.

19 J. Kirkland, Scientific Amer., 2010.

20 J. Nelson, The physics of solar cells, Imperial College Press, London, 2007.

21 S. D. Stranks, G. E. Eperon, G. Grancini, C. Menelaou, M. J. Alcocer, T. Leijtens, L. M. Herz, A. Petrozza and H. J. Snaith, Science, 2013, 342, 341-344.

22 H.-S. Kim, S. H. Im and N.-G. Park, J. Phys. Chem. C, 2014, 118, 5615-5625.

23 G. P. Smestad, F. C. Krebs, C. M. Lampert, C. G. Granqvist, K. L. Chopra, X. Mathew and H. Takakura, Sol. Energy Mater. Sol. Cells, 2008, 92, 371-373.

24 P. P. Khlyabich, B. Burkhart, A. E. Rudenko and B. C. Thompson, Polymer, 2013, 54, 5267-5298.

25 W. Schokley and H. J. Queisser, J. Appl. Phys., 1961, 32, 510519.
26 S. D. Dimitrov and J. R. Durrant, Chem. Mater., 2014, 26, 616-630.

27 S. Gunes, H. Neugebauer and N. S. Sariciftci, Chem. Rev., 2007, 107, 1324-1338.

28 A. J. Heeger, Chem. Soc. Rev., 2010, 39, 2354-2371.

29 A. J. Heeger, Adv. Mater., 2014, 26, 10-28.

30 J. Nelson, Mater. Today, 2011, 14, 462-470.

31 T. Wang, A. J. Pearson and D. G. Lidzey, J. Mater. Chem. C., 2013, 1, 7266-7293.

32 L. Dou, J. You, Z. Hong, Z. Xu, G. Li, R. A. Street and Y. Yang, Adv. Mater., 2013, 25, 6642-6671.

33 C. W. Tang, Appl. Phys. Lett., 1986, 48, 183.

34 N. S. Sariciftci, L. Smilowitz, A. J. Heeger and F. Wudl, Science, 1992, 258, 1474-1476.

35 G. Yu, J. Gao, J. C. Hummelen, F. Wudi and A. J. Heeger, Science, 1995, 270, 1789-1791.

36 J. J. M. Halls, C. A. Walsh, N. C. Greenham, E. A. Marseglia, R. H. Friend, S. C. Moratti and A. B. Holmes, Nature, 1995, 376, 498-500.

37 M. T. Dang, L. Hirsch and G. Wantz, Adv. Mater., 2011, 23, 3597-3602.

38 C.-Y. Chang, C.-E. Wu, S.-Y. Chen, C. Cui, Y.-J. Cheng, C.-S. Hsu, Y.-L. Wang and Y. Li, Angew. Chem., Int. Ed., 2011, 50, 9386-9390.

39 H. C. Liao, C. S. Tsao, T. H. Lin, C. M. Chuang, C. Y. Chen, U. S. Jeng, C. H. Su, Y. F. Chen and W. F. Su, J. Am. Chem. Soc., 2011, 133, 13064-13073.

$40 \mathrm{X}$. Yang, A. Alexeev, M. A. J. Michels and J. Loos, Macromolecules, 2005, 38, 4289-4295.

41 Y. Liang, Z. Xu, J. Xia, S. T. Tsai, Y. Wu, G. Li, C. Ray and L. Yu, Adv. Mater., 2010, 22, E135-E138.

42 J. K. Lee, W. L. Ma, C. J. Brabec, J. Yuen, J. S. Moon, J. Y. Kim, K. Lee, G. C. Bazan and A. J. Heeger, J. Am. Chem. Soc., 2008, 130, 3619-3623.

43 D. H. Kim, A. L. Ayzner, A. L. Appleton, K. Schmidt, J. Mei, M. F. Toney and Z. Bao, Chem. Mater., 2012, 25, 431-440.

44 J. Peet, J. Y. Kim, N. E. Coates, W. L. Ma, D. Moses, A. J. Heeger and G. C. Bazan, Nat. Mater., 2007, 6, 497500 .

45 M. C. Scharber, D. Mühlbacher, M. Koppe, P. Denk, C. Waldauf, A. J. Heeger and C. J. Brabec, Adv. Mater., 2006, 18, 789-794.

46 Y. Kim, S. A. Choulis, J. Nelson, D. D. C. Bradley, S. Cook and J. R. Durrant, Appl. Phys. Lett., 2005, 86, 063502.

47 A. Moliton and J.-M. Nunzi, Polym. Int., 2006, 55, 583-600. 48 C. Tanase, E. J. Meijer, P. W. M. Blom and D. M. de Leeuw, Phys. Rev. Lett., 2003, 91, 216601.

49 X. Gong, M. Tong, F. G. Brunetti, J. Seo, Y. Sun, D. Moses, F. Wudl and A. J. Heeger, Adv. Mater., 2011, 23, 22722277.

50 S. H. Park, A. Roy, S. Beaupré, S. Cho, N. Coates, J. S. Moon, D. Moses, M. Leclerc, K. Lee and A. J. Heeger, Nat. Photonics, 2009, 3, 297-302.

51 X. Guo, Z. Zhou, S. J. Lou, J. Smith and D. B. Tice, Nat. Photonics, 2013, 7, 825-833.

52 Z. He, C. Zhong, S. Su, M. Xu, H. Wu and Y. Cao, Nat. Photonics, 2012, 6, 591-595. 
53 M. Jorgensen, K. Norrman, S. A. Gevorgyan, T. Tromholt, B. Andreasen and F. C. Krebs, Adv. Mater., 2012, 24, 580-612.

54 F. C. Krebs, S. A. Gevorgyan and J. Alstrup, J. Mater. Chem., 2009, 19, 5442-5451.

55 S. Sista, M.-H. Park, Z. Hong, Y. Wu and J. Hou, Adv. Mater., 2010, 22, 380-383.

56 L. Bian, E. Zhu, J. Tang, W. Tang and F. Zhang, Prog. Polym. Sci., 2012, 37, 1292-1331.

57 S. R. Cowan, A. Roy and A. J. Heeger, Phys. Rev. B: Condens. Matter Mater. Phys., 2010, 82, 245207.

58 H. Zhou, L. Yang and W. You, Macromolecules, 2012, 45, 607-632.

59 S. Chen, C. E. Small, C. M. Amb, J. Subbiah, T.-h. Lai, S.-W. Tsang, J. R. Manders, J. R. Reynolds and F. So, Adv. Energy Mater., 2012, 2, 1333-1337.

60 C. E. Small, S. Chen, J. Subbiah, C. M. Amb, S.-W. Tsang, T.-H. Lai, J. R. Reynolds and F. So, Nat. Photonics, 2012, 6, 115-120.

61 L. Pandey, C. Risko, J. E. Norton and J.-L. Brédas, Macromolecules, 2012, 45, 6405-6414.

62 Y. Zhou, Y. Li, H. Zhong, J. Hou, Y. Ding, C. Yang and Y. Li, Nanotechnology, 2006, 17, 4041-4047.

63 D. Mühlbacher, M. Scharber, M. Morana, Z. Zhu, D. Waller, R. Gaudiana and C. Brabec, Adv. Mater., 2006, 18, 28842889.

64 I. H. Campbell, T. W. Hagler, D. L. Smith and J. P. Ferrais, Phys. Rev. Lett., 1996, 76, 1900-1903.

65 W. Yue, Y. Zhao, S. Shao, H. Tian, Z. Xie, Y. Geng and F. Wang, J. Mater. Chem., 2009, 19, 2199-2206.

66 Y. Zou, A. Najan, P. Berrouard, S. Beaupre and B. R. Aich, J. Am. Chem. Soc., 2010, 132, 5330.

67 H.-Y. Chen, J. Hou, S. Zhang, Y. Liang, G. Yang, Y. Yang, L. Yu, Y. Wu and G. Li, Nat. Photonics, 2009, 3, 649-653.

68 C. Piliego, T. W. Holcombe, J. D. Douglas, C. H. Woo, P. M. Beaujuge and J. M. J. Fréchet, J. Am. Chem. Soc., 2010, 132, 7595-7597.

69 J. L. Brédas and A. J. Heeger, Chem. Phys. Lett., 1994, 217, 507-512.

70 I. Meager, R. S. Ashraf, S. Mollinger, B. C. Schroeder, H. Bronstein, D. Beatrup, M. S. Vezie, T. Kirchartz, A. Salleo, J. Nelson and I. McCulloch, J. Am. Chem. Soc., 2013, 135, 11537-11540.

71 N. C. Cates, R. Gysel, Z. Beiley, C. E. Miller and M. F. Toney, Nano Lett., 2009, 9, 4153-4157.

72 F. C. Krebs, N. Espinosa, M. Hösel, R. R. Søndergaard and M. Jørgensen, Adv. Mater., 2014, 26, 29-39.

73 Y. He and Y. Li, Phys. Chem. Chem. Phys., 2011, 13, 19701983.

74 J. C. Hummelen, B. W. Knight, K. F. LePeq, F. Wudl and J. Yao, J. Org. Chem., 1995, 60, 532-538.

75 H. Bronstein, M. Hurhangee, E. C. Fregoso, D. Beatrup, Y. W. Soon, Z. Huang, A. Hadipour, P. S. Tuladhar, S. Rossbauer, E.-H. Sohn, S. Shoaee, S. D. Dimitrov, J. M. Frost, R. S. Ashraf, T. Kirchartz, S. E. Watkins, K. Song, T. Anthopoulos, J. Nelson, B. P. Rand, J. R. Durrant and I. McCulloch, Chem. Mater., 2013, 25, 4239-4249.
76 P. Wang, K. Yao, L. Chen, Y. Chen, F. Li, H. Wang and S. Yu, Sol. Energy Mater. Sol. Cells, 2012, 97, 34-42.

77 L. Ye, S. Zhang, D. Qian, Q. Wang and J. Hou, J. Phys. Chem. C, 2013, 117, 25360-25366.

78 M. M. Wienk, J. M. Kroon, W. J. Verhees, J. Knol, J. C. Hummelen, P. A. van Hal and R. A. Janssen, Angew. Chem., 2003, 42, 3371-3375.

79 F. B. Kooistra, V. D. Mihailetchi, L. M. Popescu, D. Kronholm and P. W. Blom, Chem. Mater., 2006, 18, 3068-3073.

80 M. A. Brady, G. M. Su and M. L. Chabinyc, Soft Matter, 2011, 7, 11065-11077.

81 F. Liu, Y. Gu, X. Shen, S. Ferdous, H.-W. Wang and T. P. Russell, Prog. Polym. Sci., 2013, 38, 1990-2052.

82 A. J. Moulé and K. Meerholz, Adv. Funct. Mater., 2009, 19, 3028-3036.

83 K. Vandewal, S. Himmelberger and A. Salleo, Macromolecules, 2013, 46, 6379-6387.

84 P. J. Brown, D. S. Thomas, A. Köhler, J. S. Wilson, J.-S. Kim, C. M. Ramsdale, H. Sirringhaus and R. H. Friend, Phys. Rev. B: Condens. Matter Mater. Phys., 2003, 67, 064203.

85 S. Shoaee, S. Subramaniyan, H. Xin, C. Keiderling, P. S. Tuladhar, F. Jamieson, S. A. Jenekhe and J. R. Durrant, Adv. Funct. Mater., 2013, 23, 3286-3298.

86 M. Aryal, K. Trivedi and W. Hu, ACS Nano, 2009, 3, 30853090.

87 D. Chen, W. Zhao and T. P. Russell, ACS Nano, 2012, 6, 1479-1485.

88 A. Casey, R. S. Ashraf, Z. Fei and M. Heeney, Macromolecules, 2014, 47, 2279-2288.

89 J. R. Tumbleston, B. A. Collins, L. Yang, A. C. Stuart, E. Gann, W. Ma, W. You and H. Ade, Nat. Photonics, 2014, 8, 385-391.

90 H. Li, F. Liu, X. Wang, C. Gu, P. Wang and H. Fu, Macromolecules, 2013, 46, 9211-9219.

91 D. Dang, W. Chen, R. Yang, W. Zhu, W. Mammo and E. Wang, Chem. Commun., 2013, 49, 9335-9337.

92 M. Y. Jo, S. J. Park, T. Park, Y. S. Won and J. H. Kim, Org. Electron., 2012, 13, 2185-2191.

93 M. Tsuji, A. Saeki, Y. Koizumi, N. Matsuyama, C. Vijayakumar and S. Seki, Adv. Funct. Mater., 2014, 24, 28-36.

94 H. Zhou, L. Yang, A. C. Stuart, S. C. Price, S. Liu and W. You, Angew Chem., Int. Ed., 2011, 50, 2995-2998.

95 S. C. Cevher, N. A. Unlu, A. C. Ozelcaglayan, D. H. Apaydin, Y. A. Udum, L. Toppare and A. Cirpan, J. Polym. Sci., Part A: Polym. Chem., 2013, 51, 1933-1941.

96 J.-M. Jiang, P.-A. Yang, T.-H. Hsieh and K.-H. Wei, Macromolecules, 2011, 44, 9155-9163.

97 S. K. Son, B. S. Kim, C.-Y. Lee, J. S. Lee, J. H. Cho, M. J. Ko, D.-K. Lee, H. Kim, D. H. Choi and K. Kim, Sol. Energy Mater. Sol. Cells, 2012, 104, 185-192.

98 K.-C. Li, J.-H. Huang, Y.-C. Hsu, P.-J. Huang, C.-W. Chu, J.-T. Lin, K.-C. Ho, K.-H. Wei and H.-C. Lin, Macromolecules, 2009, 42, 3681-3693.

99 J.-F. Lee, S. L.-C. Hsu, P.-I. Lee, H.-Y. Chuang, J.-S. Chen and W.-Y. Chou, J. Polym. Sci., Part A: Polym. Chem., 2011, 49, 4618-4625. 
100 J.-H. Kim, C. E. Song, B. Kim, I.-N. Kang, W. S. Shin and D.-H. Hwang, Chem. Mater., 2014, 26, 1234-1242.

101 W. Li, A. Furlan, W. S. Roelofs, K. H. Hendriks, G. W. van Pruissen, M. M. Wienk and R. A. Janssen, Chem. Commun., 2014, 50, 679-681.

102 P. Shen, H. Bin, L. Xiao and Y. Li, Macromolecules, 2013, 46, 9575-9586.

103 Q. Liao, J. Cao, Z. Xiao, J. Liao and L. Ding, Phys. Chem. Chem. Phys., 2013, 15, 19990-19993.

104 K. W. Song, M. H. Choi, H. J. Song, S. W. Heo, J. Y. Lee and D. K. Moon, Sol. Energy Mater. Sol. Cells, 2014, 120, 303309.

105 Y. J. Kim, Y.-J. Lee, J.-W. Jang, H. Cha, Y.-H. Kim, S.-K. Kwon and C. E. Park, J. Polym. Sci., Part A: Polym. Chem., 2013, 51, 4742-4751.

106 D. H. Kim, H. J. Song, S. W. Heo, K. W. Song and D. K. Moon, Sol. Energy Mater. Sol. Cells, 2014, 120, 94-101.

107 B. M. Kobilka, B. J. Hale, M. D. Ewan, A. V. Dubrovskiy, T. L. Nelson, V. Duzhko and M. Jeffries-El, Polym. Chem., 2013, 4, 5329-5336.

108 K. Lu, J. Fang, H. Yan, X. Zhu, Y. Yi and Z. Wei, Org. Electron., 2013, 14, 2652-2661.

109 M. Seri, M. Bolognesi, Z. Chen, S. Lu, W. Koopman, A. Facchetti and M. Muccini, Macromolecules, 2013, 46, 6419-6430.

110 K. Nie, H. Tan, X. Deng, Y. Wang, Q. Chen, Y. Huang, Y. Liu, C. Yang, Z. Huang, M. Zhu and W. Zhu, J. Polym. Sci., Part A: Polym. Chem., 2013, 51, 4103-4110.

111 Y. Deng, Y. Chen, J. Liu, L. Liu, H. Tian, Z. Xie, Y. Geng and F. Wang, ACS Appl. Mater. Interfaces, 2013, 5, 5741-5747.

112 S. Lu, M. Drees, Y. Yao, D. Boudinet, H. Yan, H. Pan, J. Wang, Y. Li, H. Usta and A. Facchetti, Macromolecules, 2013, 46, 3895-3906.

113 M. Wang, X. Hu, L. Liu, C. Duan, P. Liu, L. Ying, F. Huang and Y. Cao, Macromolecules, 2013, 46, 3950-3958.

114 S.-O. Kim, Y.-S. Kim, H.-J. Yun, I. Kang, Y. Yoon, N. Shin, H. J. Son, H. Kim, M. J. Ko, B. Kim, K. Kim, Y.-H. Kim and S.-K. Kwon, Macromolecules, 2013, 46, 3861-3869.

115 L. Dou, C.-C. Chen, K. Yoshimura, K. Ohya, W.-H. Chang, J. Gao, Y. Liu, E. Richard and Y. Yang, Macromolecules, 2013, 46, 3384-3390.

116 H.-J. Song, D.-H. Kim, E.-J. Lee and D.-K. Moon, J. Mater. Chem. A, 2013, 1, 6010.

117 C. Du, W. Li, Y. Duan, C. Li, H. Dong, J. Zhu, W. Hu and Z. Bo, Polym. Chem., 2013, 4, 2773.

118 Z. R. Owczarczyk, W. A. Braunecker, A. Garcia, R. Larsen, A. M. Nardes, N. Kopidakis, D. S. Ginley and D. C. Olson, Macromolecules, 2013, 46, 1350-1360.

119 S.-C. Lan, P.-A. Yang, M.-J. Zhu, C.-M. Yu, J.-M. Jiang and K.-H. Wei, Polym. Chem., 2013, 4, 1132-1140.

120 H.-C. Chen, Y.-H. Chen, C.-C. Liu, Y.-C. Chien, S.-W. Chou and P.-T. Chou, Chem. Mater., 2012, 24, 4766-4772.

121 L. Yaowen, L. Chen, Y. Chen, C. Li, P. Zhang, L. Gao, X. Yang, Y. Tu and X. Zhu, Sol. Energy Mater. Sol. Cells, 2013, 108, 136-145.

122 S. Subramaniyan, F. S. Kim, G. Ren, H. Li and S. A. Jenekhe, Macromolecules, 2012, 45, 9029-9037.
123 B. Kim, H. R. Yeom, M. H. Yun, J. Y. Kim and C. Yang, Macromolecules, 2012, 45, 8658-8664.

124 Y. X. Xu, C. C. Chueh, H. L. Yip, F. Z. Ding, Y. X. Li, C. Z. Li, X. Li, W. C. Chen and A. K. Jen, Adv. Mater., 2012, 24, 63566361.

125 H.-J. Song, D.-H. Kim, E.-J. Lee, S.-W. Heo, J.-Y. Lee and D.-K. Moon, Macromolecules, 2012, 45, 7815-7822.

126 Y. Ie, J. Huang, Y. Uetani, M. Karakawa and Y. Aso, Macromolecules, 2012, 45, 4564-4571.

127 Y.-R. Hong, J. Y. Ng, H. K. Wong, L. C. H. Moh, Y. J. Yip, Z.-K. Chen and T. B. Norsten, Sol. Energy Mater. Sol. Cells, 2012, 102, 58-65.

128 J.-S. Wu, Y.-J. Cheng, T.-Y. Lin, C.-Y. Chang, P.-I. Shih and C.-S. Hsu, Adv. Funct. Mater., 2012, 22, 1711-1722.

129 Q. Peng, X. Liu, D. Su, G. Fu, J. Xu and L. Dai, Adv. Mater., 2011, 23, 4554-4558.

130 T. Y. Chu, J. Lu, S. Beaupre, Y. Zhang, J. R. Pouliot, S. Wakim, J. Zhou, M. Leclerc, Z. Li, J. Ding and Y. Tao, J. Am. Chem. Soc., 2011, 133, 4250-4253.

131 S.-H. Song, S.-J. Park, S.-C. Kwon, J.-Y. Shim, Y.-E. Jin, S.-H. Park, I. Kim, K.-H. Lee and H.-S. Suh, Bull. Korean Chem. Soc., 2012, 33, 1861-1866.

132 Z.-G. Zhang, H. Fan, J. Min, S. Zhang, J. Zhang, M. Zhang, X. Guo, X. Zhan and Y. Li, Polym. Chem., 2011, 2, 16781687.

133 E. Ahmed, S. Subramaniyan, F. S. Kim, H. Xin and S. A. Jenekhe, Macromolecules, 2011, 44, 7207-7219.

134 G. Y. Chen, Y. H. Cheng, Y. J. Chou, M. S. Su, C. M. Chen and K. H. Wei, Chem. Commun., 2011, 47, 5064-5066.

135 C.-P. Chen, S.-H. Chan, T.-C. Chao, C. Ting and B.-T. Ko, J. Am. Chem. Soc., 2008, 130, 12828-12833.

136 C. Duan, K.-S. Chen, F. Huang, H.-L. Yip, S. Liu, J. Zhang, A. K.-Y. Jen and Y. Cao, Chem. Mater., 2010, 22, 6444-6452.

137 Z. Li, S.-W. Tsang, X. Du, L. Scoles, G. Robertson, Y. Zhang, F. Toll, Y. Tao, J. Lu and J. Ding, Adv. Funct. Mater., 2011, 21, 3331-3336.

138 Z. Li, J. Ding, N. Song, X. Du, J. Zhou, J. Lu and Y. Tao, Chem. Mater., 2011, 23, 1977-1984.

139 B. C. Schroeder, Z. Huang, R. S. Ashraf, J. Smith, P. D'Angelo, S. E. Watkins, T. D. Anthopoulos, J. R. Durrant and I. McCulloch, Adv. Funct. Mater., 2012, 22, 1663-1670.

140 J.-Y. Wang, S. K. Hau, H.-L. Yip, J. A. Davies, K.-S. Chen, Y. Zhang, Y. Sun and A. K. Y. Jen, Chem. Mater., 2011, 23, 765-767.

141 X. Xu, Y. Zhu, L. Zhang, J. Sun, J. Huang, J. Chen and Y. Cao, J. Mater. Chem., 2012, 22, 4329-4336.

142 J. Zhang, W. Cai, F. Huang, E. Wang, C. Zhong, S. Liu, M. Wang, C. Duan, T. Yang and Y. Cao, Macromolecules, 2011, 44, 894-901.

143 Y. Zou, A. Najari, P. Berrouard, S. Beaupré, B. R. d. Aïch, Y. Tao and M. Leclerc, J. Am. Chem. Soc., 2010, 132, 53305331.

144 J. C. Yu, J. I. Jang, B. R. Lee, G. W. Lee, J. T. Han and M. H. Song, ACS Appl. Mater. Interfaces, 2014, 6, 2067-2073.

145 M. S. Su, C. Y. Kuo, M. C. Yuan, U. S. Jeng, C. J. Su and K. H. Wei, Adv. Mater., 2011, 23, 3315-3319. 
146 E. Wang, L. Wang, L. Lan, J. Chen, J. Peng and Y. Cao, Proc. SPIE, 2008, 7052, 70520W.

147 T. Nozawa. Techon Nikkei, http://techon.nikkeibp.co.jp/ english/NEWS_EN/20120601/221131/, Downloaded Feb 2014, 2012.

148 Mitsubishi Chemical, Research \& Development, http:// www.m-kagaku.co.jp/english/r_td/strategy/technology/ topics/opv/, Dowloaded Feb 2014.

149 S. Rohr. Heliatek Press Release, http:/www.heliatek.com.

150 M. He, F. Qiu and Z. Lin, J. Phys. Chem. Lett., 2013, 4, 17881796.

151 S.-S. Li and C.-W. Chen, J. Mater. Chem. A, 2013, 1, 1057410591.

152 P. Reiss, E. Couderc, J. De Girolamo and A. Pron, Nanoscale, 2011, 3, 446-489.

153 J. N. Freitas, A. S. Goncalves and A. F. Nogueira, Nanoscale, 2014, 6, 6371-6397.

154 W. U. Huynh, J. J. Dittmer, W. C. Libby, G. L. Whiting and P. Alivisatos, Adv. Funct. Mater., 2003, 13, 73-79.

155 S. Ren, L. Y. Chang, S. K. Lim, J. Zhao, M. Smith, N. Zhao, V. Bulovic, M. Bawendi and S. Gradecak, Nano Lett., 2011, 11, 3998-4002.

156 S. Dowland, T. Lutz, A. Ward, S. P. King, A. Sudlow, M. S. Hill, K. C. Molloy and S. A. Haque, Adv. Mater., 2011, 23, 2739-2744.

157 S. D. Oosterhout, M. M. Wienk, S. S. van Bavel, R. Thiedmann, L. J. Koster, J. Gilot, J. Loos, V. Schmidt and R. A. Janssen, Nat. Mater., 2009, 8, 818-824.

158 A. A. R. Watt, D. Blake, J. H. Warner, E. A. Thomsen, E. L. Tavenner, H. Rubinsztein-Dunlop and P. Meredith, J. Phys. D: Appl. Phys., 2005, 38, 2006-2012.

159 N. C. Greenham, Z. Peng and A. P. Alivisatos, Phys. Rev. B: Condens. Matter Mater. Phys., 1996, 54, 17628-17637.

160 Z. Hens and I. Moreels, J. Mater. Chem., 2012, 22, 1040610415.

161 J. Seo, M. J. Cho, D. Lee, A. N. Cartwright and P. N. Prasad, Adv. Mater., 2011, 23, 3984-3988.

162 W. W. Yu, L. Qu, W. Guo and X. Peng, Chem. Mater., 2003, 15, 2854-2860.

163 R. Rhodes, M. Horie, H. Chen, Z. Wang, M. L. Turner and B. R. Saunders, J. Colloid Interface Sci., 2010, 344, 261-271.

164 I. Gur, N. A. Fromer, C.-P. Chen, A. G. Kanaras and A. P. Alivisatos, Nano Lett., 2007, 7, 409-414.

165 B.-R. Hyun, Y.-W. Zhong, A. C. Bartnik, L. Sun and H. D. Abruna, ACS Nano, 2008, 2206-2212.

166 C. Y. Kwong, A. B. Djurišić, P. C. Chui, K. W. Cheng and W. K. Chan, Chem. Phys. Lett., 2004, 384, 372-375.

167 W. J. E. Beek, M. M. Wienk and R. A. Janssen, Adv. Mater., 2004, 16, 1009-1013.

168 K. F. Jeltsch, M. Schädel, J.-B. Bonekamp, P. Niyamakom, F. Rauscher, H. W. A. Lademann, I. Dumsch, S. Allard, U. Scherf and K. Meerholz, Adv. Funct. Mater., 2012, 22, 397-404.

169 C. M. Evans, A. M. Love and E. A. Weiss, J. Am. Chem. Soc., 2012, 134, 17298-17305.

170 M. Nam, S. Kim, S. Kim, S. W. Kim and K. Lee, Nanoscale, 2013, 5, 8202-8209.
171 A. J. Nozik, Inorg. Chem., 2005, 44, 6893-6899.

172 L. A. Padilha, J. T. Stewart, R. L. Sandberg, W. K. Bae and W.-K. Koh, Acc. Chem. Res., 2013, 46, 1261-1269.

173 C. Smith and D. Binks, Nanomaterials, 2013, 4, 19-45.

174 J. B. Sambur, T. Novet and B. A. Parkinson, Science, 2010, 330, 63-66.

175 O. E. Semonin, J. M. Luther, S. Choi, H. Y. Chen, J. Gao, A. J. Nozik and M. C. Beard, Science, 2011, 334, 1530-1533.

176 S. S. Li, C. P. Chang, C. C. Lin, Y. Y. Lin, C. H. Chang, J. R. Yang, M. W. Chu and C. W. Chen, J. Am. Chem. Soc., 2011, 133, 11614-11620.

177 W. U. Huynh, J. J. Dittmer and A. P. Alivisatos, Science, 2002, 295, 2425-2427.

178 M. J. Greaney, S. Das, D. H. Webber, S. E. Bradforth and R. Brutchey, ACS Nano, 2012, 6, 4222-4230.

179 F. Gao, Z. Li, J. Wang, A. Rao, I. A. Howard, A. Abrusci, S. Massip, C. R. McNeill and N. C. Greenham, ACS Nano, 2014, 8, 3213-3221.

180 Y. Shi, F. Li, L. Tan and Y. Chen, ACS Appl. Mater. Interfaces, 2013, 5, 11692-11702.

181 Y. Zhou, M. Eck, C. Veit, B. Zimmermann, F. Rauscher, P. Niyamakom, S. Yilmaz, I. Dumsch, S. Allard and U. Scherf, Sol. Energy Mater. Sol. Cells, 2011, 95, 12321237.

182 E. Couderc, M. J. Greaney, R. L. Brutchey and S. E. Bradforth, J. Am. Chem. Soc., 2013, 135, 18418-18426.

183 S. Dayal, N. Kopidakis, D. C. Olson, D. S. Ginley and G. Rumbles, Nano Lett., 2010, 10, 239-242.

184 J. Albero, P. Riente, J. N. Clifford, M. A. Pericàs and E. Palomares, J. Phys. Chem. C, 2013, 117, 13374-13381.

185 S. H. Im, H. J. Kim, S. W. Kim, S. W. Kim and S. I. Seok, Nanoscale, 2012, 4, 1581-1584.

186 C. Piliego, M. Manca, R. Kroon, M. Yarema, K. Szendrei, M. R. Andersson, W. Heiss and M. A. Loi, J. Mater. Chem., 2012, 22, 24411.

187 K. M. Noone, E. Strein, N. C. Anderson, P. T. Wu, S. A. Jenekhe and D. S. Ginger, Nano Lett., 2010, 10, 26352639.

188 W. J. E. Beek, L. H. Slooff, M. M. Wienk, J. M. Kroon and R. A. J. Janssen, Adv. Funct. Mater., 2005, 15, 1703-1707.

189 J. D. Moet, L. J. A. Koster, B. de Boer and P. W. M. Blom, Chem. Mater., 2007, 5856-5861.

190 W. J. E. Beek, M. M. Wienk and R. A. J. Janssen, Adv. Funct. Mater., 2006, 16, 1112-1116.

191 W. J. E. Beek, M. M. Wienk and R. A. J. Janssen, Adv. Mater., 2004, 16, 1009-1013.

192 S. Shao, F. Liu, G. Fang, B. Zhang, Z. Xie and L. Wang, Org. Electron., 2011, 12, 641-647.

193 Z. Liu, Y. Sun, J. Yuan, H. Wei, X. Huang, L. Han, W. Wang, H. Wang and W. Ma, Adv. Mater., 2013, 25, 5772-5778.

194 J. Lim, D. Lee, M. Park, J. Song, S. Lee and M. S. Kang, J. Phys. Chem. C, 2014, 118, 3942-3952.

195 H.-C. Liao, S.-Y. Chen and D.-M. Liu, Macromolecules, 2009, 42, 6558-6563.

196 M.-C. Wu, C.-H. Chang, H.-H. Lo, Y.-S. Lin, Y.-Y. Lin, W.-C. Yen, W.-F. Su, Y.-F. Chen and C.-W. Chen, J. Mater. Chem., 2008, 18, 4097-4102. 
197 H. S. Kim, I. Mora-Sero, V. Gonzalez-Pedro, F. FabregatSantiago, E. J. Juarez-Perez, N. G. Park and J. Bisquert, Nat. Commun., 2013, 4, 2242.

198 C. S. Ponseca, T. J. Savenije, M. Abdellah, K. Zheng, A. Yartsev, T. Pascher, T. Harlang, P. Chabera, T. Pullerits, A. Stepanov, J.-P. Wolf and V. Sundstrom, J. Am. Chem. Soc., 2014, 136, 5189-5192.

199 P. Docampo, J. M. Ball, M. Darwich, G. E. Eperon and H. J. Snaith, Nat. Commun., 2013, 4, 2761.

200 K. G. Reddy, T. G. Deepak, G. S. Anjusree, S. Thomas, S. Vadukumpully, K. R. V. Subramanian, S. V. Nair and A. S. Nair, Phys. Chem. Chem. Phys., 2014, 16, 6838-6858.

201 M. A. Green, K. Emery, Y. Hishikawa, W. Warta and E. D. Dunlop, Prog. Photovolt.: Res. Appl., 2012, 20, 12-20.

202 U. Bach, D. Lupo, P. Comte, J. E. Moser, F. Weissortel, J. Salbeck, H. Spreitzer and M. Gratzel, Nature, 1998, 395, 583-585.

203 A. Kojima, K. Teshima, Y. Shirai and T. Miyasaka, J. Am. Chem. Soc., 2009, 131, 6050-6051.

204 P. Docampo, S. Guldin, T. Leijtens, N. K. Noel, U. Steiner and H. J. Snaith, Adv. Mater., 2014, 26, 4013-4030.

205 A. Hinsch, W. Veurman, H. Brandt, K. Flarup Jensen and S. Mastroianni , ChemPhysChem, 2014, 15, 1076-1087.

206 M. A. Loi and J. C. Hummelen, Nat. Mater., 2013, 12, 10871089.

207 G. Hodes and D. Cahen, Nat. Photonics, 2014, 8, 87-88.

208 J. H. Noh, S. H. Im, J. H. Heo, T. N. Mandal and S. I. Seok, Nano Lett., 2013, 13, 1764-1769.

209 O. Malinkiewicz, A. Yella, Y. H. Lee, G. M. n. Espallargas, M. Graetzel, M. K. Nazeeruddin and H. J. Bolink, Nat. Photonics, 2014, 8, 128-132.

210 A. Abrusci, S. D. Stranks, P. Docampo, H. L. Yip, A. K. Jen and H. J. Snaith, Nano Lett., 2013, 13, 3124-3128.

211 B. Cai, Y. Xing, Z. Yang, W.-H. Zhang and J. Qiu, Energy Environ. Sci., 2013, 6, 1480-1485.

212 K. Tanaka, T. Takahashi, T. Ban, T. Kondo, K. Uchida and N. Miura, Solid State Commun., 2003, 127, 619-623.

213 J. H. Im, C. R. Lee, J. W. Lee, S. W. Park and N. G. Park, Nanoscale, 2011, 3, 4088-4093.

214 H. S. Kim, C. R. Lee, J. H. Im, K. B. Lee, T. Moehl, A. Marchioro, S. J. Moon, R. Humphry-Baker, J. H. Yum, J. E. Moser, M. Gratzel and N. G. Park, Sci. Rep., 2012, 2, 591.

215 M. M. Lee, J. Teuscher, T. Miyasaka, T. N. Murakami and H. J. Snaith, Science, 2012, 338, 643-647.

216 J. T. Wang, J. M. Ball, E. M. Barea, A. Abate, J. A. AlexanderWebber, J. Huang, M. Saliba, I. Mora-Sero, J. Bisquert, H. J. Snaith and R. J. Nicholas, Nano Lett., 2014, 14, 724730.

217 D. Liu and T. L. Kelly, Nat. Photonics, 2013, 8, 133-138.

218 A. Abate, M. Saliba, D. J. Hollman, S. D. Stranks, K. Wojciechowski, R. Avolio, G. Grancini, A. Petrozza and H. J. Snaith, Nano Lett., 2014, 14, 3247-3254.

219 C. C. Stoumpos, C. D. Malliakas and M. G. Kanatzidis, Inorg. Chem., 2013, 52, 9019-9038.

220 M. Hirasawa, T. Ishihara, T. Goto, K. Uchida and N. Miura, Phys. B, 1994, 201, 427-430.

221 T. Ishihara, J. Lumin., 1994, 60-61, 269-274.
222 E. Edri, S. Kirmayer, S. Mukopadhyay, K. Gartsman, G. Hodes and D. Cahen, Nat. Commun., 2014, 5, 3461.

223 J. Burschka, N. Pellet, S. J. Moon, R. Humphry-Baker, P. Gao, M. K. Nazeeruddin and M. Gratzel, Nature, 2013, 499, 316-319.

224 J. M. Ball, M. M. Lee, A. Hey and H. J. Snaith, Energy Environ. Sci., 2013, 6, 1739-1743.

225 M. Liu, M. B. Johnston and H. J. Snaith, Nature, 2013, 501, 395-398.

226 M. Saliba, K. W. Tan, H. Sai, D. T. Moore, T. Scott, W. Zhang, L. A. Estroff, U. Wiesner and H. J. Snaith, J. Phys. Chem. C, 2014, 118, 17171-17177.

227 S. Kazim, M. K. Nazeeruddin, M. Gratzel and S. Ahmad, Angew. Chem., 2014, 53, 2812-2824.

228 D. Nanova, A. K. Kast, M. Pfannmoller, C. Muller, L. Veith, I. Wacker, M. Agari, W. Hermes, P. Erk, W. Kowalsky, R. R. Schroder and R. Lovrincic, Nano Lett., 2014, 14, 2735-2740.

229 J. Shi, J. Dong, S. Lv, Y. Xu, L. Zhu, J. Xiao, X. Xu, H. Wu, D. Li, Y. Luo and Q. Meng, Appl. Phys. Lett., 2014, 104, 063901.

230 E. Edri, S. Kirmayer, A. Henning, S. Mukhopadhyay, K. Gartsman, Y. Rosenwaks, G. Hodes and D. Cahen, Nano Lett., 2014, 14, 1000-1004.

231 W.-J. Yin, T. Shi and Y. Yan, Appl. Phys. Lett., 2014, 104, 063903.

232 J. You, Y. M. Yang, Q. Chen, M. Cai, T.-B. Song, C.-C. Chen, S. Lu, Y. Liu, H. Zhou and Y. Yang, ACS Nano, 2014, 8, 16741680.

233 N.-G. Park, J. Phys. Chem. Lett., 2013, 4, 2423-2429.

234 B. Al-Rashdi, C. Somerfield and N. Hilal, Sep. Purif. Rev., 2011, 40, 209-259.

235 V. M. Nurchi and I. Villaescusa, Coord. Chem. Rev., 2008, 252, 1178-1188.

236 P. Docampo, A. Hey, S. Guldin, R. Gunning, U. Steiner and H. J. Snaith, Adv. Funct. Mater., 2012, 22, 5010-5019.

237 I. G. Dakova, I. B. Karadjova, V. T. Georgieva and G. S. Georgiev, Microchim. Acta, 2008, 164, 55-61.

238 B. Liu, X. Lv, X. Meng, G. Yu and D. Wang, Chem. Eng. J., 2013, 220, 412-419.

239 M. Zhang, Z. Zhang, Y. Liu, X. Yang, L. Luo, J. Chen and S. Yao, Chem. Eng. J., 2011, 178, 443-450.

240 M. D. McGehee, Nature, 2013, 501, 323-325.

241 G. Hodes, Science, 2013, 342, 317-318.

242 F. Hao, C. C. Stoumpos, D. H. Cao, R. P. H. Chang and M. G. Kanatzidis, Nat. Photon., 2014, 8, 489-494.

243 S. Savagatrup, A. S. Makaram, D. J. Burke and D. J. Lipomi, Adv. Funct. Mater., 2014, 24, 1169-1181.

244 C. Roldan-Carmona, O. Malinkiewicz, A. Soriano, G. Minguez Espallargas, A. Garcia, P. Reinecke, T. Kroyer, M. I. Dar, M. K. Nazeeruddin and H. J. Bolink, Energy Environ. Sci., 2014, 7, 994-997.

245 B. Azzopardi and J. Mutale, Renewable Sustainable Energy Rev., 2010, 14, 1130-1134.

246 B. Azzopardi, C. J. M. Emmott, A. Urbina, F. C. Krebs, J. Mutale and J. Nelson, Energy Environ. Sci., 2011, 4, 3741-3753. 
247 A. J. Medford, M. R. Lilliedal, M. Jorgenson, D. Aaro, H. Pakalski and F. C. Krebs, Opt. Express, 2010, 18, A272A285.

248 P. Sommer-Larsen, M. Jorgensen, R. R. Sondergaard, M. Hosel and F. C. Krebs, Energy Technol., 2013, 1, 15-19.

249 H. Kang, S. Hong, H. Back and K. Lee, Adv. Mater., 2014, 26, 1602-1606.

250 R. Po, A. Bernardi, A. Calabrese, C. Carbonera, G. Corso and A. Pellegrino, Energy Environ. Sci., 2014, 7, 925-943.

251 http:/www.nanocotechnologies.com, date accessed July 2014.

252 C. Wadia, A. P. Alivisatos and D. M. Kammen, Environ. Sci. Technol., 2009, 43, 2072-2077.

253 Y.-Y. Lin, D.-Y. Wang, H.-C. Yen, H.-L. Chen, C.-C. Chen, C.-M. Chen, C.-Y. Tang and C.-W. Chen, Nanotechnology, 2009, 20, 405207.

254 H. Nishi, T. Nagano, S. Kuwabata and T. Torimoto, Phys. Chem. Chem. Phys., 2014, 16, 672.

255 K. K. Kasem, Surf. Interface Anal., 2011, 43, 1527-1531.

256 Y.-F. Lim, J. J. Choi and T. Hanrath, J. Nanomater., 2012, 393160.
257 Y. Bessekhouad, R. Brahimi, F. Hamdini and M. Trari, J. Photochem. Photobiol., A, 2012, 248, 15-23.

258 E. J. Luber, H. Mobarok and J. M. Buriak, ACS Nano, 2013, 7, 8136-8146.

259 C. Steinhagen, T. B. Harvey, C. J. Stolle, J. Harris and B. A. Korgel, J. Phys. Chem. Lett., 2012, 3, 2352-2356.

260 S. A. Gevorgyan, M. Jørgensen and F. C. Krebs, Sol. Energy Mater. Sol. Cells, 2008, 92, 736-745.

261 C. H. Peters, I. T. Sachs-Quintana, J. P. Kastrop, S. Beaupré, M. Leclerc and M. D. McGehee, Adv. Energy Mater., 2011, 1, 491-494.

262 T. Leijtens, G. E. Eperon, S. Pathak, A. Abate, M. M. Lee and H. J. Snaith, Nat. Commun., 2013, 4, 2885.

263 F. Matteocci, S. Razza, F. Di Giacomo, S. Casaluci, G. Mincuzzi, T. M. Brown, A. D'Epifanio, S. Licoccia and A. Di Carlo, Phys. Chem. Chem. Phys., 2014, 16, 3918-3923.

264 Y. S. Kwon, J. Lim, H.-J. Yun, Y.-H. Kim and T. Park, Energy Environ. Sci., 2014, 7, 1454-1460.

265 S. Lizin, S. Van Passel, E. De Schepper, W. Maes, L. Lutsen, J. Manca and D. Vanderzande, Energy Environ. Sci., 2013, 6, 3136-3149. 